\title{
CHEMICAL STRUCTURES, MESOGENIC PROPERTIES AND SYNTHESIS OF LIQUID CRYSTALS WITH BENT-CORE STRUCTURES
}

Nélida Gimeno and M. Blanca Ros*

Institute of Materials Science of Aragón (ICMA). University of Zaragoza - Spanish National Research Council (CSIC).

The spontaneous orientation of the molecules in mesophases can be explained by the anisotropy of repulsive forces coupled with the isotropic part of the dispersion interactions. However, it can not be ruled out that, depending on the molecular structure, other molecular interactions can play an important role (e.g. hydrogen bonds, polar forces, charge-transfer processes, etc.). In addition, the interactions between chemically incompatible structures, as well as spatial steric interactions, can determine the structural features of liquid crystal phases. A very attractive example of such a steric interaction concerns molecules with a distinct bent shape, which are the topic of this chapter.

Since the discovery of the polar characteristics of lamellar mesophases of bent-core mesogens in $1996,{ }^{[1]}$ chemists have focused their efforts on the design and synthesis of a wide variety of bentshaped compounds with fairly different structures, not only to investigate basic structure-activity relationships but also with the aim of achieving precise functional properties. All of this research has provided significant information on the chemical structure-mesomorphic properties for this type of compound and this area is reviewed in the following pages. The discussion covers the chemical structure-mesogenic properties and an analysis of the synthetic routes used to obtain these materials.

The majority of the data concern the acknowledged group of bent-core mesogens (part A), but bent mesogenic dimers (part B) and the so-called 'hockey stick' molecules (part C) are also considered (Figure 1). Furthermore, in order to induce and stabilize mesophases both low molecular weight compounds and macromolecules have been assessed. In this review an attempt is made to condense the main trends and results for molecular designs pursued in these innovative mesomorphic materials, where both new mesophases and physical properties meet and emerge as a major topic of current liquid crystal research. The results published until the end of 2011 are covered in this chapter. Additionally, due to the relative infancy of the topic, where some results are/or can be revisited, the nomenclature for the mesophases originally used by the authors has been retained in most cases.

\section{FIGURE 1}




\section{A. LIQUID CRYSTALS FROM BENT-CORE MOLECULES}

Generally speaking, the distinctive liquid crystalline phases promoted by bent-core structures have either a lamellar or a columnar nature, with numerous packing variants and the occurrence of polarity and chirality. Along with these structural characteristics, the remarkable physical properties and phenomena reported for these materials immediately generated great interest. Thus, outstanding work on the relationship between the molecular structure and the properties has been carried out and published. However, very few extensive systematic studies on structure-activity relationships can be cited and this makes it difficult to draw definitive conclusions for many aspects. Nonetheless, detailed reviews concerning the relationship between the chemical structure of bentcore mesogens and their liquid crystalline behavior have been summarized. Interestingly, although different revisions have had fundamentally different aims, they all contribute to show the development of the field in terms of the chemical structure and properties of the bent-core molecules. ${ }^{[2]}$ Research has revealed that the occurrence of the unique polarity and chirality in the mesophases of bent-core molecules strongly depends on the molecular structure and intermolecular interactions. However, many essential questions on the chemical structure-mesomorphism of these compounds remain unanswered.

There are three basic structural units in bent-shaped mesogens and these have been the focus of research aimed at designing, modulating and understanding bent-core mesomorphism: the central bent-core (BC), the rod-like lateral structure (LC) that forms the bent-shaped structure of these molecules and the terminal substituents (Figure 1). In the following sections we will cover these structural aspects and discuss the most relevant features.

\section{A1. THE BENT-CORE STRUCTURES}

The bent core, which gives this type of material its name, can be considered as the most important unit in a bent-shaped structure. In most cases, it is crucial to have an appropriate angle (typically in the range $60-140^{\circ}$ ) in the central part of the molecule to observe the characteristic mesophases for this type of compound. At the extremes of the mesogenic range, calamitic phases (for very acute angles in the so-called V-shaped molecules) or sequences of calamitic and bent-core type mesophases (for the most open angles, $\sim 140^{\circ}$ ) are observed. Another relevant factor to take into account, concerns the flexibility of the central part, although liquid crystalline behavior has been reported for both flexible and rigid bent-cores. Finally, the introduction of polar substituents in the 
bent-core is also noteworthy as it can contribute to the net polarization of the molecule and significantly modify the phase structures.

Of the organic moieties that afford appropriate angles, 1,3-phenylene $(1,3-\mathrm{Ph}),{ }^{[2 \mathrm{a}, 3]}$ 2,7naphthalene ${ }^{[2,4]}(2,7-\mathrm{Nph})$ and 3,4'-biphenylene ${ }^{[2 \mathrm{a}-\mathrm{e}, 5]}\left(3,4^{\prime}-\mathrm{Bi}\right)$ are by far the most commonly used especially the former one. Indeed, the first reports on bent-shaped molecules were based on this central core, which offers a very convenient $120^{\circ}$ bend angle. This system affords reasonable mesophase ranges $\left(20-30{ }^{\circ} \mathrm{C}\right)$, especially for the imine-ester lateral structures (PIMB series). ${ }^{[1]}$ The introduction of one more ring into the central structure, either fused (such as 2,7-naphthalene) or linked (such as 3,4'-biphenyl), retains the bend angle but the liquid crystalline range increases dramatically, leading to stabilization of the mesomorphism. This increase in the transition temperatures is especially pronounced for the naphthalene unit, whereas biphenylene affords wide phase ranges at moderate temperatures. Some representative examples of these effects are shown in Table 1.

\section{TABLE 1}

The data provided above only relate to general considerations on the behavior of these bent core systems. In the following sections we will cover the different variations introduced in these central cores and discuss the most relevant studies that deal with more flexible and more rigid central cores, including heteroaromatic bent cores.

\section{A1.1. Phenylene derivatives}

The optimal $120^{\circ}$ angle afforded by the 1,3-phenylene central core can be easily modified (either opened or closed) by the introduction of one or more substituents in the free positions of the phenylene ring. This strategy has been widely used and groups of different sizes and polarities have been introduced, mainly in position 2, but also in positions 4,4 and 6 , and 5 of the 1,3-phenylene ring, with interesting results (Table 2).

A1.1.a. Substituents in position 2. The groups most commonly attached at this position are nitro ($\left.\mathrm{NO}_{2}\right)$, cyano $(-\mathrm{CN})$ and methyl $\left(-\mathrm{CH}_{3}\right)$. Two different behaviors are reported and these are mainly related to the polarity of the group. When polar $-\mathrm{NO}_{2}$ or $-\mathrm{CN}$ groups are placed between the two lateral parts, $\mathrm{B}_{7}$ mesomorphism is induced in all cases regardless of the rest of the structural characteristics of the bent-shaped molecule. The main difference between the two groups concerns the transition temperatures. Whereas the presence of an $-\mathrm{NO}_{2}{ }^{[6]}$ group markedly reduces melting points to afford materials with wide ranges of the $\mathrm{B}_{7}$ mesophase, $-\mathrm{CN}^{[6 b, 6 c, 7]}$ promotes stabilization 
of the mesomorphism with a clear decrease in the phase range when compared to $-\mathrm{NO}_{2}$ or unsubstituted analogs.

On the other hand, the introduction of a non-polar $-\mathrm{CH}_{3}{ }^{[6 \mathrm{~d}, 8]}$ group leads to destabilization of the mesomorphism (in some cases it is lost altogether) but with retention of the same type of supramolecular arrangement $(\mathrm{SmCP})$ as in the unsubstituted compounds.

A1.1.b. Substituents in position 4. Substituents that have been placed in this position range from halogens $(-\mathrm{Cl},-\mathrm{Br})$ to polar groups $(-\mathrm{CN})$ or alkyl and ester short chains. In general, the effects of having chloro- or bromo-substituents in this position are similar, with the latter causing a slightly larger reduction in the transition temperatures due to its bigger size. The inclusion of both $-\mathrm{Cl}$ and $\mathrm{Br}$ in position 4 leads to destabilization of the mesomorphism and gives wider mesophase temperature ranges in comparison to unsubstituted analogs. ${ }^{[9]}$ Regarding the type of mesophase, in general SmCP arrangements are favored. However, in other cases more complex mesophase sequences are obtained depending on other modifications in the whole bent-shaped structure. For example, the introduction of substituents $(-\mathrm{OH} \text { or }-\mathrm{F})^{[6 \mathrm{~d}, 10]}$ in the outer ring of a 5 ring-system or a change in the direction of the ester linking units ${ }^{[11]}$ induces the appearance of sequences of calamitic and bent-core type mesophases, thus demonstrating how narrow the boundary between these two types of liquid crystals is. Indeed, if a second $-\mathrm{Cl}$ atom is added to position 6 , a stretched conformation (angle of $\sim 165^{\circ}$ ) is proposed and calamitic phases $\left(\mathrm{SmC}, \mathrm{N}\right.$ ) are favored ${ }^{[6 \mathrm{~d}, 12]}$ over $\mathrm{SmCP}$ (only monotropic phases appear at low temperature, if they appear at all). ${ }^{[10,13]}$

These mesophase sequences are also found if a $-\mathrm{CN}$ group is placed in position 4 of the phenylene ring, as this group affords an angle of $\sim 140^{\circ}$, i.e. borderline between calamitic and bent-core molecules. This angle decreases on decreasing the temperature, thus favoring the formation of polar phases. Different combinations of calamitic and polar smectic phases (N-SmC-SmA-SmCP) are then reported. ${ }^{[2 \mathrm{~d}, 14]}$ Depending on the terminal chains and lateral structures of the bent-shaped molecules, some of the calamitic phases are not observed. Interestingly, five-ring systems bearing esters with opposite dipoles show SmA-SmAP phase sequences. ${ }^{[15]}$

Finally, the introduction of an alkyl chain $\left(-\mathrm{CH}_{3}\right.$ to $\left.-\mathrm{C}_{7} \mathrm{H}_{15}\right)$, attached either directly or through an ester linkage, strongly destabilizes the mesomorphism as molecules bearing these groups are either crystalline or show only a short interval of mesophase. ${ }^{[16]}$

A1.1.c. Substituents in position 5. The influence of substituents in this position is not as clear as for the previous cases and is very dependent on the characteristics of the whole bent-core structure. In some cases, mesophases are prevented, as reported by Weissflog et al. ${ }^{[16 \mathrm{a}, 16 \mathrm{c}]}$ and Matyus et al. ${ }^{[\mathrm{bb}]}$ for 5-ring systems bearing $-\mathrm{CH}_{3},-\mathrm{OCH}_{3},-\mathrm{CN}$ or $-\mathrm{Cl}$. In other cases, when the rigid core is extended to seven rings or lateral susbtituents are added, SmCP mesomorphism is induced by 
attaching $-\mathrm{F},{ }^{[10]}-\mathrm{Cl}^{[17]}-\mathrm{CH}_{3},{ }^{[6 \mathrm{~d}]}-\mathrm{OCH}_{3}{ }^{[18]}$ or $-\mathrm{CN}^{[19]}$ groups. As a general trend, substituents in this position afford narrower mesophase ranges at lower temperatures.

\section{TABLE 2}

\section{A1.2. Naphthalene derivatives}

Apart from 2,7-naphthelene derivatives, other substitution patterns in the naphthalene ring can afford appropriate angles to generate bent-shaped molecules. ${ }^{[4 \mathrm{c}, 20]}$

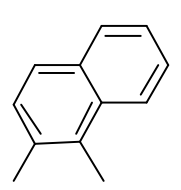

$N(1,2)$

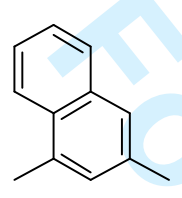

$N(1,3)$

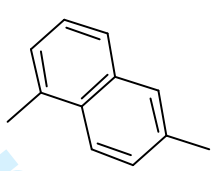

$N(1,6)$

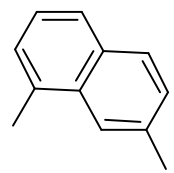

$N(1,7)$

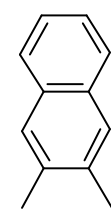

$N(2,3)$

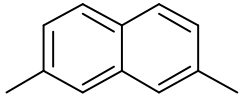

$N(2,7)$

Besides symmetric $\mathbf{N}(\mathbf{2 , 7 )}$ substitution, the asymmetric $\mathbf{N}(\mathbf{1 , 6 )}$ system also affords the SmCP mesophase over wide temperature ranges but with lower transition temperatures. Indeed, this bentcore has proven to be an attractive alternative to $\mathbf{N}(2,7)$ to generate bent-core type mesophases. ${ }^{[20 b]}$ On the other hand, $\mathbf{N}(\mathbf{1 , 3})$ and $\mathbf{N}(\mathbf{1 , 7})^{[20 \mathrm{c}]}$ favor crystalline phases. In particular, the $\mathrm{B}_{4}$ phase is formed if PIMB type structures are used. Interestingly, for the $\mathbf{N}(\mathbf{1 , 7})$ derivative, replacement of the alkoxy chains by long thioalkyl chains leads to columnar hexagonal mesomorphism above the $\mathrm{B}_{4}$ phase, giving rise to an uncommon phase sequence. ${ }^{[20 \mathrm{~d}]}$ The closest bent-core structures, namely $\mathbf{N}(\mathbf{1 , 2})$ and $\mathbf{N}(\mathbf{2 , 3})$, afford $\mathrm{V}$-shaped materials that behave as calamitic liquid crystals that show typical SmA and $\mathrm{N}$ phases. ${ }^{[20 \mathrm{e}, 20 \mathrm{f}]}$

Regarding the introduction of substituents in the naphthalene bent core, only position 1 of the $\mathbf{N}(2,7)$ system has been studied. In particular, $-\mathrm{Cl},-\mathrm{CH}_{3},-\mathrm{CN}$ and $-\mathrm{NO}_{2}$ have been placed in this position of all-ester and ester-imine linked bent-shaped structures. A decrease in the transition temperatures is observed in most cases, as occurred with 2-substitution in the resorcinol derivatives. Indeed, for the all-ester structures an analogous effect of the substituents is observed as $-\mathrm{NO}_{2}$ and $\mathrm{CN}$ favor the $\mathrm{B}_{7}$ phase whereas $-\mathrm{CH}_{3}$ and $-\mathrm{Cl}$ favor the SmCP arrangement if the terminal chains are long enough. However, $\mathrm{Col}_{\mathrm{r}}$ arrangements are observed for the shortest homologues regardless of the substitution. ${ }^{[21]}$ This is not the case for imine-containing derivatives, which show a strong tendency to organize in SmCP arrangements of different polarities in spite of the length of the terminal chain (n: 6-12) and the substituent in position 1. $\left(-\mathrm{CH}_{3},-\mathrm{CN},-\mathrm{Cl}\right) .{ }^{[4 \mathrm{~b}]}$ 


\section{A1.3. 3,4'-biphenyl derivatives}

Very few studies have been carried out in which substituents are introduced in the 3,4'-biphenyl central core and all of these concern the incorporation of halogen atoms $(-\mathrm{F},-\mathrm{Cl}) .{ }^{[2]}$ Dantlgraber et al. ${ }^{[23]}$ carried out a systematic study in which up to three fluoro-substituents were placed in the 3,4'-biphenyl bent-core of an all-ester six-ring bent-core molecule. All monofluorinated compounds, many of the difluorinated compounds and a few trifluorinated materials showed the $\mathrm{SmCP}_{\mathrm{A}}$ mesophase. For the rest of di- and trifluorinated compounds this $\mathrm{SmCP}_{\mathrm{A}}$ was replaced by columnar phases. Thus, the supramolecular arrangement achieved depends strongly on the number and position of the $-\mathrm{F}$ substituents. Regarding transition temperatures, the introduction of $-\mathrm{F}$ leads to a slight destabilization of the mesomorphism (with respect to the parent compound without fluorine). This destabilization becomes more marked on increasing the number of fluorosubstituents or on placing them adjacent to the ester group.

\section{A1.4. Other bent cores}

Numerous other molecules that contain different and varied bent cores have been reported in recent years. A number of these systems will be discussed here, starting with those in which the rigidity of the central core is retained (Table 3), as in previous examples, and ending with more flexible and more unusual bent-core structures.

The rigidity and the angle of the central core are maintained by using meta-terphenyl units as the bent-core. ${ }^{[5 b]}$ In comparison to the 3,4'-biphenyl unit, two main effects are observed due to the enlargement of the central rigid core. On the one hand, markedly increased transition temperatures are observed due to the additional benzene ring. On the other hand, an enhanced tendency to form a columnar arrangement is found. On enlarging the rigid core, partial overlap of the aromatic rings takes place and this favors the ribbon structure of the columnar phase. As a consequence, longer chains are necessary to break the frustration of the layers and promote lamellar mesomorphism. This tendency to columnar mesomorphism was also confirmed for more elongated bent cores, including examples in which triple bonds connect the aromatic rings. ${ }^{[5 \mathrm{~b}]}$

Analogous systems have been described by Shen et al. ${ }^{[24]}$ and these incorporate a 2,6diphenylpyridine bent-core. In these molecules columnar arrangements are also favored but the transition temperatures increase even more. This trend of increasing transition temperatures is widespread when heteroaromatic units are used as bent-cores, including pyridine, pyrazole and oxadiazole based bent-cores. 
As far as pyridine derivatives are concerned, Nozary et al. ${ }^{[25]}$ reported a bent-core molecule based on a 2,6-bis(benzimidazol-2-yl)pyridine and this showed columnar mesomorphism. This bent-core can be used as a ligand for some metals but all attempts to prepare mesogenic complexes were unsuccessful. Indeed, some effort has been focused on using metals in bent-core liquid crystals, ${ }^{[26]}$ but these have only been successful in a few cases. Cavero et al. ${ }^{[27]}$ succeeded in inducing B-type phases $\left(\mathrm{B}_{6}\right.$ or sequences of $\mathrm{N}-\mathrm{B}_{\mathrm{x}}$ phases) by using roof-shaped pyrazaboles. Sanchez et al. ${ }^{[28]}$ described a series of photoluminescent boron difluoride $\beta$-diketonate derivatives that show the $\mathrm{B}_{1}$ phase.

\section{TABLE 3}

Heteroaromtic 5-membered rings have frequently been used to prepare bent-shaped molecules but only in a few cases have bent-core type mesophases been observed.

For example, the bend angle afforded by [2]-benzothiophene materials ${ }^{[29]}$ is too large and prevents the compact packing that is typical of bent-core liquid crystals. This gives rise to materials that only form calamitic phases. Similarly, most of the materials bearing either 1,2,4- or 1,3,4-oxadiazole ${ }^{[30]}$ as the central core show only nematic and non-polar smectic phases. The possible biaxiality of the nematic phases of this type of material is still a matter of debate. The only example of a 1,3,4oxadiazole-based bent-shaped molecule to show a B phase was described by Kang et al. ${ }^{[30 \mathrm{~d}]}$ This phase appeared alone or below a nematic phase depending on the length of the lateral cores (1).

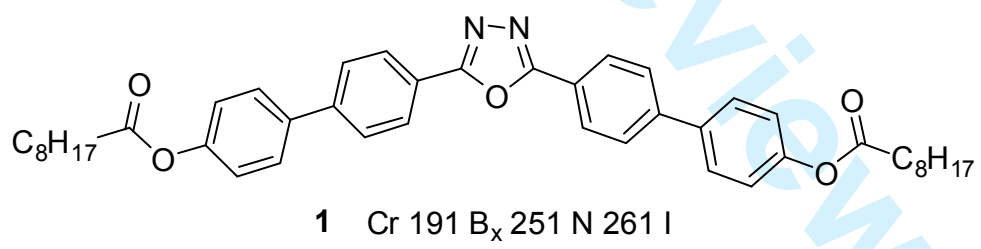

If we consider systems with a flexible bent-core, the most common example is the use of an alkyl chain that joins two rod-like units in a dimeric arrangement. However, this type of bent-core design will be analyzed in a separate section (section B). The extreme case is the use of a single methylene group. This $\mathrm{sp}^{3}$ unit affords an appropriate angle $\left(\sim 109^{\circ}\right)$ to promote B-type mesophases. Indeed, several examples ${ }^{[31]}$ of bent-core molecules bearing this central unit have been reported to provide wide temperature ranges of columnar $\left(\mathrm{Col}_{\mathrm{r}}, \mathrm{B}_{1 \mathrm{rev}}\right)$, lamellar $(\mathrm{SmCP})$, columnar to lamellar sequences or the $\mathrm{B}_{7}$ phase depending on the lateral structures and terminal chains. It has also been reported that other 'single point' units (Table 4), such as $-\mathrm{O}-,{ }^{[32]}-\mathrm{S}-,-\mathrm{C}=\mathrm{O}-$ and $-\mathrm{S}=\mathrm{O}-,{ }^{[4 c]}$ are able to promote $\mathrm{Col}_{\mathrm{r}}$ or SmCP organizations, thus demonstrating that the polarity of the central core 
has an additional effect on the supramolecular arrangement achieved. However, other central architectures, such as $-\mathrm{N}\left(\mathrm{CH}_{3}\right)$-, only gave rise to calamitic bilayer SmA mesomorphism. ${ }^{[33]}$

\section{TABLE 4}

In all of the above examples the central unit joins two phenyl rings. However, closer bend angles result if the linking unit is substituted by more flexible cyclohexyl rings (2). This central core favors nematic mesomorphism as well as non-typical phases such as the columnar nematic or a rather rare lamello-columnar phase, as described by Lesac et al. ${ }^{[34]}$

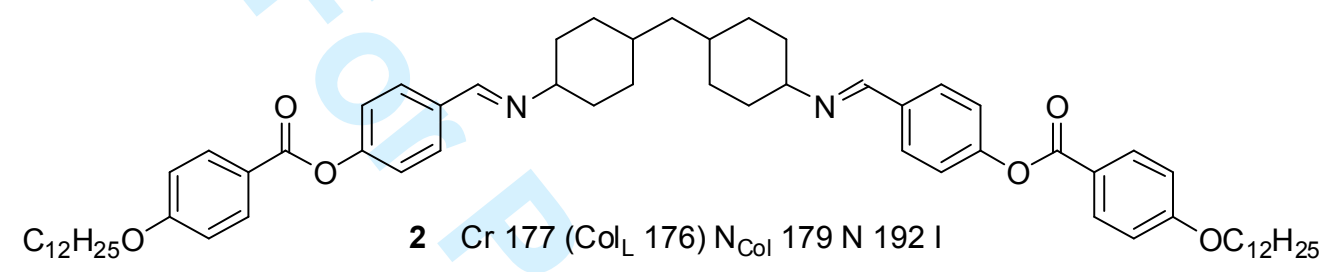

Weissflog's group described several series of compounds based on a carbonyl center unit extended by attachment of different linear or cyclic flexible units $(3,4)$ to yield asymmetric molecules as opposed to the symmetrical molecules described above. In the series bearing a methyleneoxycarbonyl unit, ${ }^{[35]}$ columnar mesomorphism was found unless a methoxy group was attached to the phenyl ring joined to the methylene unit - in this case monotropic SmCP mesomorphism was observed.

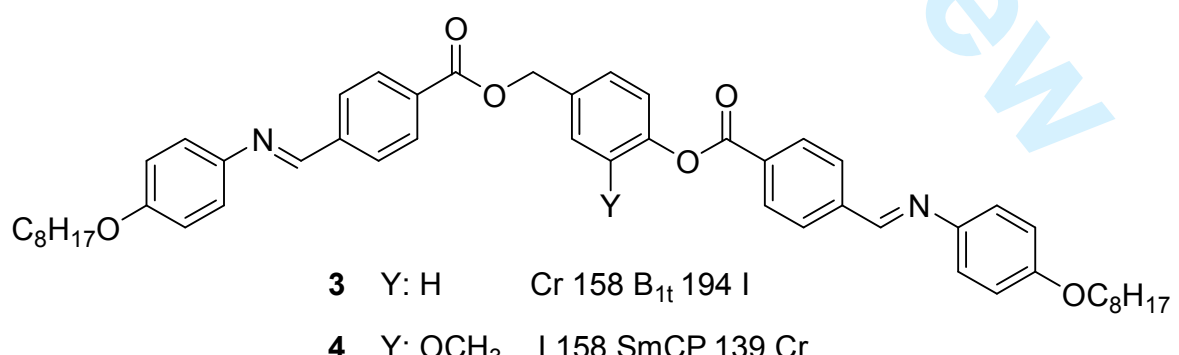

Piperidine or piperazine units have also been connected to $-\mathrm{C}=\mathrm{O}-$ groups to give highly asymmetric bent-shaped structures. Whereas five-ring systems ${ }^{[36]}$ tend to form mesophases that are typical of bent molecules ( $\mathrm{SmCP}$ and $\mathrm{B}_{1}$ phases), six-ring compounds ${ }^{[37]}$ combine classical calamitic and bent-core mesophases, or sequences of the two types of phases, the nature of which depends strongly on the lateral structures and the terminal chains (Table 5). 


\section{TABLE 5}

Other flexible structures in the bent core have been analyzed. For example, a chiral carbohydratebased molecule (5) was described by Gesekus et al. ${ }^{[38]}$ An atypical cholesteric- $\mathrm{B}_{2}$ phase sequence was reported for this material. Besides, larger and bulkier flexible bent cores, such as adamantane and $m$-carborane, have been placed at the center of the molecule by Pociecha et al. ${ }^{[39]}$ and these materials show only short intervals of $\mathrm{B}_{4}$ phase and $\mathrm{B}_{6}$ phases, respectively.

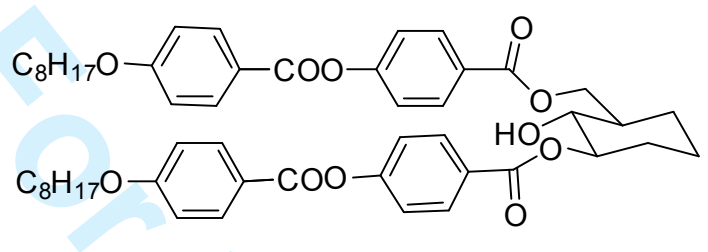

5 I $180 \mathrm{~N}^{*}\left(140 \mathrm{~B}_{2}\right) 134 \mathrm{Cr}$

Interestingly, mesomorphism in the urea derivatives reported by Glettner et al. ${ }^{[40]}$ can be modulated by changing the ring size and other structural parameters (6-8). Whereas the five-ring urea shows extremely high transition temperatures and only non-polar (calamitic) phases, larger rings (6 or 7 members) afford (on cooling) sequences of non-polar and polar phases (SmA-SmCP or SmA$\mathrm{SmAP})$ at moderate temperatures.

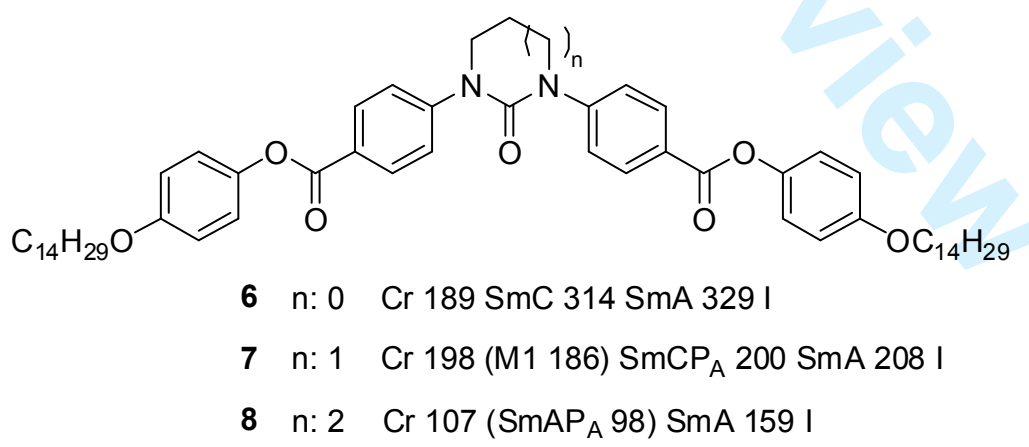

\section{A2. THE LATERAL STRUCTURES}

The rod-like lateral structures that form the bent-core of these bent molecules play a crucial role in inducing and modulating the liquid crystalline arrangement. In designing these compounds a variety of structural modifications have been considered, in particular the linking groups that connect the central unit to the lateral one or the groups that join the aromatic rings within the lateral core. Other 
structural units that have been modified include the number of aromatic units in the core, which controls the neat bent-shaped structure versus a 'hockey-stick' form, the incorporation of lateral substituents in this part of the molecule, and the incorporation of similar or different lateral cores. Furthermore, it can be stated that the lateral structures of bent-core molecules have been successfully used to assess the potential of bent-core liquid crystals as functional materials. For example, some authors have incorporated in this part of the molecule several well-known active functional moieties, ${ }^{[41]}$ such as electron donor- $\pi$-acceptor units, ${ }^{[41 \mathrm{~b}]}$ tetrathiafulvalene ${ }^{[41 \mathrm{a}]}$ or thiophene rings, ${ }^{[41 \mathrm{c}, 41 \mathrm{~d}]}$ in order to take advantage of the compact and polar packing of the bent-core mesophases for nonlinear optics or organic electronics.

The majority of bent-core molecules are based on covalent bonds, but the versatile supramolecular chemistry approach has also been exploited to generate the lateral part of bent-core structures. Several series of H-bonding complexes have been synthesized by using a large variety of carboxylic acids as H-bond donors and different pyridine-based molecules as $\mathrm{H}$-acceptors. This approach led to bent-core like liquid crystalline phases. ${ }^{[42]}$

The most representative examples of the approaches outlined above will be discussed in the following sections.

\section{A2.1. Linking groups.}

The influence of the rod-like lateral core on bent-core mesomorphism is strongly dependent on its polarity, linearity, flexibility and/or length, and hence on the chemical structure of the connecting bonds incorporated in the lateral core. Few systematic studies have been carried out on linking bonds, ${ }^{[5 \mathrm{~d}, 32,43]}$ but a large number of independent results reveal that both the chemical structure and the bond direction have a dramatic effect on the formation of this kind of mesomorphism (Tables 6 , 7,8 and 9).

In general, ester $(-\mathrm{COO}-)$ and imine $(-\mathrm{CH}=\mathrm{N}-)$ groups are the most commonly used, although numerous other groups have been also considered. The effect of the different connectors will be covered, taking Niori's 1,3-phenylene-based structures (PIMB series) as a starting point and extending the discussion to other bent cores (namely 3,4'-biphenyl and 2,7-naphthalene) where appropriate. Given the particular interest in this area, directional effects of imine and ester linkages will be discussed in a separate section.

A2.1.a. Imine $(-\mathrm{CH}=\mathrm{N}-$ ). Imine linkers have been extensively used as they were present in the first examples of bent-shaped mesogens reported by Niori et al. ${ }^{[1]}$ These linkers are well-known to provide wide mesophase temperature ranges at relatively high temperatures. Interestingly, the 
incorporation of imine linkages favors the appearance of polymorphism much more than other linking units, although the low chemical and thermal stability is the main drawback of this linker. Fluorination of this linkage was reported by Wrobel et al. ${ }^{[4]}$ and this structural change gave lower transition temperatures and stabilization of $\mathrm{B}_{2}$ and $\mathrm{B}_{1}$ arrangements.

A2.1.b. Ester, thioester and amide groups (-COO-, $-\mathrm{COS}-,-\mathrm{CONH}-)$. Ester groups have been widely used as linking units for different reasons. Compounds with ester groups tend to show lower transition temperatures while maintaining excellent mesomorphic properties in comparison to imine analogs. Esters are also well known to be chemically and thermally stable and can prepared using straightforward synthetic approaches. Thus, ester groups are present in most of the bent-shaped structures in various positions and in combination with other linking units. Interestingly, the direction of the ester group within the molecule can have marked effects on material properties and these will be discussed later. Similarly, thioester (-COS-) linked bent-shaped structures were described by Nguyen et al. ${ }^{[43 \mathrm{~d}, 45]}$ This unit promotes stabilization of the mesomorphism - especially for short chains - to afford enantiotropic mesophases. Similar mesomorphic properties are observed for the analogs with the longest chains. Finally, the related amide group has hardly been used in this context. Gomola et al. ${ }^{[46]}$ reported a series of bent-shaped asymmetrical structures bearing one amide or methylamide linking unit close to the central core. Stabilization of the mesomorphism was observed for the materials containing the amide linking group in comparison to the methylamide (not mesomorphous) and ester derivatives. This effect is thought to be due to intermolecular hydrogen bonding interactions. A novel $\mathrm{Sm}_{\mathrm{A}} \mathrm{P}_{\mathrm{AR}}$ phase was also formed as a result of the presence of hydrogen bonding.

A2.1.c. Azo and azoxy groups $(-N=N-,-N=N(O)-$ ). In general, the introduction of the attractive photoactive azo linkage destabilizes the mesomorphism, giving rise to non-mesomorphic materials or short mesophase ranges. ${ }^{[32]}$ This drawback has been overcome by using different strategies. ${ }^{[47]}$ For example, combination of only one azo linker with imine and ester connectors to afford mesomorphic asymmetric molecules with varied supramolecular arrangements. ${ }^{[47 \mathrm{~b}-\mathrm{d}, 47 \mathrm{~g}]}$ An alternative strategy to favor mesomorphism while retaining two azo linkers consists of extending the rod-like part by adding more aromatic rings to the lateral structure. ${ }^{[47 \mathrm{a}, 47 \mathrm{f}]}$ A different approach involves using $3,4^{\prime}$-biphenyl ${ }^{[5 \mathrm{~d}, 43 \mathrm{~b}]}$ or 2,7 -naphthalene ${ }^{[47 \mathrm{e}]}$ units as better pro-mesogenic bent cores. In general, the azo group does not have any clear effect on the supramolecular arrangement, which depends mostly on other factors such as the chain length.

The azoxy linker does, also, deserve special mention as it was present in the original bent-core structures described by Vorlander and later studied by Pelzl et al. ${ }^{[48]}$ The compound with the 
ethyloxy terminal chain showed the $\mathrm{B}_{6}$ phase. This linker was subsequently used by Pintre et al. ${ }^{[5 \mathrm{~d}, 43 \mathrm{~b}]}$ to afford broader mesophase ranges than the azo analogs and induce a USmCP phase rather than a columnar arrangement. An azoxy linker was also used asymmetrically to promote similar effects on temperatures, but in this case the $\mathrm{SmC}_{\mathrm{A}} \mathrm{P}_{\mathrm{A}}$ phase was reported for both materials, a situation in contrast to that found for the asymmetric compounds (Table 7).

A2.1.d. Double and triple carbon bonds $(-\mathrm{HC}=\mathrm{CH}-,-\mathrm{C} \equiv \mathrm{C}-$ ). Carbon-carbon double bonds have rarely been used as linkers in bent-shaped liquid crystals. In all cases such bonds have been used to connect the outer rings of the bent-shaped structure in combination with substituents in those rings, as exemplified in Gorecka's group studies. ${ }^{[46,49]}$ In general, double bonds promote a remarkable increase in the transition temperatures in comparison with imine and ester derivatives. The same effect is observed when carbon-carbon triple bonds are used as connectors. ${ }^{[24]}$ Thus, lateral substituents are frequently added when these linkers are present in order to lower transition temperatures and favor mesomorphism. Besides, these linkers have also been used in other bentcore systems that show nematic mesomorphism. ${ }^{[27,50]}$

A2.1.e. Cinnamoyloxy and $\alpha$-methylcinnamoyloxy ( $\left.-\mathrm{CH}=\mathrm{CH}-\mathrm{COO}-,-\mathrm{CH}=\mathrm{C}\left(\mathrm{CH}_{3}\right) \mathrm{COO}-\right)$. The enlargement of the ester linkage by using a cinnamoyloxy or $\alpha$-methylcinnamoyloxy group has become quite a widespread and straightforward alternative to simple ester linkers. The effect of this moiety strongly depends on the length of the terminal chain and the bent-core used. ${ }^{[51]}$ In symmetrical 1,3-phenylene derivatives, ${ }^{[8 \mathrm{~b}, 51 \mathrm{a}]}$ the $-\mathrm{CH}=\mathrm{CH}-\mathrm{COO}-$ linkage stabilizes columnar mesomorphism for shorter chains, but liquid crystal arrangements are prevented for longer chains in comparison to the ester derivatives. On the other hand, if only one cinnamoyloxy-derived linkage is introduced, ${ }^{[51 \mathrm{c}]}$ the thermal properties remain similar to those of the all-ester structure. This type of linkage has also been introduced in bent-shaped structures based on 3,4'-biphenyl ${ }^{[22 b]}$ and 2,7naphthalene..$^{[51 \mathrm{~b}, 51 \mathrm{~d}]}$ In general, melting points increase with respect to the all-ester derivatives whereas the clearing points are slightly lowered when the cinnamoyloxy linkage is used and strongly decreased for the $\alpha$-methylcinnamoyloxy compounds due to steric effects (Tables 6 and 7).

\section{TABLE 6}

\section{TABLE 7}

In some rare examples, the different linking units discussed above have been used randomly to give highly asymmetric molecules. In these cases, the incorporation of different lateral cores becomes an 
attractive way to modify properties such as the type and range of mesophase or transition temperatures. ${ }^{[47 b, 52]}$

A2.1.f. Effect of the direction of the linking group. Regarding ester and imine linkages, extensive research has been carried out aimed at understanding the effect that the direction of the linkers has on the transition temperatures and the supramolecular arrangements obtained. The linker direction has been demonstrated by theorical calculations to influence the values of the dipolar moment as well as the bending angles and the molecular lengths. ${ }^{[53]}$ The direction also affects the repartition of charge densities on the different aromatic rings and hence the mesomorphic behavior. ${ }^{[54]}$

Weissflog et al. ${ }^{[16 c, 55]}$ carried out a systematic study of the effect of the direction of the ester linkage in a series of 1,3-phenylene-based bent-core molecules ${ }^{[55 a]}$ (Table 8). A strong effect of the direction of the ester groups on the mesophase stability was found; differences of more than $70{ }^{\circ} \mathrm{C}$ were observed in the clearing points on changing the ester direction. Moreover, this change also has a marked effect on the supramolecular arrangement obtained, as a wide variety of mesophases have been described even for minor structural changes (even when only one ester direction is changed). Regarding mesomorphism, isomers with lower clearing temperatures tend to form lamellar phases, whereas those with higher temperatures preferentially form columnar arrangements. Further studies on the influence of the direction of the ester linkage have been reported for other bent-shaped designs such as dimers ${ }^{[55 \mathrm{~b}]}$ or silylated molecules, ${ }^{[56]}$ with similar conclusions drawn.

\section{TABLE 8}

As far as the imine linker is concerned, despite the fact that systematic studies have not been carried out, the large number of bent-shaped molecules that contain this group allows some general trends to be established regarding its incorporation (Table 9). ${ }^{[2 a, 43 d, 57]}$ When the imine linkage is located in the outer positions, wide mesophase ranges are observed if the nitrogens are further from the central core, whereas mesomorphism is completely suppressed if the linker is in the opposite direction regardless of the orientation of the internal ester groups. This effect is also found, albeit not so pronounced, if the imines are located close to the bent-core. Once again, mesomorphism is favored if the nitrogen is further away of the bent-core unit.

\section{TABLE 9}

\section{A2.2. Aromatic structures.}

Regardless of the connectivity, the number and the chemical characteristics of the aromatic units within the lateral structures also allow modulation of the formation of mesophases that are 
characteristic of bent molecules. In recent years some results concerning this type of mesomorphism for compounds with only $3^{[58]}(\mathbf{9})$ or $4^{[59]}(\mathbf{1 0}, \mathbf{1 1})$ aromatic rings and long terminal tails have been reported, with different types of $\mathrm{B}$ phases observed.
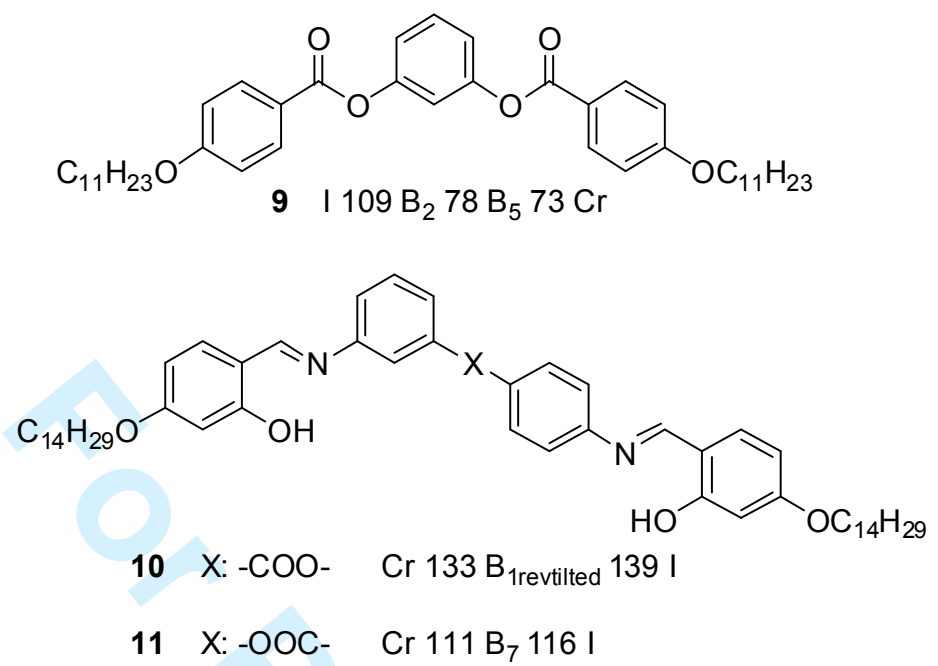

However, the majority of molecules contain 5 or more aromatic units in the lateral systems, as can be seen by the examples gathered in this chapter. Apart from $p$-substituted phenyl rings, other rigid aromatic structures have been used to extend the rigid core and this topic is reviewed below (Table $10)$.

A2.2.a. Biphenyl-and naphthyl-based lateral structures. The biphenyl moiety has been mainly used to replace the outer phenyl rings to afford systems containing seven aromatic rings in all-ester connected structures. ${ }^{[60]}$ In comparison to the analogous five-ring systems, the introduction of two more aromatic rings results in a remarkable stabilization of the mesomorphism without a change in the type of phase observed. In fact, the broad mesophase ranges obtained allow the introduction of substituents in the different aromatic rings without loss of the mesomorphic properties, as will be seen later. Interestingly, for analogous bent-shaped molecules that contain inner imine linkages, ${ }^{[61]}$ the same effects on temperatures are observed in comparison to five-ring systems. However, in this case the supramolecular arrangements change from $\mathrm{B}_{1}$ and $\mathrm{B}_{2}$ phases to $\mathrm{B}_{4}$ and $\mathrm{B}_{7}$ phases on introducing biphenyl moieties. Nevertheless, if the biphenyl moiety is placed in only one of the lateral structures, ${ }^{[43 \mathrm{c}, 62]}$ mesomorphism is preserved and temperatures are not significantly affected. Shen et al. ${ }^{[2]}$ studied a related heteroaromatic moiety, i.e. 2-phenylpyrimidine. Surprisingly, the heteroaromatic ring destabilizes the mesomorphism and favors an intercalated Sm phase. Regarding the naphthyl moiety, Yang et al. ${ }^{[43 \mathrm{a}]}$ showed that the thermal properties are intermediate between phenyl and biphenyl, with wider mesophase ranges than phenyl derivatives but at lower temperatures than biphenyl-containing analogs. 
A2.2.b. Sulfur-containing lateral structures. Pintre et al. ${ }^{[41 \mathrm{a}]}$ succeeded in preparing mesomorphic materials containing tetrathiafulvelene (TTF) units either in one (12) or both lateral structures. Depending on the number of TTF units and the number of aromatic rings, different mesophases $\left(\mathrm{Col}_{\mathrm{ob}}, \mathrm{SmCP}, \mathrm{USmCP}\right)$ were induced.

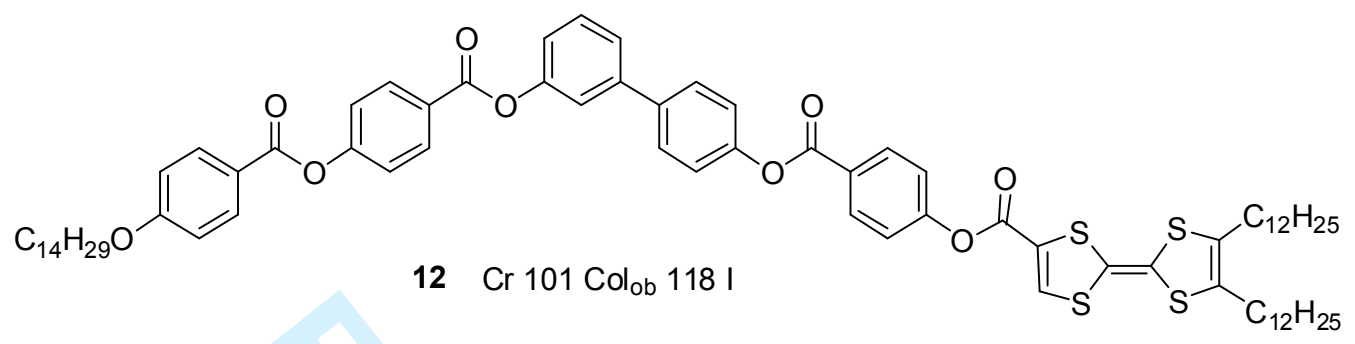

Furthermore, Kozmik et al. ${ }^{[41 \mathrm{c}]}$ and Geese et al. ${ }^{[41 \mathrm{~d}]}$ simultaneously reported the preparation of bentshaped structures containing thiophene units. If two heterocyclic units were placed in the outer position of 1,3-phenylene- or 2,7-naphthalene-based structures, mesomorphism was not observed. However, if 3,4'-biphenyl was used as the central core, wide mesophase ranges were obtained at moderate temperatures. SmCP mesomorphism was also observed if a single thiophene moiety was incorporated in the naphthalene derivative or if two dithiophene units were used for the 1,3phenylene derivative.

\section{TABLE 10}

\section{$\underline{\text { A2.3.Lateral substituents. }}$}

Chemists have also considered the incorporation of substituents on the lateral cores of bent-shaped molecules as an appropriate tool to change the intermolecular interactions and hence the liquid crystal packing. This approach offers broad possibilities to include groups and change intermolecular interactions, either based on the chemical nature of the substituent or its position in the molecule. Thus, changes in the polarity, polarizability or the length/width ratio of the molecule have been controlled. Different types of polar groups such as $-\mathrm{NO}_{2},-\mathrm{CH}_{3},-\mathrm{CF}_{3},-\mathrm{OCH}_{3}$, halogens, or $-\mathrm{OH}$ have been placed either on the outer or the inner aromatic rings of the rod-like cores. Among these substituents, the fluorine atom has been the subject of a large number of systematic studies and will be discussed separately.

A2.3.a. Substituents on the outer rings. One of the most interesting studies into substituents on the outer rings deals with the effect of different halogen atoms. Gorecka's group ${ }^{[49]}$ reported on these effects in several series of bent-core mesogens bearing double bonds as external linking groups (Table 11). For these systems an increase in the size of the halogen $(\mathrm{F}<\mathrm{Cl}<\mathrm{Br}<\mathrm{I})$ leads to 
destabilization of the mesomorphism, which in some cases is even lost for iodo-substituted systems depending of the characteristics of the overall structure. Furthermore, the same authors combined halogen atoms $(-\mathrm{Cl}$ or $-\mathrm{I})$ with the $-\mathrm{NO}_{2}$ group to yield asymmetric structures. This modification did not markedly change the transition temperatures, but promoted columnar arrangements $\left(\mathrm{B}_{1}\right.$, $\left.\mathrm{B}_{1 \text { revt }}\right)$ as opposed to the $\mathrm{B}_{7}$ phase found for halogen analogs. Indeed, the tendency of the $-\mathrm{NO}_{2}$ group to favor this type of mesomorphism was confirmed for the di-nitro analog ${ }^{[46]}$ and for the dinitro materials reported by Prasad et al., ${ }^{[63]}$ which showed the $\mathrm{B}_{1}$ phase regardless of the chain length. Other studies also explored the effect of halogens as well as $-\mathrm{CH}_{3}$ and $-\mathrm{CF}_{3}$ in different bent-core structures. ${ }^{[10,64]}$ These studies revealed that mesomorphism is favored for substitution in position $\mathrm{A}$, but both $-\mathrm{CH}_{3}$ and $-\mathrm{CF}_{3}$ have a detrimental effect on the mesomorphic properties, in most cases preventing the formation of mesophases or giving rise only to short mesophase range in comparison to, for example, bromo-substituted analogs - a substituent that is similar in size.

Significant research has also been carried out on the hydroxyl group $(-\mathrm{OH})$ placed on the outer ring, especially for salicylaldimine lateral structures. This moiety has been widely used in rod-like liquid crystals and is well known to stabilize the imine group, thus improving its stability to heat and moisture. In the case of bent-core liquid crystals, the presence of this substituent promotes a strong stabilization of the mesomorphism in comparison of the non-substituted analog, both in 1,3phenylene ${ }^{[6 \mathrm{~d}, 65]}$ and 3,4'-biphenylene ${ }^{[66]}$ derivatives. In contrast, Pintre et al. ${ }^{[5 \mathrm{~d}]}$ explored the effect of the hydroxyl group in the inner and outer rings of all-ester connected 3,4'-biphenyl-based bentcore structures. This change destabilized the mesomorphism in comparison to the non-substituted compound.

\section{TABLE 11}

A2.3.b. Substituents on the inner rings. Apart from the examples with fluoro-substituents, there are very few examples with substituents on the inner rings. The introduction of $-\mathrm{Cl},-\mathrm{CH}_{3}$ or $-\mathrm{OCH}_{3}$ dramatically reduces the mesomorphism and the transition temperatures in comparison with nonsubstituted compounds, to afford materials with $\mathrm{B}_{2}$ and $\mathrm{B}_{7}$ phases (13-15). ${ }^{[60,67]}$ This decrease is more pronounced on increasing the size of the substituent, probably due to steric effects.

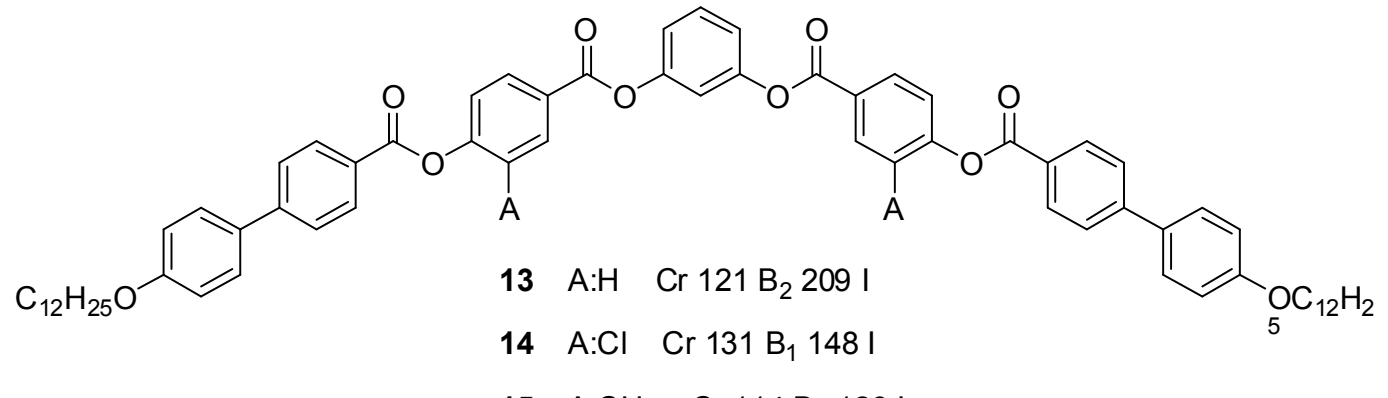

$15 \mathrm{~A}: \mathrm{CH}_{3} \quad \mathrm{Cr} 114 \mathrm{~B}_{2} 129$ । 
A2.3.c. Fluoro-substituents. Sadashiva's group ${ }^{[2 f, 19,68]}$ carried out the most systematic and broad studies focused on the $-\mathrm{F}$ substituent in the lateral structure. This atom has distinct effects on the properties of bent-core mesogens due to the fact that it is slightly larger than $-\mathrm{H}$, it is electronegative in character and it has a strong influence on the conformation of adjacent groups - and hence on the intermolecular interactions. However, the effect of this substituent strongly depends on its position in the lateral structure and the number present, as stated for different bent-core compounds, namely unsubstituted $\mathrm{d}^{[2 \mathrm{f}, 68 \mathrm{a}, 68 \mathrm{~b}]}$ or substituted ${ }^{[2 \mathrm{f}, 19,68 \mathrm{e}]}$ 1,3-phenylene and 2,7naphthyl ${ }^{[68 \mathrm{c}, 68 \mathrm{~d}]}$ compounds (Table 12). Additionally, it can be seen from these studies that the type of mesophase induced in each case is also determined by the length of the terminal chains.

The presence of fluoro-substituent(s) in the lateral structures can destabilize or preclude the formation of liquid crystalline phases, in particular when these atoms are introduced in the inner positions. The fluoro-substituent can also be used to induce mesophases in non-mesogenic molecules due to mesophase stabilization or reduction of the transition temperatures. On the other hand, fluoro-substituents in outer phenyl rings can considerably change the type of mesophase and, interestingly, this approach has been used to promote novel bent-core mesophases. It is worth noting that the presence of $-\mathrm{F}$ in the positions ortho- to the terminal tails (position A) promotes ferroelectric switching. Thus, a number of columnar and lamellar ferroelectric mesophases, the nature of which depends on the bent-core structure and tail length, have been reported.

\section{TABLE 12}

\section{A3. THE TERMINAL CHAINS}

Systematic studies on the influence of the terminal substituents or chains on the liquid crystal behavior of bent-shaped mesogens are limited. At the beginning, most of these systematic works were focused on the influence that the chain length had in the modulating the mesomorphism. In most cases, alkoxy chains were used. However, over the years, the great potential of terminal chains has been demonstrated. These chains have been used to induce microsegregation by introducing siloxanes, carbosilanes or fluorinated moieties; these units can be easily decorated with functional groups at the end of the chains (vinylidene, butadiene, acrylates, methacryates, carboxylic acids) as a way to access macromolecular structures or they can be made chiral to explore the influence of molecular chirality on bent-core mesomorphism.

In this section, a review not only of the different types of terminal chains used, but also the phenomena associated with the introduction of such chains is considered. Most studies are focused 
on bent-core molecules with only one terminal chain on each side of the bent-core structure. However, it is worth mentioning that a few examples of polycatenar bent-shaped structures have been reported and these give rise to materials that show traditional columnar phases, in some cases with polar order along the columns. ${ }^{[69]}$ Bent-core structures bearing a terminal chain on one side and a polar group on the other have also been explored. ${ }^{[70]}$ Different mesophases are induced depending on the nature of the polar group, with $-\mathrm{CN}$ and $-\mathrm{NO}_{2}$ being the most widely studied. Interestingly, the presence of polar groups on one end induces in most cases a mesophase sequence that includes a transition from a partially bilayer uniaxial $\mathrm{SmA}\left(\mathrm{SmA}_{d}\right)$ to a biaxial $\mathrm{SmA}$ phase $\left(\mathrm{SmA}_{d} \mathrm{P}_{\mathrm{A}}\right)$, with the lower temperature phase being polar with antiferroelectric switching ${ }^{[70 \mathrm{c}-\mathrm{e}]}$ or an uncommon randomly polarized $\operatorname{SmA}\left(\operatorname{SmA}_{d} P_{R}\right) \cdot{ }^{[70 f, 70 g]}$

\section{A3.1. Alkoxy, alkyl, thioalkyl and ester chains}

Hydrocarbon chains connected to the rigid structure by an ether linkage are by far the most common in bent-core liquid crystals. Indeed, from the early days in this field to the present this type of chain has been exploited in numerous systematic studies into changes in the bent-core or the lateral structures. As some of the effects on the thermal and mesogenic properties of these materials have been discussed in previous sections, we will focus here on two general aspects: the number of carbons of the alkoxy chain and the incorporation of two terminal chains different in lengths (Table $13)$.

As a general trend, the ratio between flexible and rigid structures, i.e. between terminal chains and aromatic cores, affects the microsegregation of these parts and hence the supramolecular arrangements achieved. Shorter terminal chains give rise to intercalation of the molecules and this generates $\mathrm{B}_{6}$ or nematic phases. On increasing the number of carbons in the chain, the balance between the two parts of the molecule precludes intercalation, giving rise to modulated layers or ribbons (columnar phases). In cases where the chains are sufficiently long, segregation is allowed and SmCP phases are obtained. ${ }^{[3 a, 3 b, 4 a, 71]}$ In some cases, for very long chains (18 carbons or more), columnar arrangements appear once again. ${ }^{[31 \mathrm{~b}, 68 \mathrm{~d}]}$ Although these trends are quite widespread in bent-core liquid crystals, many other variants (bent-core structure, lateral substituents, linking groups, etc.) must be taken into account before attempting to predict the mesomorphism of a single molecule.

Interestingly, this trend has also been demonstrated for bent-core molecules bearing two alkoxy terminal chains of different lengths. Columnar or smectic mesomorphism is observed depending on the total sum of carbons ${ }^{[72]}$ (Table 13). The introduction of unsymmetrical chain lengths also lowers the melting and clearing temperatures with respect to the symmetrical compounds. ${ }^{[5 \mathrm{c}]}$ 


\section{TABLE 13}

Albeit to a lesser extent, other linking units have been used to connect hydrocarbon chains to the rigid core, including direct linking and thioether or ester linkers. Hydrocarbon terminal chains have been investigated to a much lesser extent, probably due to their higher synthetic complexity and their comparable behavior to alkoxy chains - as envisaged by Watanabe and Takezoe in their pioneering studies. ${ }^{[1,71 a, 73]}$ In general, alkyl chains induce the same type of mesophases but over wider ranges and at lower temperatures. However, in the PIMB series alkyl chains also promote a stabilization of the $\mathrm{B}_{3}$ phase and lead to the disappearance of the $\mathrm{B}_{4}$ phase (Table 13).

The sulfur atom versus oxygen promotes two different effects - lowering of the melting and clearing points and the induction of new mesomorphism. For example, in symmetrical systems based on 1,3-phenylene, a $B_{7}$ phase has been reported for thioalkyl $\left(\mathrm{C}_{8}-\mathrm{C}_{12}\right)$ chains and this replaces the SmCP phase found for the alkoxy analogs (Table 14). ${ }^{[74]}$ Indeed, if only one alkoxy chain is replaced by a thioalkyl chain the coexistence of $\mathrm{SmCP}$ and $\mathrm{B}_{7}$ phases is found. ${ }^{[43 \mathrm{c}]}$ In the case of the 2,7-naphthalene bent-core, which is also symmetrical, an $\mathrm{SmCP}_{\mathrm{F}}$ phase is induced by the $n$-dodecylthio chain in comparison to the $\mathrm{SmCP}_{\mathrm{A}}$ phase shown by the $n$-dodecyloxy analogs ${ }^{[75]}$ (Table 14). However, if the materials are based on asymmetrical bent cores (i.e. 1,7-naphthalene ${ }^{[20 \mathrm{~d}]}$ or 3,4'-biphenyl $\left.{ }^{[31 \mathrm{~b}]}\right)$ columnar arrangements $\left(\mathrm{Col}_{h}, \mathrm{Col}_{\mathrm{r}}\right)$ appear above the $\mathrm{B}_{4}$ phase or instead of the SmCP phase, respectively, for long terminal chains $\left(\geq \mathrm{C}_{12}\right)$.

\section{TABLE 14}

As in the case of thioether linkages, the introduction of simple ester or ester-derived connections between the rigid core and the terminal chains leads to a lowering of the phase transition temperatures and also the induction and/or appearance of unusual and varied mesomorphism. Pioneering studies by Bedel et al. ${ }^{[43 d, 54,76]}$ were focused on an isophthalic acid derivative (Table 15, Series I). The introduction of the ester linkage gives rise to rich mesomorphism that strongly depends on the number of $\mathrm{C}$ atoms; ranging from common $\left(\mathrm{SmCP}_{\mathrm{A}}\right)$ or undulated $\left(\mathrm{USmCP}_{\mathrm{A}}\right)$ lamellar phases to complex bilayer de Gennes structures $\left(\mathrm{SmC}_{\mathrm{S}} \mathrm{G}_{2} \mathrm{P}_{\mathrm{A}}\right)$. Based on the same rigid structure Pelzl et al. ${ }^{[77]}$ changed the simple esters to acrylester and oxyacetic esters. The former change stabilized the mesomorphism due to the enlargement of the rigid central core, whereas the latter destablized the mesomorphism (or even led to its disappearance) with respect to the basic ester linkage. 
However, different results have been reported for an alternative bent core (Series II). The ester linkage favors $\mathrm{B}_{7}$-type arrangements for the longest terminal chains and the $\mathrm{B}_{2}$ phase for the shorter chains (showing an odd-even effect of the local tilt director and polar arrangements). ${ }^{[78]}$

\section{TABLE 15}

\section{A3.2. Alkenyl and alkynyl terminal chains}

The introduction of alkenyl or alkynyl fragments in the terminal chains of bent-shaped molecules has become quite common as a route to macromolecular materials. However, this is not the only interest in these chains as they are well known to decrease both melting temperatures and clearing points, as already proven for calamitic liquid crystals.

Most of the work dealing with unsaturated chains is based on terminal chains of different lengths that bear vinyl ending groups. This moiety can undergo different types of polymerization. In general, the inclusion of this group has led to a lowering both in the melting and isotropization temperatures in bent-core liquid crystals, as found in calamitic materials. The introduction of vinylcapped terminal chains to different rigid cores has provided different series of monomers with a wide variety of mesophases, ${ }^{[79]}$ ranging from $\mathrm{SmCP}$ mesophases with either ferro- ${ }^{[79 a]}$ or antiferroelectric ${ }^{[79 b]}$ ground states, dark conglomerate (DC) phases, ${ }^{[21 b]}$ columnar, ${ }^{[21 b]}$ nematic ${ }^{[12 b, 79 b]}$ or $\mathrm{B}_{7}{ }^{[12 \mathrm{~b}]}$ phases. Likewise, results reported by Sentman et al. ${ }^{[79 \mathrm{~d}]}$ showed that the reactive 1,3-diene ended tails are compatible with mesomorphism and lead to similar properties to the saturated analogs ( $\mathrm{B}_{4}$ and SmCP phases).

With different aims in mind, double or triple carbon bonds have also been incorporated in inner positions of the terminal chains. The main effect observed by Gimeno et al. ${ }^{[31 \mathrm{~b}]}$ on the introduction of double bonds in the middle of the terminal chain was, apart from the lowering of melting and clearing temperatures, the vitrification of the mesophase. Pelzl et al. ${ }^{[77]}$ carried out a vast study on the introduction of a triple bond in different positions of the chain. In this case, a marked destabilization of the mesomorphism was observed, but when the triple bond was closer to the rigid part a slightly less marked destabilization or even a clear increase in the mesophase stability was achieved.

\section{A3.3. Chiral terminal chains}

The effect of molecular chirality on the supramolecular chirality of the mesophases provided by bent-core molecules, a phenomenon arising from the spontaneous breakdown of achiral symmetry 
that is characteristic of these molecules, is currently a topic of great interest. ${ }^{[80]}$ A straightforward strategy to obtain chiral bent-core liquid crystals is to introduce terminal chains bearing stereogenic centers, although chirality has also been introduced in the central and lateral structures, as mentioned in previous sections. In general, a decrease in the melting and clearing points is observed on introducing a chiral sterogenic carbon. However, the most interesting phenomena caused by the incorporation of a chiral center are related to the induction of ferro- and antiferroelectricity and also modulated phases.

The first reports on chiral bent-core liquid crystals ${ }^{[80 a, 80 b]}$ concerned the unusual mesomorphic behavior of the derivative P-8-O-PIMB6* (Table 16), which shows a racemic $\mathrm{SmC}_{\mathrm{A}} \mathrm{P}_{\mathrm{F}}$ ground state with chirality changing from layer to layer in spite of the molecular chirality of the single molecule. Ferroelectricity was confirmed by electrooptical, dielectric and SHG studies.

\section{TABLE 16}

Interestingly, further studies on the same rigid structure proved that ferroelectrity was found if the stereogenic center was located in an even position with respect to the rigid skeleton, whereas antiferroelectric switching appeared for odd placement of the chiral center. ${ }^{[80 \mathrm{c}, 80 \mathrm{~d}]}$ This trend was confirmed for a series of materials containing chiral 3-(alkoxy)propoxy ${ }^{[80 \mathrm{e}]}$ terminal chains, which showed the antiferroelectric switching expected for a compound with the stereogenic center in an odd position in the chain. This odd/even behavior was ascribed to the different direction of the methyl group connected to the chiral center, a change that gives rise to different interlayer steric interactions.

However, this odd/even effect in ferroelectricity could not be confirmed in an analogous series based on an asymmetric 1,6-naphthalene central core. ${ }^{[80 \mathrm{f}]}$ In this case the properties were attributed to a decrease in the interlayer steric interactions between the terminal chains. This decreased interaction is a consequence of the disruption in close packing caused by the asymmetric bent-core. Other types of chiral terminal chains have been used. ${ }^{[81]}$ Lee et al. ${ }^{[81 \mathrm{~b}]}$ and Coleman et al. ${ }^{[81 \mathrm{c}]}$ used chiral terminal chains based on citronellol. Lee et al. found a SmC* phase on introducing these chains into the same basic structure substituted in the 3-position of the $p$-alkoxyaniline Schiff base moiety. Interestingly, Coleman et al. identified a $\mathrm{B}_{7}$ phase for the compound bearing two citronellyl chains. This phase was also reported and was studied in depth by the same authors for a racemic compound (17) (MHOBOW) bearing only one chiral chain. ${ }^{[81 \mathrm{a}]}$ 


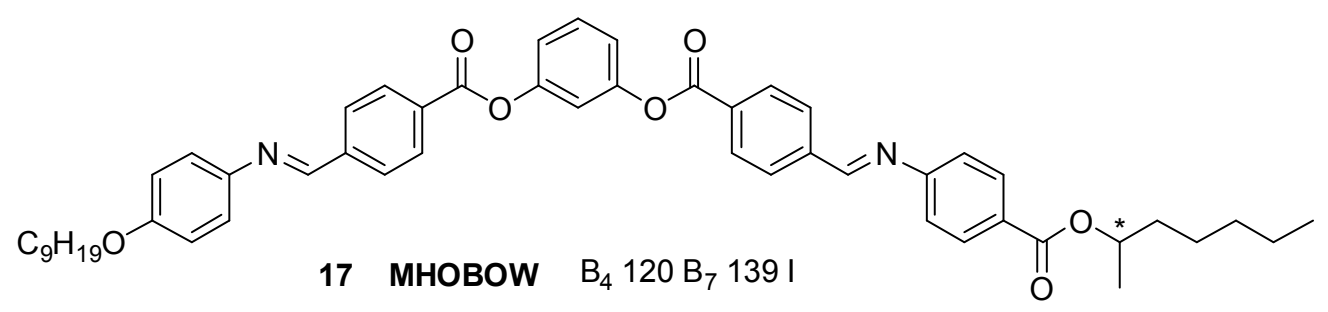

Recently, Ocak et al. ${ }^{[81 \mathrm{~d}]}$ studied a different series of materials containing chiral terminal chains of different lengths. The chains were either racemic or enantiomeric in nature and were attached to a all-ester linked rigid structure. Surprisingly, only those compounds that incorporated a $-\mathrm{CN}$ unit in the 4-position of the central core were mesogenic, thus confirming the exceptional properties of this bent core. Interestingly, the mesomorphism promoted in these materials is very rich, ranging from blue phases (BPIII) for the benzoyloxybenzoate derivatives with optically active short and long chains, to an $\mathrm{SmA}^{*}$ (de Vries type)- $\mathrm{SmC}^{*}-\mathrm{SmC}_{\mathrm{S}} \mathrm{P}_{\mathrm{A}} *$ sequence for the long chain molecule containing biphenyl lateral structures.

A3.4. Tetraethyleneglycol, fluorinated and silylated terminal chains.

Microsegregation effects can be induced if a third block, which is chemically incompatible with aromatic and hydrocarbon moieties, is introduced into the terminal chains of the bent-core structure. These effects have been achieved in bent-core liquid crystals by the introduction of $n$ tetra(ethyleneglycol)-based tails, semi- or perfluorinated chains, silyl-terminated tails (carbosilane or siloxane) or by a combination of the above (perfluoroalkyl and oligosiloxane) (Table 17).

As described by Gimeno et al., ${ }^{[31 b]}$ the introduction of $n$-tetra(ethyleneglycol) terminal chains lowers both the melting and the isotropization temperatures and this leads to SmCP mesomorphism at room temperature and vitrification of the mesophase below room temperature. The effect of the semiperfluorinated terminal chains is somehow the opposite, as stabilization of the mesophase is observed on the introduction of fluorinated fragments. This stabilization is also accompanied by a remarkable increase in the transition temperatures, as reported by Shen et al. ${ }^{[5 b]}$ and Kovalenko et al. $^{[82]}$ These effects were confirmed when semifluorinated chains with different proportions of fluorinated fragment $\left(\mathrm{C}_{4} \mathrm{H}_{8} \mathrm{C}_{6} \mathrm{~F}_{13}\right.$ or $\left.\mathrm{C}_{6} \mathrm{H}_{12} \mathrm{C}_{4} \mathrm{~F}_{9}\right)$ were incorporated into bent-shaped structures derived from 1,3-benzene, 3,4'-biphenyl and terphenyl units. Interestingly, the induction of lamellar vs. columnar arrangements was observed on using fluorinated tails in some cases. Intermediate 
behavior was also reported for the compound bearing both an $n$-decyloxy chain and a semifluorinated chain.

\section{TABLE 17}

In contrast to the scarce examples of fluorinated and oxyethylene-containing compounds, much more attention has been paid to the attachment of Si-containing groups to the end of the terminal chains. As a general trend, the introduction of any type of silylated units into bent-core materials promotes the stabilization of the mesomorphism.

A3.4.a. Oligo(siloxane) derivatives. Tschierke's group have been working on the attachment of linear or branched siloxane units of different sizes to one or both sides of the terminal chains of bent-core molecules. ${ }^{[83]}$ As mentioned before, stabilization of the mesomorphism is observed regardless of the size and type of siloxane unit. However, the switching behavior and mesophase arrangement are strongly affected by these features (Table 18). On introducing linear Si-containing groups on one side, ${ }^{[83 \mathrm{a}]}$ induction of ferroelectric switching in the SmCP phase was observed only if the number of siloxane units was high enough. The non-silylated compound or those with lower silicon contents showed common antiferroelectric switching in the SmCP mesophase with no segregation of the silylated parts, as evidenced by X-ray diffraction. However, an increase in the number of silylated units ${ }^{[83 \mathrm{~d}]}$ or branching ${ }^{[83 \mathrm{e}]}$ promoted ferroelectric behavior and optically isotropic domains corresponding to a dark conglomerate (DC) mesophase. Furthermore, X-ray experiments provided evidence for the appearance of a third sublayer from the silylated units. Another consequence of the presence of Si-containing molecules is the molecular switching by rotation along the long axis of the molecule, which changes the chirality of the layers and hence the superstructural chirality. This situation is in contrast to the most common switching, which occurs along the cone and preserves chirality.

\section{TABLE 18}

The appearance of the ferroelectric SmCP phase with an optically isotropic texture and chiral segregation is very common in Si-containing compounds. ${ }^{[83 \mathrm{~b}, 83 \mathrm{c}]}$ It is also worth mentioning the quaternary block materials described by Reddy et al. ${ }^{[84]}$ These bent-core molecules contain four different units: oligo(dimethylsiloxane) and perfluoroalkyl terminal chains, an alkyl spacer and an aromatic bent-core unit. It was found that, depending on the ratio between fluoro and silyl units, ferro- or antiferroelecric behavior can be tuned $(\mathbf{1 8}, \mathbf{1 9})$. 


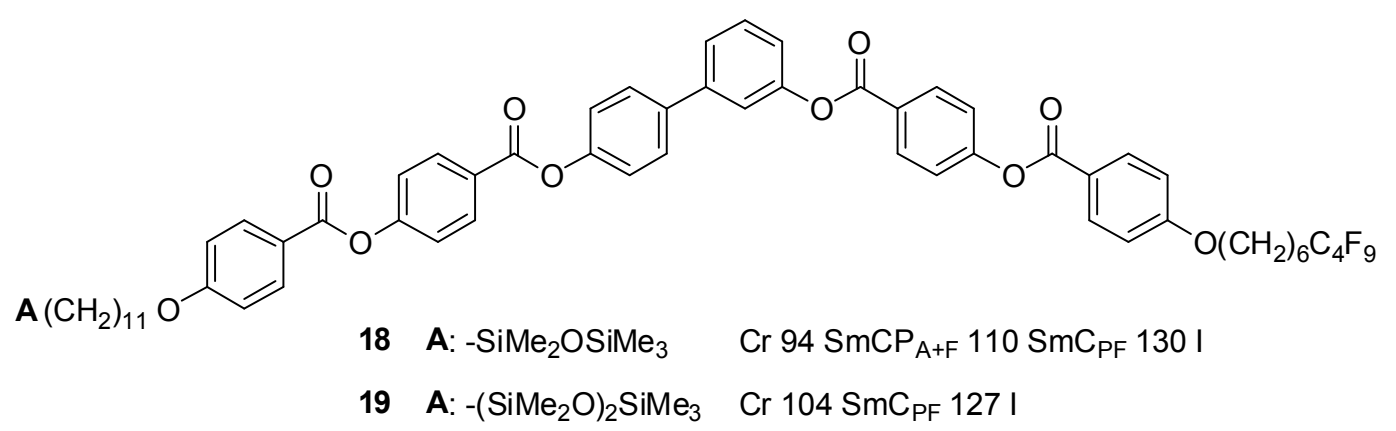

Besides these studies on the $3,4^{\prime}$-biphenyl central core, other investigations ${ }^{[56,85]}$ concerning 2,7naphthalene ${ }^{[85 a]}$ substituted 1,3-phenylene ${ }^{[85 b]}$ or 1,3 -phenylene ${ }^{[56]}$ have also been reported. In general, it can be concluded that if bulky groups are present on both sides of the bent-core molecule, frustrated phases, either undulated or columnar, are favored. However, if there is only one bulky group, $\mathrm{SmCP}_{\mathrm{F}}$ phases (DC type) are more common.

A3.4.b. Carbosilane derivatives. The use of this type of unit affords materials that are chemically more stable and have similar mesomorphic properties to siloxanes, with ferroelectric switching and the DC mesophase favored to a greater extent than with siloxanes. ${ }^{[86]}$ As with siloxanes, however, the introduction of very bulky branched groups ${ }^{[83 \mathrm{~d}, 83 \mathrm{e}]}$ leads to the appearance of high temperature columnar phases due to the voluminous size of the groups (Table 19).

TABLE 19

\section{B. BENT-CORE MESOPHASES FROM DIMERS, OLIGOMERS, DENDRIMERS AND}

\section{POLYMERS.}

\section{B1. DIMERS AND OLIGOMERS.}

As stated by the IUPAC Commission, a liquid crystal oligomer or mesogenic oligomer is a mesogen constituted of molecules, each with more than one mesogenic group. In the particular case of systems with two mesogenic units, they are called liquid crystal dimers or mesogenic dimers, also known as twin mesogens. These materials can be classified into different types depending on the linker that joins the two mesogenic units. We focus here only on the so-called tail-to-tail twin mesogens, which have a flexible spacer linking the two groups. Within this group, one can 
distinguish symmetric mesogenic dimers, i.e. when the two mesogenic units are identical and asymmetric dimers, in which the two mesogenic structures are different. Initially, this type of liquid crystal dimer was attractive as a model for higher molecular weight structures, such as main-chain and side-chain polymers. However, these materials have become interesting in their own right as they show complex and novel mesomorphism, which is remarkably different from that of the corresponding monomers.

Taking into account the scope of this chapter, only research strictly related to bent-core liquid crystals will be covered in this section. Several reviews on mesogenic dimers have already been published. ${ }^{[87]}$ With this aim in mind, this review concerns three types of compounds that differ in the structure of the mesogenic units: mesogenic dimers containing two rod-like units that show bent-core liquid crystalline mesophases, mesogenic dimers bearing one rod-like and one bentshaped unit, and mesogenic dimers consisting of two bent-core units.

\section{B1.1. Mesogenic dimers containing two rod-like units.}

Bent-core liquid crystal mesophases have been mainly found for calamitic dimers linked by an alkyl chain with an odd number of carbons. This structural feature leads to an appropriate angle to give a bent-shaped conformation. Watanabe and Takezoe's ${ }^{[88]}$ group described the first example of such a compound, which contained a typical rod-like core connected by a pentamethylene spacer (20), namely the lateral structure present in the OPIMB series. These dimers showed different smectic mesomorphism depending on the length of the terminal chain; ranging from non-polar single layer SmC phases (n: 4, 6) to $\mathrm{B}_{1}(\mathrm{n}: 8-12)$ and $\mathrm{SmC}_{\mathrm{A}} \mathrm{P}_{\mathrm{A}}$ with a bilayer character (n:14-18).

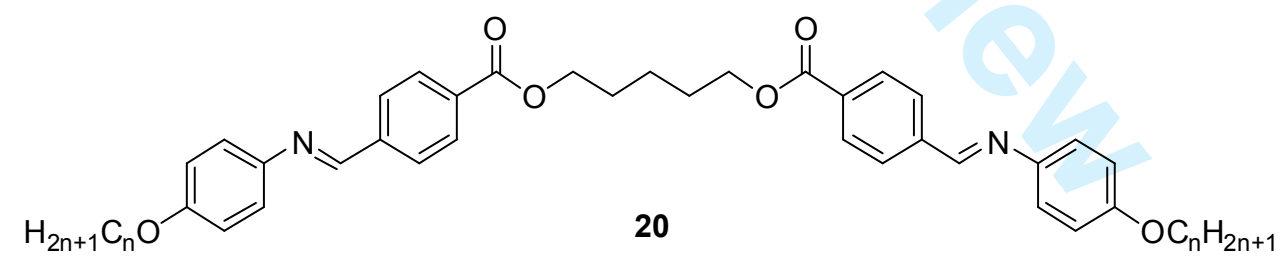

Analogous molecules - but with the ester linkage in the opposite direction and the same or opposite direction of the imine group - were described by Prasad et al. ${ }^{[89]}$ (Table 20). Interestingly, calamitic phases were described for odd spacers (5 methylene units) whereas B-type phases were proposed when even spacers ( 4 or 8 methylene units) were used. All even-membered dimers showed a high polar tilted smectic phase (named as $\mathrm{X}_{1}$ ) above a crystalline $\mathrm{B}_{3}$-like phase (named as $\mathrm{X}_{2}$ ).

TABLE 20 
Bent-core mesophases have been also reported by other authors ${ }^{[90]}$ (Table 21$)$. Depending on the terminal chain length ( $>\mathrm{n}: 8)$ monotropic and enantitropic $\mathrm{B}_{1}$ mesophases are formed by salicylaldimine-based dimers (Series I). ${ }^{[90 a, 90 b]}$

\section{TABLE 21}

On the other hand, the stabilization of columnar mesomorphism was also reported in Series II. ${ }^{[90 c]}$ With a focus on the parity of the spacer in this system, these authors found that even spacers $(\mathrm{m}: 6$, 8) led to classical calamitic mesophases whereas odd spacers ( $\mathrm{m}: 5,7)$ led to $\mathrm{B}_{1}\left(\mathrm{Col}_{\mathrm{r}}\right)$ phases if the terminal chains were sufficiently long. Interestingly, parent dimers without the --OH substituent (Series III $)^{[90 \mathrm{~d}]}$ showed calamitic phases $(\mathrm{SmB}, \mathrm{SmC}, \mathrm{SmA}, \mathrm{N})$ for the even-membered dimers and B phases $\left(\mathrm{B}_{6}\right)$ for the odd-membered ones.

An odd-even effect for the spacer was also found in biphenyl-based dimers described by BialeckaFlorjanczyk et al. ${ }^{[91]}$ These compounds showed the $\mathrm{B}_{4}$ phase for the odd-membered dimers and classical smectic phases for the even-membered ones. Elongated biphenyl-based systems with chiral terminal chains and a hexyl spacer were prepared by Nishiyama et al. ${ }^{[92]}$ and studied in detail by Lagerwall et al. ${ }^{[93]}$ These compounds (21) had a rod-like conformation in the nematic phase and a bent-shaped conformation when smectic mesophases were formed. Furthermore, the use of thioether spacers was reported to stabilize the antiferroelectric phases. ${ }^{[92 \mathrm{~b}]}$

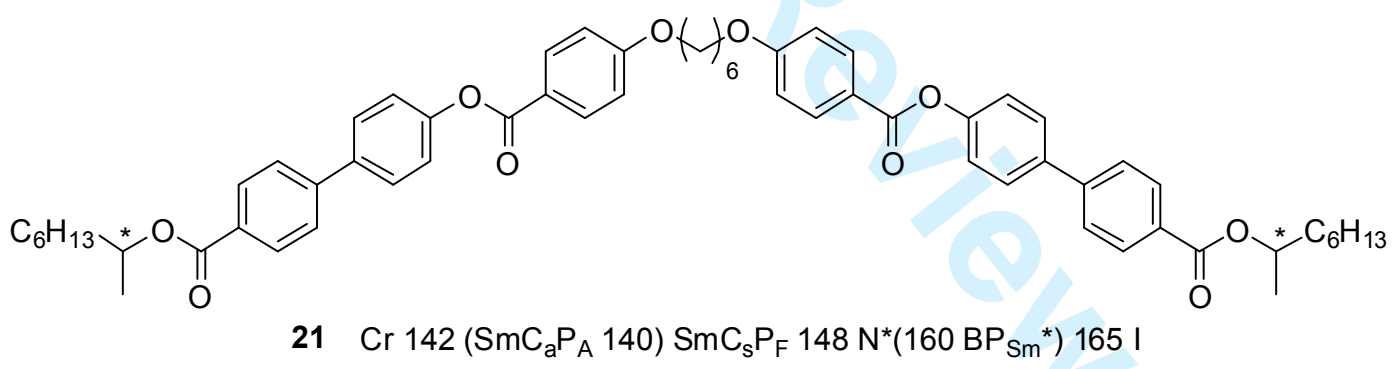

B1.2. Mesogenic dimers bearing one rod-like and one bent-shaped unit.

This type of asymmetric dimer has not been explored in great detail. The first examples were reported by Yelamaggad et al. ${ }^{[94]}$ and these consisted of bent-core structures attached to a cyanobiphenyl unit by a flexible spacer $(\mathrm{n}: 4-6)(\mathbf{2 2}, \mathbf{2 3}) .{ }^{\left[{ }^{[94}\right]}$ The compound with a pentamethylene spacer was not mesogenic, but the hexamethylene derivative showed, for the first time, the widely sought biaxial nematic $\left(\mathrm{N}_{\mathrm{b}}\right)$ phase in a low-molar mass system. 


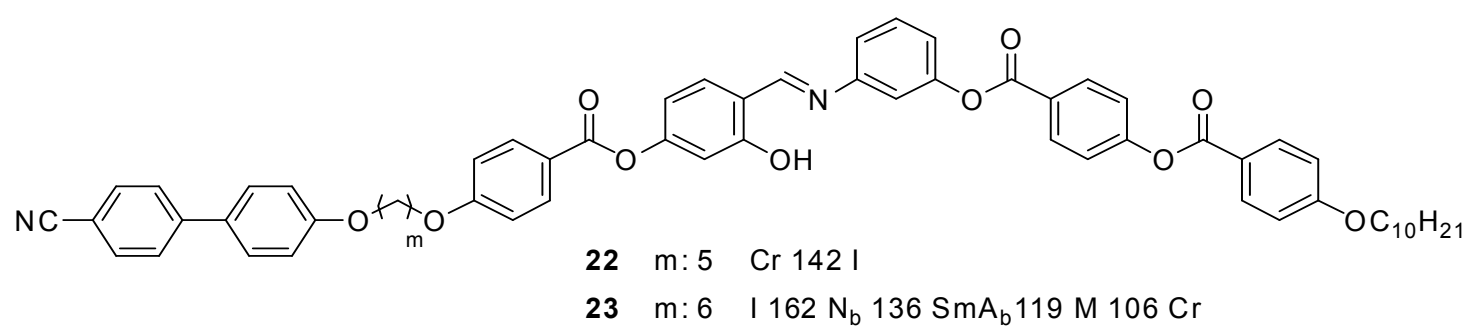

Closely related symmetric trimers, formed by two cyanobiphenyl units attached to the terminal ends of a five-ring bent-shaped structure by two $-\left(\mathrm{CH}_{2}\right)_{\mathrm{n}}-$ spacers of varying length, rendered an enantiotropic uniaxial nematic mesophase regardless of the spacer characteristics. This result was unexpected as it was envisaged that this change would stabilize the biaxial mesomorphism. Alternatively, an N-SmA sequence was also reported by Lee et al. ${ }^{[95]}$ in a cyanobiphenyl-based dimer with a hexamethylene spacer, although the odd-membered dimers showed only a $\mathrm{N}$ phase (n: 5) or were not mesogenic (n: 7).

Apart from cyanobiphenyl units, cholesterol $(\mathbf{2 4}, \mathbf{2 5})$ was attached to bent-core structures through odd/even methylene spacers by Yelamaggad et al. ${ }^{[94 \mathrm{c}]}$ The even methylene spacers yielded only $\mathrm{Col}_{\mathrm{r}}$ phases, whereas odd-membered dimers yielded interesting BP-N*-M ( $\mathrm{Col}_{\mathrm{r}}$ or tilted smectics)

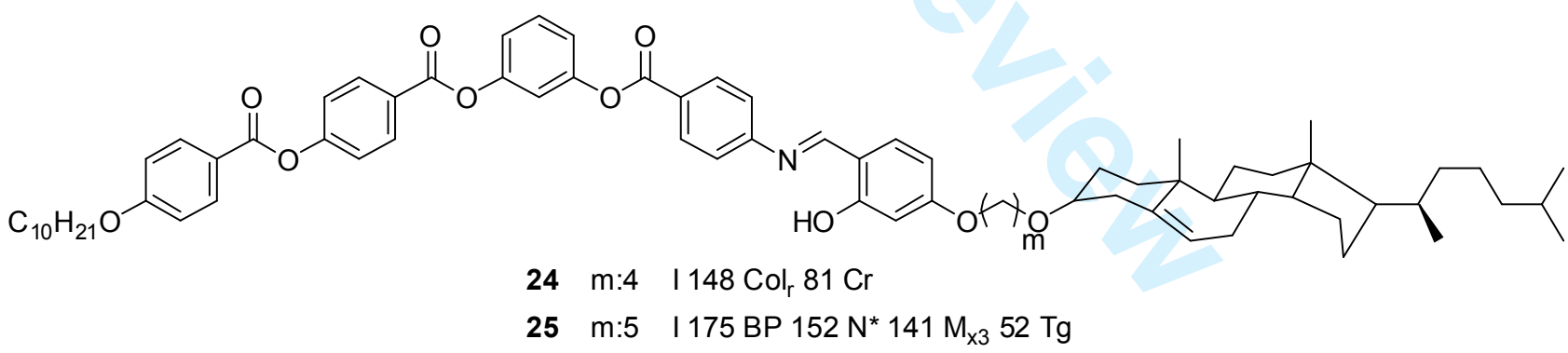

Weissflog's group ${ }^{[55 b, 96]}$ carried out the only systematic study on bent-core/calamitic mesogenic dimers (Table 22). A wide variety of mesophases were found, ranging from classical calamitic phases $(\mathrm{N}, \mathrm{SmA}, \mathrm{SmC})$ to typical and novel polar phases $\left(\mathrm{Col}_{\mathrm{r}}, \mathrm{Col}_{\mathrm{ob}} \mathrm{P}_{\mathrm{FE}}, \mathrm{USmC}_{\mathrm{a}} \mathrm{P}_{\mathrm{AF}}\right)$.

TABLE 22 


\section{$\underline{\text { B1.3. Mesogenic dimers and oligomers consisting of bent-core units. }}$}

The unexpected mesomorphic behavior observed for rod-like mesogenic dimers in comparison with single components has motivated the preparation of symmetric dimers bearing two bent-shaped structures. Umadevi et al. ${ }^{[97]}$ used traditional hydrocarbon spacers to join two unsubstituted or fluoro-substituted 1,3-phenylene bent-cores (BAN1) (Figure 2). All of the materials showed the same type of mesophase, $\mathrm{Col}_{\mathrm{ob}} \mathrm{P}_{\mathrm{F}}$, regardless of the spacer (7-12 methylene units) and the terminal chain length (alkoxy tails with 8-12,14, 16, 18 carbon atoms). When the spacer was fixed, longer terminal chains led to more marked mesophase stabilization. On the other hand, when the terminal chain was fixed, an odd-even effect on the clearing temperature (higher for the odd ones) was observed. The same bent-core structures, but with different length spacers, were reported by Achten et al. ${ }^{[98]}$ Interestingly, these authors also have introduced a trisiloxane spacer, which gave rise to a ferroelectric SmCP mesophase in all cases.

A similar approach to that described above was proposed by Kosata et al. ${ }^{[99]}$ for different bent-core moieties. The presence of a flexible spacer, namely a tetraethylene glycol, promoted 2D columnar phases regardless of the bent-core structure, but mesomorphism was not observed for compounds with alkyl spacers. Additionally, siloxane spacers allowed decoupling of the mesogenic units and this gave rise to a SmCP mesophase. Interestingly, ferroelectric switching was observed for the dimer whereas antiferroelectric switching was reported for the single bent-core analog.

\section{FIGURE 2}

Siloxanes and carbosilanes have also been used by Tschierske's group ${ }^{[100]}$ as spacers in $3,4^{\prime}-$ biphenyl bent-core based dimers (BAN2) (Figure 3). Depending on the number of siloxane units in the spacer, either ferroelectric (odd number of siloxanes) or antiferroelectric (even) switchable polar smectic phases can be induced. However, ferroelectric switching was only observed for carbosilane analogs.

\section{FIGURE 3}

Oligomers can be considered as an intermediate step between dimers and polymers. All of the oligomers reported to date that contain bent-shaped moieties are Si-based (Figure 4). ${ }^{[100 c]}$ All of these materials showed optically isotropic mesophases regardless of the length of the terminal chain $\left(C_{n}\right)$ and the spacer $\left(C_{m}\right)$ to the siloxane backbone (Figure 4). A distorted $\mathrm{SmC}_{\mathrm{a}} \mathrm{P}_{\mathrm{A}}$ mesophase layer organization was reported for the compounds with longer chains (m: 10,11; n: 8, 12,16) and a nonswitchable Col phase was described for the shorter analog (m:10, n:8). A systematic study and discussion on the influence of the Si-containing linkers upon the mesophase type and switching 
behavior of oligomers and dendritic liquid crystalline materials was reported by the same group. ${ }^{[100 \mathrm{~d}]}$ Interestingly, whereas linear and branched oligosiloxane or carbosilane backbones induce optically isotropic mesophases and ferroelectric switching, rigid cyclic units (siloxanes$4 \times \mathrm{BAN}$ and silsesquioxanes-8xBAN) promote strongly birefringent antiferroelectric smectic phases.

\section{FIGURE 4}

This trend was confirmed by Pan et al. ${ }^{[101]}$ for other bent-core liquid crystals based on polyhedral oligomeric silsesquioxane (POSS) cores (8xBAN). It was also found that an increase in the content of the silylated part favored monolayer arrangements vs. the bilayer organizations of the materials with lower silicon contents.

\section{B2. DENDRIMERS AND POLYMERS.}

Very few results on bent-core based macromolecules, such as dendrimers, side-chain and mainchain polymers or networks, have been reported but those that have been published are very interesting. Such materials have been made with the aim of combining the unique properties of bent-core liquid crystals and the great advantages of high molecular weight materials (stability, processability, mechanical properties, flexibility, etc.). It would be desirable to obtain these properties at room temperature, either in a mesophase or in a glassy state.

\section{B2.1. Mesogenic bent-core dendrimers.}

The scarce studies on branched or dendritic bent-core based macromolecules show that these materials behave in a different way to dimers or oligomers. A series of carbosilane- and siloxanebased dendritic structures was described by Tschierke et al. ${ }^{[100 \mathrm{~d}]}{ }^{[102]} \mathrm{A} \mathrm{SmCP}_{\mathrm{R}}$ mesophase with a very broad temperature range was reported for a carbosilane dendrimer and this phase structure can be frozen at room temperature. In this mesophase the molecules are tilted within the layer, but with the polar and tilt directions changing randomly from layer to layer. On applying a sufficiently strong electric field, a ferroelectric state can be achieved with very high Ps. Alternatively, dendritic structures with 3, 4, 6 and 15 bent-core units showed non-classical antiferroelectric switching monolayer smectic phases with dark conglomerate textures coexisting with achiral domains. This type of behavior was observed regardless of the number of units and the type of dendritic core.

Completely different behavior was reported for non-silylated dendrimers bearing bent-core units. Low generations of covalent PPI dendrimers reported by Kardas et al. ${ }^{[103]}$ form either rectangular columnar or non-polar smectic phases with a bilayer structure, depending on the length of the inner 
spacer connecting the bent-shaped units to the dendritic core. Once again this behavior was independent of the terminal chain length. Stabilization of the lamellar or columnar mesomorphism was also described by Vergara et al. ${ }^{[104]}$ for a large number of ionic PPI and PEI bent-core based dendritic molecules, with remarkable differences in the transition temperatures not observed on changing the generation of the dendrimer and the length of the spacer.

\section{B2.2. Mesogenic bent-core side-chain polymers.}

The first example of this type of polymer was reported by Keith et al., ${ }^{[105]}$ who prepared a polysiloxane backbone with a 1:15 bent-core/dimethylsiloxane ratio (Figure 5). This diluted sidechain copolymer showed an optically isotropic ferroelectric SmCP mesophase, which had chiral domains, over a wide temperature range. Polysilylated backbones were also used by Achten et al. ${ }^{[100 \mathrm{c}]}$ and Bubnov et al. ${ }^{[106]}$ with other bent-core designs (Figure 5). All of the macromolecules showed an optically isotropic SmCP mesophase (the nature of the switching was not studied due to the high viscosity of the materials) and the length of the terminal chain and spacer did not have a significant influence on the transition temperatures. Interestingly, in some cases these materials could be homeotropically aligned by shearing.

\section{FIGURE 5}

In addition to the Si-based bent-core liquid crystals already mentioned, unique examples of block copolymers that bring together the bent-core moieties and polystyrene blocks have been prepared by Tenetti et al. ${ }^{[107]}$ In this case, lamellar or columnar mesomorphism can be promoted depending on the content of the bent-core based block. On the other hand, the same authors ${ }^{[108]}$ were able to prepare acrylate- and methacrylate-based homopolymers containing 3,4'-biphenyl bent-core monomers. The compounds largely form lamellar liquid crystal mesophases (SmCP), but their high viscosity and glass transition temperatures seriously limit their electro-optical response.

Side-chain bent-core liquid crystalline polymers have also been obtained by hydrogen-bonding interactions. ${ }^{[109]}$ Polymeric materials that show either columnar or lamellar phases (depending on the nature of the bent-core structure) were obtained successfully by two different routes; either reactive bent-core monomers were formed by self-assembly and then submitted to in situ photopolymerization or bent-core units were directly self-assembled onto a previously prepared polymer. The second approach has been used to attach different amounts of bent-core units to a poly(styrene- $b$-4-vinylpyridine) block copolymer $\left(\mathrm{PS}_{115}-b-\mathrm{P} 4 \mathrm{VP}_{112}\right) .{ }^{[110]}$ On increasing the amount of bent-core units the mesophase morphology changed from lamellae to cylinders, while in both 
cases the P4VP/bent-core complex retained a bilayer SmA phase within the liquid crystalline domains. Copolymers bearing both hydrogen-bonded and covalently bonded units have also been reported. ${ }^{[111]}$ In these materials polar smectic phases can be stabilized by modulating the proportions of the different components.

Finally, a different approach to obtain bent-core side-chain polymers is the direct side-attachment of the bent-core mesogenic units to the polymer backbone to obtain the so-called bent-core mesogenjacketed liquid crystalline polymers (Figure 6), which form columnar mesophases. ${ }^{[112]}$

\section{FIGURE 6}

\section{B2.3. Mesogenic bent-core main-chain polymers.}

Only a few examples of main-chain polymers have been synthesized but these are very attractive systems (Figure 7). ${ }^{[113]}$ Choi et al. ${ }^{[113 a]}$ reported the first examples of main-chain polymers bearing an azomethine-derived bent-shaped mesogen as a repeating unit. These compounds showed nematic, $\mathrm{B}_{2}$ or $\mathrm{B}_{1}$ mesomorphism depending on the characteristics of the bent-core unit. Alternatively, the same authors also reported main-chain polymers based on bent-core structures with very acute angles and they claimed the formation of smectic $\mathrm{C}$ phases and ferroelectric behavior for one example. ${ }^{[113 c]}$

Bent-core monomers or bent-shaped and calamitic repeat units were also combined by Galli et al., ${ }^{[113 b]}$ who used either acyclic diene metathesis polymerization (ADMET) or alternating diene metathesis polycondensation (ALMET) to prepare both homopolymers and a block copolymer, both of which showed columnar but mainly nematic organizations. Interestingly, Gimeno et al. ${ }^{[113 \mathrm{~d}]}$ reported the first example of a bent-core main-chain polymer to show the dark conglomerate mesophase over a wide temperature range. This phase vitrified at room temperature.

\section{FIGURE 7}

\section{B2.4. Polymeric networks.}

With a different aim in mind, but using rather similar approaches, direactive bent-core monomers have been used to create polymeric networks (Figure 8). ${ }^{[79 d, 114]}$ The first example of a highly crosslinked network was obtained by in situ polymerization of a mixture of an acrylate reactive bent-core monomer (26) (70\%) and a non-reactive one (27). ${ }^{[114 \mathrm{a}]}$ The new material showed a switchable SmCP mesophase. On the other hand, the thermal and radical photopolymerization was carried out for 1,3-dienoxy bent-core monomers $(\mathbf{2 8}) .{ }^{[79 d]}$ The in situ photopolymerization of the SmCP phase 
of biphenyl-based acrylates or methacrylates, afforded free-films that retained the SmCP-like order at room temperature (29). ${ }^{[14 b]}$ In contrast, nematic or columnar mesomorphism was reported for a series of ladder-type polyethers depending on the substituents attached to the central phenyl ring of the bent-core monomer (30). ${ }^{[114 c]}$

\section{FIGURE 8}

\section{AT THE BOUNDARY OF BENT-CORE LIQUID CRYSTALS}

Closely related to bent-core mesogens are the so called 'hockey-stick' molecules, which were first described by Dingemans et al. ${ }^{[115]}$ in 2001. These molecules can be regarded as intermediate between the classical rod-like and the bent-core compounds, both in shape and in electrooptical behavior. In these compounds the steric interactions are too small to promote typical polar bent-core mesophases.

Two main molecular designs have been employed for this new type of mesogen. In one class, molecules have a bent aromatic core in which the angle of the molecular long axis results from cores in strongly non-symmetric four- or five-ring aromatic systems. In the second type the bend is introduced by a hydrocarbon chain attached in the meta-position of a terminal phenyl ring.

\section{C1. HIGHLY ASYMMETRIC BENT-CORE MOLECULES.}

Both 1,2,4- and 1,3,4-oxadiazole rings have been used to provide the bending angle in this sort of mesogen, as exemplified by the materials reported by Gallardo's group. ${ }^{[16]}$ Depending on the number and type of rings and the length of terminal chains it was possible to induce different sequences, with SmA, SmC and N mesophases observed. Furthermore, the asymmetric 1,3,4oxadiazole-based molecule (31) described by Kang et al. ${ }^{[30 \mathrm{~d}]}$ showed, in addition to $\mathrm{N}$ and $\mathrm{SmC}$ mesophases, a low temperature Bx phase that had chiral domains.

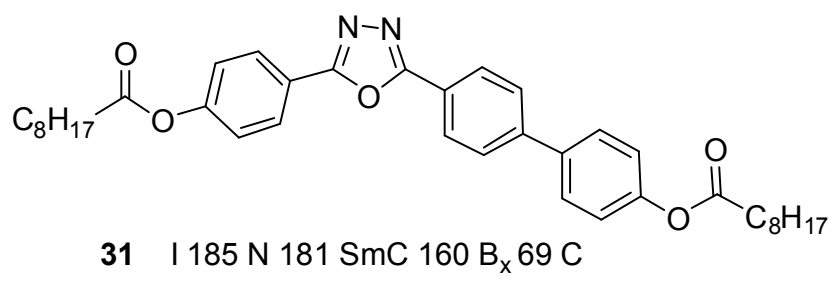


Alternatively, most of the 'hockey stick' mesogens bear typical cores used in bent-shaped liquid crystals. ${ }^{[117]}$ Yu et al. ${ }^{[17 a]}$ described 1,3-phenylene-based compounds that, depending on the ratio of aromatic rings in the lateral structures, were either not mesogenic (1/2 ratio) or, with more asymmetric molecules (1/3 ratio), showed a columnar $B_{1}$ mesophase or the anticlinic smectic mesophase (SmCa), a rather common mesophase for 'hockey stick'compounds (Figure 9).

\section{FIGURE 9}

2,7-Naphthalene-based molecules $(\mathbf{3 2})^{[117 b]}$ followed the same pattern, with the SmCa phase obtained in most cases along with SmC and $\mathrm{N}$ mesosphases depending on the length of the terminal chains and the substituents (Figure 10). Additionally, depending on the alkoxy chain lengths, the I$\mathrm{N}-\mathrm{SmA}-\mathrm{SmCa}\left(\mathrm{C}_{7}\right.$ and $\left.\mathrm{C}_{8}\right)$ or $\mathrm{N}-\mathrm{SmCa}\left(\mathrm{C}_{9}\right.$ and $\left.\mathrm{C}_{10}\right)$ phase sequences have been reported for $3,4^{\prime}-$ biphenyl derivatives (33). In this series a single SmCa phase was observed for compounds with longer tails $\left(\mathrm{C}_{11}-\mathrm{C}_{18}\right){ }^{[117 \mathrm{~d}]}$

Alternatively, N-benzoylpiperazine ${ }^{[117 c]}$ achiral structures (34) have also been reported to provide $\mathrm{SmA}$ and SmC phases that can be transformed into polar organizations by applying electric fields. An SmI phase that showed ferroelectric switching was also reported.

FIGURE 10

\section{C2. meta-SUBSTITUTED MESOGENS.}

The first example of this type of 'hockey-stick' molecule was reported by Hird et al. ${ }^{[118]}$ (Figure 11). Notably, the 2,3,4-trifluoroterphenyl systems form a $\mathrm{Col}_{\mathrm{h}}$ mesophase generated through the assembly of molecules into a disk-shaped entity through aromatic-fluoroaromatic stacking, while a non-conventional lamellar mesomorphism (SmA, SmC) can be induced for phenyl ester analogs regardless of the length of the terminal chains.

\section{FIGURE 11}

Unsubstituted rod-like structures that contain three or four aromatic rings are certainly the most common designs in these mesogens (Table 23). Different mesophases can be induced (N, SmA or $\mathrm{SmC})^{[119]}$ depending on both the rigid core structure and the terminal chain lengths (at the meta- or para- positions). Interestingly, two different types of SmC phase can be found in many of these compounds: the classical synclinic $\mathrm{SmC}(\mathrm{SmCs})$ and the anticlinic $\mathrm{SmC}(\mathrm{SmCa})$ phase. This trend has been related to the two conformations that this type of molecule can adopt: one conformation can be regarded as relatively extended and the other is more bent, i.e. like a 'hockey stick'. 
Yu et al. ${ }^{[19 c]}$ were able to stabilize the SmCa phase both by modulating the length of the chain (n: 4-10) in the meta-position and by increasing the number of aromatic rings from 3 to 4 while fixing an $n$-dodecyloxy chain in the para-position. These authors - along with Enz et al. ${ }^{[120]}$ - proved that short terminal chains in the meta-position favor anticlinic arrangements whereas terminal chains that are too long, promote synclinic organizations when the chain in the para-position is fixed at 10 or 12 carbon atoms. However, this trend can be changed when a methyl group is introduced orthoto the meta-located chain, ${ }^{[121]}$ resulting in suppression of the SmCs phase for the shorter chains and wide ranges of $\mathrm{N}-\mathrm{SmCa}$ mesomorphism for the longer ones.

TABLE 23

\section{SYNTHETIC PATHWAYS TO BENT-CORE LIQUID CRYSTALS}

The synthetic strategies reported to date for the preparation of bent-core liquid crystals can be divided in two large groups depending on the symmetry of the target bent-core molecule (Figures 12 and 13). A schematic summary of the most common synthetic strategies used to prepare these materials is shown below.

\section{FIGURES 12 AND 13}

D1. STRATEGY A (for symmetric molecules): Symmetric molecules are those that contain two identical lateral parts (including the rigid lateral structure and terminal chain) and the preparation of these materials has been achieved in two ways depending on the structural requirements:

Strategy A1. The most common way to prepare symmetric bent-shaped molecules is the attachment of two appropriately functionalized extended lateral structures to a bifunctional central core. The central core (if not commercially available) and the lateral structure are prepared separately and coupled under suitable conditions to obtain the final product. A representative example is shown in Scheme 1. ${ }^{[10]}$

\section{SCHEME 1}

Strategy A2. The second strategy involves sequential building of the lateral structures by attachment of small fragments to both sides of central bent-core (see Scheme 2). ${ }^{[17]}$ 


\section{SCHEME 2}

D2. STRATEGY B (for non-symmetric molecules): Generally, when the complexity of the bent-core molecules increases, the number of synthetic steps required achieving the desired design rises proportionally. In a bent-shaped molecule, if the lateral structures or the terminal chains are not identical or functional groups must be incorporated in only one of the terminal chains (as necessary to prepare dimers, oligomers or side-chain polymers and dendrimers), more elaborate syntheses are required.

Strategy B1. In most cases, non-symmetric molecules are built by initially attaching one complete lateral structure to the central bent core to obtain half of the molecule. The other different extended lateral structure is then attached in a single step, as shown in Scheme $3 .^{[5 \mathrm{c}]}$

\section{SCHEME 3}

Strategy B2. A different approach to prepare asymmetric molecules involves the preparation of half of the molecule and the subsequent addition of small fragments to build the whole structure, as shown in Scheme 4. ${ }^{[104]}$

\section{SCHEME 4}

\section{REFERENCES}

[1] Niori, T. (1996) Journal of Materials Chemistry 6, 1231.

[2] (a) Pelzl, G., Diele, S., and Weissflog, W. (1999) Advanced Materials 11, 707; (b) Walba, D. M. (2003) Topics in Stereochemistry, Materials-Chirality 24, 457; (c) Hird, M. (2005) Liquid Crystals Today 14, 9; (d) Weissflog, W., Shreenivasa Murthy, H. N., Diele, S., Pelzl, G., Percec, V., Li, M. H., and Matharu, A. S. (2006) Philosophical Transactions of the Royal Society A: Mathematical, Physical and Engineering Sciences 364, 2657; (e) Takezoe, H., and Takanishi, Y. (2006) Japanese Journal of Applied Physics, Part 1: Regular Papers and Short Notes and Review Papers 45, 597; (f) Reddy, R. A., and Tschierske, C. (2006) Journal of Materials Chemistry 16, 907.

[3] (a) Sekine, T., Takanishi, Y., Niori, T., Watanabe, J., and Takezoe, H. (1997) Japanese Journal of Applied Physics, Part 2: Letters 36, L1201; (b) Schröder, M. W., Diele, S., Pelzl, G., and Weissflog, W. (2004) ChemPhysChem 5, 99; (c) Kurosu, H., Kawasaki, M., Hirose, M., Yamada, M., Kang, S., Thisayukta, J., Sone, M., Takezoe, H., and Watanabe, J. (2004) Journal of Physical Chemistry A 108, 4674.

[4] (a) Thisayukta, J., Nakayama, Y., Kawauchi, S., Takezoe, H., and Watanabe, J. (2000) Journal of the American Chemical Society 122, 7441; (b) Svoboda, J., Novotná, V., Kozmík, V., Glogarová, M., Weissflog, W., Diele, S., and Pelzl, G. (2003) Journal of Materials Chemistry 13, 2104; (c) Gimeno, 
N., Clemente, M. J., Forcén, P., Serrano, J. L., and Ros, M. B. (2009) New Journal of Chemistry 33, 2007.

[5] (a) Shen, D., Diele, S., Wirt, I., and Tschierske, C. (1998) Chemical Communications, 2573; (b) Shen, D., Pegenau, A., Diele, S., Wirth, I., and Tschierske, C. (2000) Journal of the American Chemical Society 122, 1593; (c) Achten, R., Cuypers, R., Giesbers, M., Koudijs, A., Marcelis, A. T. M., and Sudhölter, E. J. R. (2004) Liquid Crystals 31, 1167; (d) Pintre, I. C., Gimeno, N., Serrano, J. L., Ros, M. B., Alonso, I., Folcia, C. L., Ortega, J., and Etxebarria, J. (2007) Journal of Materials Chemistry 17, 2219.

[6] (a) Pelzl, G., Diele, S., Jákli, A., Lischka, C., Wirth, I., and Weissflog, W. (1999) Liquid Crystals 26, 135; (b) Umadevi, S., and Sadashiva, B. K. (2005) Liquid Crystals 32, 1233; (c) Umadevi, S., and Sadashiva, B. K. (2006) Chemistry of Materials 18, 5186; (d) Yelamaggad, C. V., Mathews, M., Nagamani, S. A., Rao, D. S. S., Prasad, S. K., Findeisen, S., and Weissflog, W. (2007) Journal of Materials Chemistry 17, 284.

[7] (a) Reddy, R. A., and Sadashiva, B. K. (2002) Liquid Crystals 29, 1365; (b) Shreenivasa Murthy, H. N., and Sadashiva, B. K. (2003) Liquid Crystals 30, 1051.

[8] (a) Diele, S., Grande, S., Kruth, H., Lischka, C., Pelzl, G., Weissflog, W., and Wirth, I. (1998) Ferroelectrics 212, 169; (b) Mátyus, E., and Fodor-Csorba, K. (2003) Liquid Crystals 30, 445.

[9] (a) Pelzl, G., Diele, S., Grande, S., Jákli, A., Lischka, C., Kresse, H., Schmalfuss, H., Wirth, I., and Weissflog, W. (1999) Liquid Crystals 26, 401; (b) Weissflog, W., Lischka, C., Diele, S., Pelzl, G., and Wirth, I. (1999) Molecular Crystals and Liquid Crystals Science and Technology Section A: Molecular Crystals and Liquid Crystals 328, 101; (c) Dehne, H., Pötter, M., Sokolowski, S., Weissflog, W., Diele, S., Pelzl, G., Wirth, I., Kresse, H., Schmalfuss, H., and Grande, S. (2001) Liquid Crystals 28, 1269.

[10] Weissflog, W., Nádasi, H., Dunemann, U., Pelzl, G., Diele, S., Eremin, A., and Kresse, H. (2001) Journal of Materials Chemistry 11, 2748.

[11] Shreenivasa Murthy, H. N., Bodyagin, M., Diele, S., Baumeister, U., Pelzl, G., and Weissflog, W. (2006) Journal of Materials Chemistry 16, 1634.

[12] (a) Weissflog, W., Lischka, C., Diele, S., Pelzl, G., Wirth, I., Grande, S., Kresse, H., Schmalfuss, H., Hartung, H., and Stettler, A. (1999) Molecular Crystals and Liquid Crystals Science and Technology Section A: Molecular Crystals and Liquid Crystals 333, 203; (b) Fodor-Csorba, K., Vajda, A., Jákli, A., Slugov, C., Trimmel, G., Demus, D., Gács-Baitz, E., Holly, S., and Galli, G. (2004) Journal of Materials Chemistry 14, 2499.

[13] Kwon, S. S., Kim, T. S., Lee, C. K., Choi, H., Shin, S. T., Park, J. K., Zin, W. C., Chien, L. C., Choi, S. S., and Choi, E. J. (2006) Liquid Crystals 33, 1005.

[14] (a) Weissflog, W., Kovalenko, L., Wirth, I., Diele, S., Pelzl, G., Schmalfuss, H., and Kresse, H. (2000) Liquid Crystals 27, 677; (b) Wirth, I., Diele, S., Eremin, A., Pelzl, G., Grande, S., Kovalenko, L., Pancenko, N., and Weissflog, W. (2001) Journal of Materials Chemistry 11, 1642.

[15] (a) Kovalenko, L., Schröder, M. W., Amaranatha Reddy, R., Diele, S., Pelzl, G., and Weissflog, W. (2005) Liquid Crystals 32, 857; (b) Keith, C., Prehm, M., Panarin, Y. P., Vij, J. K., and Tschierske, C. (2010) Chemical Communications 46, 3702.

[16] (a) Weissflog, W., Lischka, C., Benné, I., Scharf, T., Pelzl, G., Diele, S., and Kruth, H. (1997) Proceedings of SPIE - The International Society for Optical Engineering 3319, 14; (b) Matraszek, J., Mieczkowski, J., Szydlowska, J., and Gorecka, E. (2000) Liquid Crystals 27, 429; (c) Weissflog, W., Pelzl, G., Kresse, H., Baumeister, U., Brand, K., Schröder, M. W., Tamba, M. G., Findeisen-Tandel, S., Kornek, U., Stern, S., Eremin, A., Stannarius, R., and Svoboda, J. (2010) Journal of Materials Chemistry 20, 6057.

[17] Umadevi, S., and Sadashiva, B. K. (2005) Liquid Crystals 32, 287.

[18] Radhika, S., Sadashiva, B. K., and Raghunathan, V. A. (2008) Ferroelectrics 364, 20.

[19] Reddy, R. A., and Sadashiva, B. K. (2004) Liquid Crystals 31, 1069.

[20] (a) Lee, S. K., Naito, Y., Shi, L., Tokita, M., Takezoe, H., and Watanabe, J. (2007) Liquid Crystals 34, 935; (b) Lee, S. K., Tokita, M., Takezoe, H., and Watanabe, J. (2008) Ferroelectrics 365, 1; (c) Lee, S. K., Shi, L., Ishige, R., Kang, S., Tokita, M., and Watanabe, J. (2008) Chemistry Letters 37, 1230; 
(d) Li, X., Kang, S., Lee, S. K., Tokita, M., and Watanabe, J. (2010) Japanese Journal of Applied Physics 49; (e) Choi, E. J., Cui, X., Ohk, C. W., Zin, W. C., Lee, J. H., Lim, T. K., and Jang, W. G. (2010) Journal of Materials Chemistry 20, 3743; (f) Alonso, I., Martinez-Perdiguero, J., Ortega, J., Folcia, C. L., Etxebarria, J., Gimeno, N., and Ros, M. B. (2010) Liquid Crystals 37, 1465.

[21] (a) Kozmík, V., Kuchař, M., Svoboda, J., Novotná, V., Glogarová, M., Baumeister, U., Diele, S., and Pelzl, G. (2005) Liquid Crystals 32, 1151; (b) Kozmík, V., Kovářová, A., Kuchař, M., Svoboda, J., Novotná, V., Glogarová, M., and Kroupa, J. (2006) Liquid Crystals 33, 41; (c) Kohout, M., Svobodaa, J., Novotná, V., Glogarová, M., and Pociecha, D. (2010) Liquid Crystals 37, 987.

[22] (a) Liao, C. T., Liu, J. Y., Jiang, M. H., Zou, S. F., Wu, N. C., Wu, Z. L., and Lee, J. Y. (2010) Molecular Crystals and Liquid Crystals 533, 115; (b) Liao, C. T., Lee, J. Y., and Lai, C. C. (2011) Molecular Crystals and Liquid Crystals 534, 95.

[23] Dantlgraber, G., Shen, D., Diele, S., and Tschierske, C. (2002) Chemistry of Materials 14, 1149.

[24] Shen, D., Diele, S., Pelzl, G., Wirth, I., and Tschierske, C. (1999) Journal of Materials Chemistry 9 , 661.

[25] (a) Rivera, J. P., Nozary, H., and Piguet, C. (2002) Ferroelectrics 276, 157; (b) Nozary, H., Piguet, C., Rivera, J. P., Tissot, P., Morgantini, P. Y., Weber, J., Bernardinelli, G., Bünzli, J. C. G., Deschenaux, R., Donnio, B., and Guillon, D. (2002) Chemistry of Materials 14, 1075.

[26] Yelamaggad, C. V., Nagamani, S. A., Nair, G. G., Rao, D. S. S., Prasad, S. K., and Jakli, A. (2002) Liquid Crystals 29, 1181.

[27] (a) Cavero, E., De La Fuente, M. R., Beltránp, E., Romero, P., Serrano, J. L., and Giménez, R. (2007) Chemistry of Materials 19, 6230; (b) Cavero, E., Lydon, D. P., Uriel, S., De La Fuente, M. R., Serrano, J. L., and Giménez, R. (2007) Angewandte Chemie - International Edition 46, 5175.

[28] Sánchez, I., Mayoral, M. J., Ovejero, P., Campo, J. A., Heras, J. V., Cano, M., and Lodeiro, C. (2010) New Journal of Chemistry 34, 2937.

[29] Kovářová, A., Svoboda, J., Novotná, V., Glogarová, M., Salamonczyk, M., Pociecha, D., and Gorecka, E. (2010) Liquid Crystals 37, 1501.

[30] (a) Torgova, S. I., Karamysheva, L. A., Geivandova, T. A., and Strigazzi, A. (2001) Molecular Crystals and Liquid Crystals Science and Technology Section A: Molecular Crystals and Liquid Crystals 365, 99; (b) Karamysheva, L. A., Agafonova, I. F., Geivandova, T. A., Torgova, S. I., and Becchi, M. (2002) Proceedings of SPIE - The International Society for Optical Engineering 4759, 46; (c) Torgova, S. I., Geivandova, T. A., Francescangeli, O., and Strigazzi, A. (2003) Pramana - Journal of Physics 61, 239; (d) Kang, S., Saito, Y., Watanabe, N., Tokita, M., Takanishi, Y., Takezoe, H., and Watanabe, J. (2006) Journal of Physical Chemistry B 110, 5205; (e) Apreutesei, D., and Mehl, G. H. (2007) Journal of Materials Chemistry 17, 4711; (f) Görtz, V., Southern, C., Roberts, N. W., Gleeson, H. F., and Goodby, J. W. (2009) Soft Matter 5, 463.

[31] (a) Lee, S. K., Shi, L., Tokita, M., and Watanabe, J. (2008) Chemistry Letters 37, 1134; (b) Gimeno, N., Barbeŕa, J., Serrano, J. L., Ros, M. B., De La Fuente, M. R., Alonso, I., and Folcia, C. L. (2009) Chemistry of Materials 21, 4620.

[32] Thisayukta, J., Nakayama, Y., and Watanabe, J. (2000) Liquid Crystals 27, 1129.

[33] Majumdar, K. C., Chattopadhyay, B., Chakravorty, S., Pal, N., and Sinha, R. K. (2008) Tetrahedron Letters 49, 7149.

[34] Lesac, A., Loc Nguyen, H., Narančić, S., Baumeister, U., Diele, S., and Bruce, D. (2006) Liquid Crystals 33, 167.

[35] (a) Pelz, K., Weissflog, W., Baumeister, U., and Diele, S. (2003) Liquid Crystals 30, 1151; (b) Vakhovskaya, Z., Lorenzo Chao, J., Baumeister, U., Pelz, K., Schröder, M. W., Weissflog, W., and Kresse, H. (2009) Phase Transitions 82, 470.

[36] Dunemann, U., Schröder, M. W., Pelzl, G., Diele, S., and Weissflog, W. (2005) Liquid Crystals 32, 151.

[37] Schröder, M. W., Diele, S., Pelzl, G., Dunemann, U., Kresse, H., and Weissflog, W. (2003) Journal of Materials Chemistry 13, 1877.

[38] Gesekus, G., Dierking, I., Gerber, S., Wulf, M., and Vill, V. (2004) Liquid Crystals 31, 145. 
[39] Pociecha, D., Ohta, K., Januszko, A., Kaszynski, P., and Endo, Y. (2008) Journal of Materials Chemistry 18, 2978.

[40] Glettner, B., Hein, S., Reddy, R. A., Baumeister, U., and Tschierske, C. (2007) Chemical Communications, 2596.

[41] (a) Pintre, I. C., Serrano, J. L., Ros, M. B., Ortega, J., Alonso, I., Martínez-Perdiguero, J., Folcia, C. L., Etxebarria, J., Goc, F., Amabilino, D. B., Puigmartí-Luis, J., and Gomar-Nadal, E. (2008) Chemical Communications, 2523; (b) Pintre, I. C., Serrano, J. L., Ros, M. B., Martínez-Perdiguero, J., Alonso, I., Ortega, J., Folcia, C. L., Etxebarria, J., Alicante, R., and Villacampa, B. (2010) Journal of Materials Chemistry 20, 2965; (c) Kozmík, V., Poláek, P., Seidler, A., Kohout, M., Svoboda, J., Novotná, V., Glogarová, M., and Pociecha, D. (2010) Journal of Materials Chemistry 20, 7430; (d) Geese, K., Prehm, M., and Tschierske, C. (2010) Journal of Materials Chemistry 20, 9658.

[42] (a) Gimeno, N., Ros, M. B., Serrano, J. L., and De La Fuente, M. R. (2004) Angewandte Chemie International Edition 43, 5235; (b) Pérez, A., Gimeno, N., Vera, F., Ros, M. B., Serrano, J. L., and De La Fuente, M. R. (2008) European Journal of Organic Chemistry, 826; (c) Gimeno, N., Ros, M. B., Serrano, J. L., and De la Fuente, M. R. (2008) Chemistry of Materials 20, 1262; (d) Wang, L. Y., Chiang, I. H., Yang, P. J., Li, W. S., Chao, I. T., and Lin, H. C. (2009) Journal of Physical Chemistry B 113, 14648.

[43] (a) Yang, P. J., and Lin, H. C. (2006) Liquid Crystals 33, 587; (b) Folcia, C. L., Alonso, I., Ortega, J., Etxebarria, J., Pintre, I., and Ros, M. B. (2006) Chemistry of Materials 18, 4617; (c) Lee, S. K., Kang, S., Tokita, M., and Watanabe, J. (2010) Liquid Crystals 37, 593; (d) Nguyen, H. T., Bedel, J. P., Rouillon, J. C., Marcerou, J. P., and Achard, M. F. (2003) Pramana - Journal of Physics 61, 395.

[44] Wrobel, S., Haase Kilian, W., Chien, L. C., and Chong-Kwang, L. (2000) Ferroelectrics 243, 277.

[45] (a) Rouillon, J. C., Marcerou, J. P., Laguerre, M., Nguyen, H. T., and Achard, M. F. (2001) Journal of Materials Chemistry 11, 2946; (b) Nguyen, H. T., Rouillon, J. C., Marcerou, J. P., Bedel, J. P., Barois, P., and Sarmento, S. (1999) Molecular Crystals and Liquid Crystals Science and Technology Section A: Molecular Crystals and Liquid Crystals 328, 177.

[46] Gomola, K., Guo, L., Pociecha, D., Araoka, F., Ishikawa, K., and Takezoe, H. (2010) Journal of Materials Chemistry 20, 7944.

[47] (a) Prasad, V. (2001) Molecular Crystals and Liquid Crystals Science and Technology Section A: Molecular Crystals and Liquid Crystals 363, 167; (b) Prasad, V., Kang, S. W., and Kumar, S. (2003) Journal of Materials Chemistry 13, 1259; (c) Prasad, V., and Jákli, A. (2004) Liquid Crystals 31, 473; (d) Prasad, V., Kang, S. W., Qi, X., and Kumar, S. (2004) Journal of Materials Chemistry 14, 1495; (e) Rahman, L., Asik, J., Kumar, S., and Tschierske, C. (2008) Liquid Crystals 35, 1263; (f) Huang, Y. M., Ma, Q. I., and Zhai, B. G. (2010) Key Engineering Materials 428-429, 79; (g) Mathews, M., Kang, S., Kumar, S., and Li, Q. (2011) Liquid Crystals 38, 31.

[48] (a) Vorlander, D., and Apel, A. (1932) Berichte Der Deutschen Chemischen Gesellschaft 65, 1101; (b) Pelzl, G., Wirth, I., and Weissflog, W. (2001) Liquid Crystals 28, 969.

[49] (a) Mieczkowski, J., Szydlowska, J., Matraszek, J., Pociecha, D., Gorecka, E., Donnio, B., and Guillon, D. (2002) Journal of Materials Chemistry 12, 3392; (b) Mieczkowski, J., Gomola, K., Koseska, J., Pociecha, D., Szydlowska, J., and Gorecka, E. (2003) Journal of Materials Chemistry 13, 2132; (c) Pyc, P., Mieczkowski, J., Pociecha, D., Gorekca, E., Donnio, B., and Guillon, D. (2004) Journal of Materials Chemistry 14, 2374; (d) Gomola, K., Guo, L., Dhara, S., Shimbo, Y., Gorecka, E., Pociecha, D., Mieczkowski, J., and Takezoe, H. (2009) Journal of Materials Chemistry 19, 4240; (e) Gomola, K., Guo, L., Gorecka, E., Pociecha, D., Mieczkowski, J., Ishikawa, K., and Takezoe, H. (2009) Chemical Communications, 6592.

[50] (a) Wang, K., Jákli, A., Li, H., Yang, Y., and Wen, J. (2001) Liquid Crystals 28, 1705; (b) Li, Z., Salamon, P., Jakli, A., Wang, K., Qin, C., Yang, Q., Liu, C., and Wen, J. (2010) Liquid Crystals 37, 427; (c) Seltmann, J., Marini, A., Mennucci, B., Dey, S., Kumar, S., and Lehmann, M. (2011) Chemistry of Materials 23, 2630.

[51] (a) Mátyus, E., and Keseru, K. (2001) Journal of Molecular Structure: THEOCHEM 543, 89; (b) Amaranatha Reddy, R., Sadashiva, B. K., and Dhara, S. (2001) Chemical Communications, 1972; (c) 
Murthy, H. N. S., and Sadashiva, B. K. (2004) Liquid Crystals 31, 1347; (d) Amaranatha Reddy, R., Sadashiva, B. K., and Raghunathan, V. A. (2004) Chemistry of Materials 16, 4050.

[52] (a) Niori, T., Yamamoto, J., and Yokoyama, H. (2004) Molecular Crystals and Liquid Crystals 409, 475; (b) Niori, T., Yamamoto, J., and Yokoyama, H. (2004) Molecular Crystals and Liquid Crystals 411, 283/[1325]; (c) Majumdar, K. C., Shyam, P. K., and Chakravorty, S. (2010) Liquid Crystals 37, 1237.

[53] (a) Krishnan, S. A. R., Weissflog, W., and Friedemann, R. (2005) Liquid Crystals 32, 847; (b) Ananda Rama Krishnan, S., Weissflog, W., Pelzl, G., Diele, S., Kresse, H., Vakhovskaya, Z., and Friedemann, R. (2006) Physical Chemistry Chemical Physics 8, 1170.

[54] Bedel, J. P., Rouillon, J. C., Marcerou, J. P., Laguerre, M., Nguyen, H. T., and Achard, M. F. (2001) Liquid Crystals 28, 1285.

[55] (a) Weissflog, W., Naumann, G., Kosata, B., Schröder, M. W., Eremin, A., Diele, S., Vakhovskaya, Z., Kresse, H., Friedemann, R., Ananda Rama Krishnan, S., and Pelzl, G. (2005) Journal of Materials Chemistry 15, 4328; (b) Tamba, M. G., Baumeister, U., Pelzl, G., and Weissflog, W. (2010) Liquid Crystals 37, 853.

[56] Amaranatha Reddy, R., Baumeister, U., Chao, J. L., Kresse, H., and Tschierske, C. (2010) Soft Matter 6, 3883.

[57] (a) Bedel, J. P., Rouillon, J. C., Marcerou, J. P., Laguerre, M., Achard, M. F., and Nguyen, H. T. (2000) Liquid Crystals 27, 103; (b) Bedel, J. P., Rouillon, J. C., Marcerou, J. P., Laguerre, M., Nguyen, H. T., and Achard, M. F. (2002) Journal of Materials Chemistry 12, 2214; (c) Subala, S., Sundar, S., Tamilenthi, V. P., and Sastry, S. (2011) Recent Research in Science and Technology 3, 120.

[58] (a) Chalapathi, P. V., Srinivasulu, M., Goud, B. V. S., Pisipati, V. G. K. M., and Potukuchi, D. M. (2005) Ferroelectrics 322, 53; (b) Huang, Y. M., and Ma, Q. (2010) Liquid Crystals 37, 1119; (c) Chalapathi, P. V., Srinivasulu, M., Pisipati, V. G. K. M., Satyanarayana, C., and Potukuchi, D. M. (2011) Physica B: Condensed Matter (Amsterdam, Netherlands) 406, 2081.

[59] Deb, R., Nath, R. K., Paul, M. K., Rao, N. V. S., Tuluri, F., Shen, Y., Shao, R., Chen, D., Zhu, C., Smalyukh, I. I., and Clark, N. A. (2010) Journal of Materials Chemistry 20, 7332.

[60] Sadashiva, B. K., Shreenivasa Murthy, H. N., and Dhara, S. (2001) Liquid Crystals 28, 483.

[61] Prasad, V. (2001) Liquid Crystals 28, 1115.

[62] Balamurugan, S., Kannan, P., Chuang, M. T., and Wu, S. L. (2010) Industrial and Engineering Chemistry Research 49, 7121.

[63] Prasad, V., Shankar Rao, D. S., and Krishna Prasad, S. K. (2003) Molecular Crystals and Liquid Crystals 397, 79/[379].

[64] (a) Lee, C. K., Kwon, S. S., Chien, L. C., and Choi, E. J. (2000) Bulletin of the Korean Chemical Society 21, 1155; (b) Lee, C. K., Kwon, S. S., Zin, W. C., Kim, D. C., Shin, S. T., Song, J. H., Choi, E. J., and Chien, L. C. (2003) Liquid Crystals 30, 415; (c) Shin, S. T., Choi, H., Lee, C. K., Kwon, S. S., Kim, T. S., Choi, E. J., Kim, S. Y., Zin, W. C., Kim, D. C., and Chien, L. C. (2004) Liquid Crystals 31, 935; (d) Dunemann, U., Schröder, M. W., Reddy, R. A., Pelzl, G., Diele, S., and Weissflog, W. (2005) Journal of Materials Chemistry 15, 4051.

[65] (a) Yelamaggad, C. V., Hiremath, U. S., Nagamani, S. A., Shankar Rao, D. S., and Krishna Prasad, S. (2001) Journal of Materials Chemistry 11, 1818; (b) Walba, D. M., Körblova, E., Shao, R., and Clark, N. A. (2001) Journal of Materials Chemistry 11, 2743; (c) Achten, R., Koudijs, A., Karczmarzyk, Z., Marcelis, A. T. M., and Sudholter, E. J. R. (2004) Liquid Crystals 31, 215; (d) Maeda, Y., Niori, T., Yamamoto, J., and Yokoyama, H. (2005) Thermochimica Acta 431, 87.

[66] Liao, C. T., Liu, J. Y., Zou, S. F., Wu, N. C., Wu, Z. L., and Lee, J. Y. (2010) Journal of the Chinese Chemical Society 57, 124.

[67] (a) Sadashiva, B. K., Raghunathan, V. A., and Pratibha, R. (2000) Ferroelectrics 243, 249; (b) Novotná, V., Hamplová, V., Kašpar, M., Glogarová, M., and Pociecha, D. (2005) Liquid Crystals 32, 1115.

[68] (a) Amaranatha Reddy, R., and Sadashiva, B. K. (2003) Liquid Crystals 30, 1031; (b) Murthy, H. N. S., and Sadashiva, B. K. (2004) Liquid Crystals 31, 1337; (c) Amaranatha Reddy, K., and Sadashiva, 
B. K. (2004) Journal of Materials Chemistry 14, 1936; (d) Amaranatha Reddy, R., Raghunathan, V. A., and Sadashiva, B. K. (2005) Chemistry of Materials 17, 274; (e) Reddy, R. A., and Sadashiva, B. K. (2003) Liquid Crystals 30, 273.

[69] (a) Gorecka, E., Pociecha, D., Mieczkowski, J., Matraszek, J., Guillon, D., and Donnio, B. (2004) Journal of the American Chemical Society 126, 15946; (b) Gorecka, E., Pociecha, D., Matraszek, J., Mieczkowski, J., Shimbo, Y., Takanishi, Y., and Takezoe, H. (2006) Physical Review E - Statistical, Nonlinear, and Soft Matter Physics 73, 1.

[70] (a) Sadashiva, B. K., Amaranatha Reddy, R., Pratibha, R., and Madhusudana, N. V. (2002) Journal of Materials Chemistry 12, 943; (b) Shreenivasa Murthy, H. N., and Sadashiva, B. K. (2004) Liquid Crystals 31, 361; (c) Shreenivasa Murthy, H. N., and Sadashiva, B. K. (2004) Liquid Crystals 31, 567; (d) Amaranatha Reddy, R., and Sadashiva, B. K. (2004) Journal of Materials Chemistry 14, 310; (e) Guo, L., Dhara, S., Sadashiva, B. K., Radhika, S., Pratibha, R., Shimbo, Y., Araoka, F., Ishikawa, K., and Takezoe, H. (2010) Physical Review E - Statistical, Nonlinear, and Soft Matter Physics 81; (f) Radhika, S., Sadashiva, B. K., and Pratibha, R. (2010) Liquid Crystals 37, 417; (g) Gupta, M., Datta, S., Radhika, S., Sadashiva, B. K., and Roy, A. (2011) Soft Matter 7, 4735.

[71] (a) Sekine, T., Niori, T., Sone, M., Watanabe, J., Choi, S. W., Takanishi, Y., and Takezoe, H. (1997) Japanese Journal of Applied Physics, Part 1: Regular Papers and Short Notes and Review Papers 36, 6455; (b) Weissflog, W., Wirth, I., Diele, S., Pelzl, G., Schmalfuss, H., Schoss, T., and Warflinger, A. (2001) Liquid Crystals 28, 1603.

[72] (a) Bedel, J. P., Nguyen, H. T., Rouillon, J. C., Marcerou, J. P., Sigaud, G., and Barois, P. (1999) Molecular Crystals and Liquid Crystals Science and Technology Section A: Molecular Crystals and Liquid Crystals 332, 163; (b) Ogino, K., Kang, S., Doi, T., Takahashi, T., Takezoe, H., and Watanabe, J. (2005) Chemistry Letters 34, 450.

[73] Niori, T., Sekine, T., Watanabe, J., Furukawa, T., and Takezoe, H. (1997) Molecular Crystals and Liquid Crystals Science and Technology Section A: Molecular Crystals and Liquid Crystals 301, 337.

[74] (a) Heppke, G., Parghi, D. D., and Sawade, H. (2000) Liquid Crystals 27, 313; (b) Heppke, G., Parghi, D. D., and Sawade, H. (2001) Molecular Crystals and Liquid Crystals Science and Technology, Section A: Molecular Crystals and Liquid Crystals 352, 745/311; (c) Lee, S. K., Li, X., Kang, S., Tokita, M., and Watanabe, J. (2010) Journal of Materials Chemistry 20, 3615.

[75] Li, X. D., Lee, S. K., Kang, S. M., Tokita, M., Kawauchi, S., and Watanabe, J. (2009) Chemistry Letters 38, 424.

[76] Bedel, J. P., Rouillon, J. C., Marcerou, J. P., Nguyen, H. T., and Achard, M. F. (2004) Physical Review E - Statistical, Nonlinear, and Soft Matter Physics 69, 061702.

[77] Pelzl, G., Tamba, M. G., Findeisen-Tandel, S., Schröder, M. W., Baumeister, U., Diele, S., and Weissflog, W. (2008) Journal of Materials Chemistry 18, 3017.

[78] (a) Umadevi, S., J?kli, A., and Sadashiva, B. K. (2006) Soft Matter 2, 875; (b) Umadevi, S., Jákli, A., and Sadashiva, B. K. (2006) Soft Matter 2, 215.

[79] (a) Lee, C. K., Kwon, S. S., Shin, S. T., Choi, E. J., Lee, S., and Chien, L. C. (2002) Liquid Crystals 29, 1007; (b) Fodor-Csorba, K., Vajda, A., Galli, G., Jákli, A., Demus, D., Holly, S., and Gács-Baitz, E. (2002) Macromolecular Chemistry and Physics 203, 1556; (c) Kwon, S. S., Kim, T. S., Lee, C. K., Shin, S. T., Oh, L. T., Choi, E. J., Kim, S. Y., and Chien, L. C. (2003) Bulletin of the Korean Chemical Society 24, 274; (d) Sentman, A. C., and Gin, D. L. (2003) Angewandte Chemie - International Edition 42, 1815.

[80] (a) Gorecka, E., Pociecha, D., Araoka, F., Link, D. R., Nakata, M., Thisayukta, J., Takanishi, Y., Ishikawa, K., Watanabe, J., and Takezoe, H. (2000) Physical Review E - Statistical Physics, Plasmas, Fluids, and Related Interdisciplinary Topics 62, R4524; (b) Nakata, M., Link, D. R., Araoka, F., Thisayukta, J., Takanishi, Y., Ishikawa, K., Watanabe, J., and Takezoe, H. (2001) Liquid Crystals 28, 1301; (c) Kumazawa, K., Nakata, M., Araoka, F., Takanishi, Y., Ishikawa, K., Watanabe, J., and Takezoe, H. (2004) Journal of Materials Chemistry 14, 157; (d) Lee, S. K., Heo, S., Lee, J. G., Kang, K. T., Kumazawa, K., Nishida, K., Shimbo, Y., Takanishi, Y., Watanabe, J., Doi, T., Takahashi, T., and Takezoe, H. (2005) Journal of the American Chemical Society 127, 11085; (e) Seng, K. L., Chang, W. P., Jong, G. L., Kang, K. T., Nishida, K., Shimbo, Y., Takanishi, Y., and Takezoe, H. (2005) 
Liquid Crystals 32, 1205; (f) Seng, K. L., Tokita, M., Shimbo, Y., Kang, K. T., Takezoe, H., and Watanabe, J. (2007) Bulletin of the Korean Chemical Society 28, 2241.

[81] (a) Walba, D. M., Körblova, E., Shao, R., Maclennan, J. E., Link, D. R., Glaser, M. A., and Clark, N. A. (2000) Science 288, 2181; (b) Lee, C. K., Kwon, S. S., Kim, T. S., Choi, E. J., Shin, S. T., Zin, W. C., Kim, D. C., Kim, J. H., and Chien, L. C. (2003) Liquid Crystals 30, 1401; (c) Coleman, D. A., Fernsler, J., Chattham, N., Nakata, M., Takanishi, Y., Körblova, E., Link, D. R., Shao, R. F., Jang, W. G., Maclennan, J. E., Mondainn-Monval, O., Boyer, C., Weissflog, W., Pelzl, G., Chien, L. C., Zasadzinski, J., Watanabe, J., Walba, D. M., Takezoe, H., and Clark, N. A. (2003) Science 301, 1204; (d) Ocak, H., Bilgin-Eran, B., Prehm, M., Schymura, S., Lagerwall, J. P. F., and Tschierske, C. (2011) Soft Matter 7, 8266.

[82] Kovalenko, L., Weissflog, W., Grande, S., Diele, S., Pelzl, G., and Wirth, I. (2000) Liquid Crystals 27, 683.

[83] (a) Dantlgraber, G., Eremin, A., Diele, S., Hauser, A., Kresse, H., Pelzl, G., and Tschierske, C. (2002) Angewandte Chemie - International Edition 41, 2408; (b) Keith, C., Amaranatha Reddy, R., Baumeister, U., and Tschierske, C. (2004) Journal of the American Chemical Society 126, 14312; (c) Keith, C., Reddy, R. A., Hauser, A., Baumeister, U., and Tschierske, C. (2006) Journal of the American Chemical Society 128, 3051; (d) Keith, C., Reddy, R. A., Prehm, M., Baumeister, U., Kresse, H., Chao, J. L., Hahn, H., Lang, H., and Tschierske, G. (2007) Chemistry - A European Journal 13, 2556; (e) Zhang, Y., O'Callaghan, M. J., Baumeister, U., and Tschierske, C. (2008) Angewandte Chemie - International Edition 47, 6892.

[84] Reddy, R. A., Dantlgraber, G., Baumeister, U., and Tschierske, C. (2006) Angewandte Chemie International Edition 45, 1928.

[85] (a) Reddy, R. A., Baumeister, U., Keith, C., and Tschierske, C. (2007) Journal of Materials Chemistry 17, 62; (b) Reddy, R. A., Baumeister, U., Keith, C., Hahn, H., Lang, H., and Tschierske, C. (2007) Soft Matter 3, 558.

[86] (a) Keith, C., Amaranatha Reddy, R., Hahn, H., Lang, H., and Tschierske, C. (2004) Chemical Communications 10, 1898; (b) Zhang, Y., Baumeister, U., Tschierske, C., O'Callaghan, M. J., and Walker, C. (2010) Chemistry of Materials 22, 2869.

[87] (a) Imrie, C. T. (1999) Struct. Bonding 95, 149; (b) Imrie, C. T., and Henderson, P. A. (2002) Current Opinion in Colloid and Interface Science 7, 298; (c) Imrie, C. T., and Henderson, P. A. (2007) Chemical Society Reviews 36, 2096; (d) Yelamaggad, C. V., Shanker, G., Hiremath, U. S., and Krishna Prasad, S. (2008) Journal of Materials Chemistry 18, 2927; (e) Imrie, C. T., Henderson, P. A., and Yeap, G. Y. (2009) Liquid Crystals 36, 755.

[88] (a) Choi, S. W., Zennyoji, M., Takanishi, Y., Takezoe, H., Niori, T., and Watanabe, J. (1999) Molecular Crystals and Liquid Crystals Science and Technology Section A: Molecular Crystals and Liquid Crystals 328, 185; (b) Izumi, T., Naitou, Y., Tokita, M., and Watanabe, J. (2006) Japanese Journal of Applied Physics, Part 1: Regular Papers and Short Notes and Review Papers 45, 4991; (c) Takanishi, Y., Toshimitsu, M., Nakata, M., Takada, N., Izumi, T., Ishikawa, K., Takezoe, H., Watanabe, J., Takahashi, Y., and lida, A. (2006) Physical Review E - Statistical, Nonlinear, and Soft Matter Physics 74.

[89] (a) Prasad, V., Shankar Rao, D. S., and Krishna Prasad, S. (2000) Liquid Crystals 27, 585; (b) Prasad, V., Shankar Rao, D. S., and Rishna Prasad, S. (2001) Liquid Crystals 28, 761.

[90] (a) Yelamaggad, C. V., Anitha Nagamani, S., Hiremath, U. S., Shankar Rao, D. S., and Krishna Prasad, S. (2002) Liquid Crystals 29, 1401; (b) Achten, R., Koudijs, A., Karczmarzyk, Z., Marcelis, A. T. M., and Sudhölter, E. J. R. (2004) Liquid Crystals 31, 215; (c) Šepelj, M., Lesac, A., Baumeister, U., Diele, S., Bruce, D. W., and Hameršak, Z. (2006) Chemistry of Materials 18, 2050; (d) Šepelj, M., Lesac, A., Baumeister, U., Diele, S., Nguyen, H. L., and Bruce, D. W. (2007) Journal of Materials Chemistry 17, 1154.

[91] Białecka-Florjańczyk, E., Śledzińska, I., Górecka, E., and Przedmojski, J. (2008) Liquid Crystals 35, 401.

[92] (a) Nishiyama, I., Yamamoto, J., Goodby, J. W., and Yokoyama, H. (2002) Liquid Crystals 29, 1409; (b) Nishiyama, I., Yamamoto, J., Goodby, J. W., and Yokoyama, H. (2004) Liquid Crystals 31, 1495. 
[93] Lagerwall, J. P. F., Giesselmann, F., Wand, M. D., and Walba, D. M. (2004) Chemistry of Materials $16,3606$.

[94] (a) Yelamaggad, C. V., Prasad, S. K., Nair, G. G., Shashikala, I. S., Rao, D. S. S., Lobo, C. V., and Chandrasekharr, S. (2004) Angewandte Chemie - International Edition 43, 3429; (b) Prasad, S. K., Nair, G. G., Sandhya, K. L., and Shankar Rao, D. S. (2005) Molecular Crystals and Liquid Crystals 436, 83/[1037]; (c) Yelamaggad, C. V., Shashikala, I. S., Liao, G., Shankar Rao, D. S., Prasad, S. K., Li, Q., and Jakli, A. (2006) Chemistry of Materials 18, 6100.

[95] Lee, G., Jeong, H., Araoka, F., Ishikawa, K., Lee, J. G., Kang, K. T., Cepic, M., and Takezoe, H. (2010) Liquid Crystals 37, 883.

[96] Tamba, M. G., Kosata, B., Pelz, K., Diele, S., Pelzl, G., Vakhovskaya, Z., Kresse, H., and Weissflog, W. (2006) Soft Matter 2, 60.

[97] (a) Umadevi, S., Sadashiva, B. K., Shreenivasa Murthy, H. N., and Raghunathan, V. A. (2006) Soft Matter 2, 210; (b) Umadevi, S., and Sadashiva, B. K. (2007) Liquid Crystals 34, 673.

[98] Achten, R., Koudijs, A., Giesbers, M., Marcelis, A. T. M., Sudhölter, E. J. R., Schroeder, M. W., and Weissflog, W. (2007) Liquid Crystals 34, 59.

[99] Kosata, B., Tamba, G. M., Baumeister, U., Pelz, K., Diele, S., Pelzl, G., Galli, G., Samaritani, S., Agina, E. V., Boiko, N. I., Shibaev, V. P., and Weissflog, W. (2006) Chemistry of Materials 18, 691.

[100] (a) Dantlgraber, G., Diele, S., and Tschierske, C. (2002) Chemical Communications, 2768; (b) Keith, C., Reddy, R. A., Baumeister, U., Hahn, H., Lang, H., and Tschierske, C. (2006) Journal of Materials Chemistry 16, 3444; (c) Achten, R., Koudijs, A., Giesbers, M., Amaranatha Reddy, R., Verhulst, T., Tschierske, C., Marcelis, A., and Sudhölter, E. (2006) Liquid Crystals 33, 681; (d) Keith, C., Dantlgraber, G., Reddy, R. A., Baumeister, U., Prehm, M., Hahn, H., Lang, H., and Tschierske, C. (2007) Journal of Materials Chemistry 17, 3796.

[101] Pan, Q., Chen, X., Fan, X., Shen, Z., and Zhou, Q. (2008) Journal of Materials Chemistry 18, 3481.

[102] Dantlgraber, G., Baumeister, U., Diele, S., Kresse, H., Lühmann, B., Lang, H., and Tschierske, C. (2002) Journal of the American Chemical Society 124, 14852.

[103] Kardas, D., Prehm, M., Baumeister, U., Pociecha, D., Amaranatha Reddy, R., Mehl, G. H., and Tschierske, C. (2005) Journal of Materials Chemistry 15, 1722.

[104] Vergara, J., Gimeno, N., Cano, M., Barberá, J., Romero, P., Serrano, J. L., and Ros, M. B. (2011) Chemistry of Materials 23, 4931.

[105] Keith, C., Reddy, R. A., and Tschierske, C. (2005) Chemical Communications, 871.

[106] Bubnov, A., Novotná, V., Pociecha, D., Kaåpar, M., Hamplová, V., Galli, G., and Glogarová, M. (2011) Macromolecular Chemistry and Physics 212, 191.

[107] Tenneti, K. K., Chen, X., Li, C. Y., Shen, Z., Wan, X., Fan, X., Zhou, Q. F., Rong, L., and Hsiao, B. S. (2009) Macromolecules 42, 3510.

[108] Chen, X., Tenneti, K. K., Li, C. Y., Bai, Y., Wan, X., Fan, X., Zhou, Q. F., Rong, L., and Hsiao, B. S. (2007) Macromolecules 40, 840.

[109] Barberá, J., Gimeno, N., Pintre, I., Ros, M. B., and Serrano, J. L. (2006) Chemical Communications, 1212.

[110] Tenneti, K. K., Chen, X., Li, C. Y., Wan, X., Fan, X., Zhou, Q. F., Rong, L., and Hsiao, B. S. (2007) Macromolecules 40, 5095.

[111] (a) Wang, L. Y., Tsai, H. Y., and Lin, H. C. (2010) Macromolecules 43, 1277; (b) Yang, P. J., Wang, L. Y., Tang, C. Y., and Lin, H. C. (2010) Journal of Polymer Science, Part A: Polymer Chemistry 48, 764.

[112] (a) Chen, X., Tenneti, K. K., Li, C. Y., Bai, Y., Zhou, R., Wan, X., Fan, X., and Zhou, Q. F. (2006) Macromolecules 39, 517; (b) Xu, Y., Yang, Q., Shen, Z., Chen, X., Fan, X., and Zhou, Q. (2009) Macromolecules 42, 2542.

[113] (a) Choi, E. J., Ahn, J. C., Chien, L. C., Lee, C. K., Zin, W. C., Kim, D. C., and Shin, S. T. (2004) Macromolecules 37, 71; (b) Galli, G., Demel, S., Slugovc, C., Stelzer, F., Weissflog, W., Diele, S., and Fodor-Csorba, K. (2005) Molecular Crystals and Liquid Crystals 439, 43/[1909]; (c) Choi, E. J., Kim, E. C., Ohk, C. W., Zin, W. C., Lee, J. H., and Lim, T. K. (2010) Macromolecules 43, 2865; (d) Gimeno, N., Sánchez-Ferrer, A., Sebastián, N., Mezzenga, R., and Ros, M. B. (2011) Macromolecules 44, 9586. 
[114] (a) Keum, C. D., Kanazawa, A., and Ikeda, T. (2001) Advanced Materials 13, 321; (b) Barberá, J., Gimeno, N., Monreal, L., Piñol, R., Ros, M. B., and Serrano, J. L. (2004) Journal of the American Chemical Society 126, 7190; (c) Balamurugan, S., and Kannan, P. (2009) Journal of Molecular Structure 934, 44.

[115] Dingemans, T. J., Murthy, N. S., and Samulski, E. T. (2001) Journal of Physical Chemistry B 105, 8845.

[116] (a) Cristiano, R., Vieira, A. A., Ely, F., and Gallardo, H. (2006) Liquid Crystals 33, 381; (b) Gallardo, H., Cristiano, R., Vieira, A. A., Neves Filho, R. A. W., and Srivastava, R. M. (2008) Synthesis, 0605; (c) Gallardo, H., Cristiano, R., Vieira, A. A., Neves Filho, R. A. W., Srivastava, R. M., and Bechtold, I. H. (2008) Liquid Crystals 35, 857.

[117] (a) Yu, F. C., and Yu, L. J. (2006) Chemistry of Materials 18, 5410; (b) Novotná, V., Žurek, J., Kozmík, V., Svoboda, J., Glogarová, M., Kroupa, J., and Pociecha, D. (2008) Liquid Crystals 35, 1023; (c) Weissflog, W., Dunemann, U., Findeisen-Tandel, S., Tamba, M. G., Kresse, H., Pelzl, G., Diele, S., Baumeister, U., Eremin, A., Stern, S., and Stannarius, R. (2009) Soft Matter 5, 1840; (d) Radhika, S., Srnivasa, H. T., and Sadashiva, B. K. (2011) Liquid Crystals 38, 785.

[118] Hird, M., Goodby, J. W., Gough, N., and Toyne, K. J. (2001) Journal of Materials Chemistry 11, 2732.

[119] (a) Wu, J., Okamoto, H., and Takenaka, S. (2001) Chemistry Letters, 116; (b) Das, B., Grande, S., Weissflog, W., Eremin, A., Schröder, M. W., Pelzl, G., Diele, S., and Kresse, H. (2003) Liquid Crystals 30, 529; (c) Yu, F. C., and Yu, L. J. (2008) Liquid Crystals 35, 799.

[120] Enz, E., Findeisen-Tandel, S., Dabrowski, R., Giesselmann, F., Weissflog, W., Baumeister, U., and Lagerwall, J. (2009) Journal of Materials Chemistry 19, 2950.

[121] Chakraborty, A., Das, B., Das, M. K., Findeisen-Tandel, S., Tamba, M. G., Baumeister, U., Kresse, H., and Weissflog, W. (2011) Liquid Crystals 38, 1085. 
Table 1. Transition temperatures $\left({ }^{\circ} \mathrm{C}\right)$ of some bent-core mesogens that contain different central bent cores (BC).<smiles>[X]c1ccc(OC(=O)c2cccc(OC(=O)c3ccc([X])cc3)c2)cc1</smiles>

\begin{tabular}{|c|c|c|c|}
\hline BC & $\mathbf{X}$ & $\mathbf{n}$ & Thermal properties $\left({ }^{\circ} \mathrm{C}\right)$ \\
\hline \multirow{2}{*}{$1,3-\mathrm{Ph}$} & \multirow{2}{*}{$-\mathrm{N}=\mathrm{CH}-$} & 8 & $\mathrm{~B}_{4} 140 \mathrm{~B}_{3} 152 \mathrm{~B}_{2} 174 \mathrm{I}$ \\
\hline & & 14 & $\mathrm{~B}_{4} 140 \mathrm{~B}_{2} 170 \mathrm{I}$ \\
\hline \multirow{2}{*}{ 2,7-Nph } & \multirow{2}{*}{$-\mathrm{N}=\mathrm{CH}-$} & 8 & $\mathrm{~B}_{4} 208 \mathrm{~B}_{2} 235 \mathrm{I}$ \\
\hline & & 14 & $\mathrm{~B}_{4} 204 \mathrm{~B}_{2} 225 \mathrm{I}$ \\
\hline $3,4^{\prime}-\mathrm{Bi}$ & $-\mathrm{N}=\mathrm{CH}-$ & 14 & Cr 140 SmCP 207 I \\
\hline \multirow{2}{*}{$1,3-\mathrm{Ph}$} & \multirow{2}{*}{$-\mathrm{COO}-$} & 8 & Cr $125\left(B_{1} 121\right) \mathrm{I}$ \\
\hline & & 14 & Cr 104 SmCP 118 I \\
\hline \multirow{2}{*}{ 2,7-Nph } & \multirow{2}{*}{$-\mathrm{COO}-$} & 8 & Cr $159 \mathrm{~B}_{1} 182 \mathrm{I}$ \\
\hline & & 14 & Cr 116 SmCP 172 I \\
\hline \multirow{2}{*}{$3,4^{\prime}-\mathrm{Bi}$} & \multirow{2}{*}{$-\mathrm{COO}-$} & 8 & $\mathrm{Cr} 131 \mathrm{Col}_{\mathrm{r}} 172 \mathrm{I}$ \\
\hline & & 14 & Cr 85 SmCP 162 I \\
\hline
\end{tabular}


Table 2. Transition temperatures $\left({ }^{\circ} \mathrm{C}\right)$ of some bent-shaped mesogens with different substituents on the central bent cores (BC).

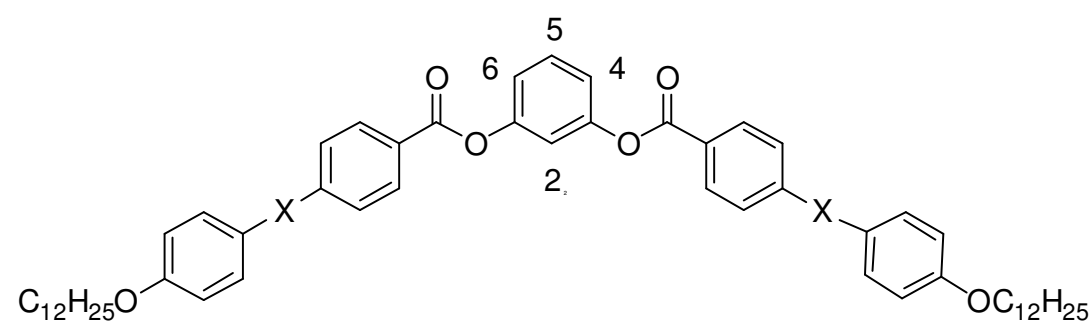

\begin{tabular}{|c|c|c|}
\hline $\mathbf{X}$ & Substituent & Thermal properties $\left({ }^{\circ} \mathrm{C}\right)$ \\
\hline$-\mathrm{N}=\mathrm{CH}-$ & - & $\mathrm{B}_{4} 141 \mathrm{~B}_{2} 170 \mathrm{I}$ \\
\hline$-\mathrm{N}=\mathrm{CH}-$ & $2-\mathrm{NO}_{2}$ & $\mathrm{Cr} 85 \mathrm{~B}_{7} 173 \mathrm{I}$ \\
\hline$-\mathrm{N}=\mathrm{CH}-$ & $2-\mathrm{CN}$ & $\mathrm{Cr} 160 \mathrm{~B}_{7} 192 \mathrm{I}$ \\
\hline$-\mathrm{N}=\mathrm{CH}-$ & $2-\mathrm{CH}_{3}$ & $\mathrm{~B}_{4} 148 \mathrm{~B}_{2} 164 \mathrm{I}$ \\
\hline$-\mathrm{N}=\mathrm{CH}-$ & $4-\mathrm{Cl}$ & $\mathrm{Cr} 75 \mathrm{~B}_{2} 127 \mathrm{I}$ \\
\hline$-\mathrm{N}=\mathrm{CH}-$ & $4,6-\mathrm{Cl}$ & Cr 111 SmĈ 113 SmC 121 N 137 I \\
\hline$-\mathrm{N}=\mathrm{CH}-$ & $4-\mathrm{CN}$ & Cr 65 SmCP 122 SmC141 SmA 188 I \\
\hline$-\mathrm{COO}-$ & $4-\mathrm{CN}$ & $\begin{array}{c}\text { Cr } 103\left(\mathrm{SmCP}_{\mathrm{A}}^{\prime \prime} 68 \mathrm{SmCP}_{\mathrm{A}}^{\prime} 75\right. \\
\left.\mathrm{SmCP}_{\mathrm{A}} 94\right) \mathrm{SmC} 109 \mathrm{~N} 129 \mathrm{I}\end{array}$ \\
\hline$-\mathrm{OOC}-$ & $4-\mathrm{CN}$ & $\mathrm{Cr} 106 \mathrm{SmAP}_{\mathrm{A}} 112 \mathrm{SmA} 185 \mathrm{I}$ \\
\hline$-\mathrm{OOC}-$ & $5-\mathrm{OCH}_{3}$ & $\mathrm{Cr} 109 \mathrm{SmCP}_{\mathrm{A}} 120 \mathrm{I}$ \\
\hline$-\mathrm{OOC}-$ & $5-\mathrm{Cl}$ & CrI 90 CrII 108 CrIII 138 I \\
\hline
\end{tabular}


Table 3. Transition temperatures $\left({ }^{\circ} \mathrm{C}\right)$ of some bent-shaped mesogens with different rigid bent cores $(\mathrm{BC})$.<smiles>CCCCCCCCOc1ccc(C(=O)Oc2ccc(C(=O)Oc3cccc(C(=O)Oc4ccc(C(=O)Oc5ccc(OCCC)cc5)cc4)c3)cc2)cc1</smiles>

\begin{tabular}{|c|c|c|}
\hline & Thermal properties $\left({ }^{\circ} \mathrm{C}\right)$ \\
\hline & 12 & $\mathrm{Cr} 106 \mathrm{SmCP} 159 \mathrm{I}$ \\
\hline & 14 & $\mathrm{Cr} 85 \mathrm{SmCP} 162 \mathrm{I}$ \\
\hline
\end{tabular}


Table 4. Transition temperatures $\left({ }^{\circ} \mathrm{C}\right)$ of some bent-shaped mesogens with different central units $(\mathrm{A})$ at the bent cores.

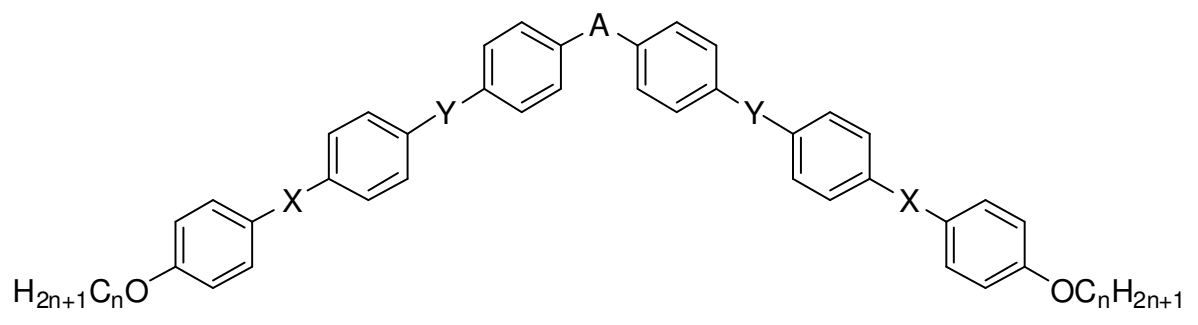

\begin{tabular}{|c|c|c|c|c|}
\hline $\mathbf{A}$ & $\mathbf{X}$ & $\mathbf{Y}$ & $\mathbf{n}$ & Thermal properties $\left({ }^{\circ} \mathrm{C}\right)$ \\
\hline$-\mathrm{CH}_{2}-$ & $-\mathrm{COO}-$ & $-\mathrm{COO}-$ & 14 & $\mathrm{Cr} 124 \mathrm{SmCP}_{162} \mathrm{I}$ \\
\hline$-\mathrm{S}-$ & $-\mathrm{COO}-$ & $-\mathrm{COO}-$ & 14 & $\mathrm{Cr} 151 \mathrm{Col}_{\mathrm{r}} 156 \mathrm{I}$ \\
\hline$-\mathrm{S}=\mathrm{O}-$ & $-\mathrm{COO}-$ & $-\mathrm{COO}-$ & 14 & $\mathrm{Cr} 144 \mathrm{SmCP} 162 \mathrm{I}$ \\
\hline$-\mathrm{C}=\mathrm{O}-$ & $-\mathrm{COO}-$ & $-\mathrm{COO}-$ & 14 & $\mathrm{Cr} 156 \mathrm{SmCP} 195 \mathrm{I}$ \\
\hline$-\mathrm{C}=\mathrm{O}-$ & $-\mathrm{N}=\mathrm{CH}-$ & $-\mathrm{COO}-$ & 8 & $\mathrm{Cr} 249 \mathrm{~B}_{2} 264 \mathrm{I}$ \\
\hline$-\mathrm{O}-$ & $-\mathrm{N}=\mathrm{CH}-$ & $-\mathrm{COO}-$ & 8 & $\mathrm{Cr} 216 \mathrm{~B}_{1} 247 \mathrm{I}$ \\
\hline$-\mathrm{CH}_{2}-$ & $-\mathrm{N}=\mathrm{CH}-$ & $-\mathrm{COO}-$ & 8 & $\mathrm{Cr} 182 \mathrm{~B}_{2} 238 \mathrm{I}$ \\
\hline$-\mathrm{CH}_{2}-$ & $-\mathrm{N}=\mathrm{CH}-$ & $-\mathrm{COO}-$ & 16 & $\mathrm{I} 217 \mathrm{~B}_{7} 164 \mathrm{Cr}$ \\
\hline$-\mathrm{N}(\mathrm{Me})-$ & $-\mathrm{COO}-$ & $-\mathrm{N}=\mathrm{CH}-$ & 16 & $\mathrm{Cr} 133 \mathrm{SmA}$ \\
$2159 \mathrm{SmA}$ & $207 \mathrm{I}$ \\
\hline
\end{tabular}


Table 5. Transition temperatures $\left({ }^{\circ} \mathrm{C}\right)$ of bent-shaped mesogens containing piperidine or piperazine.

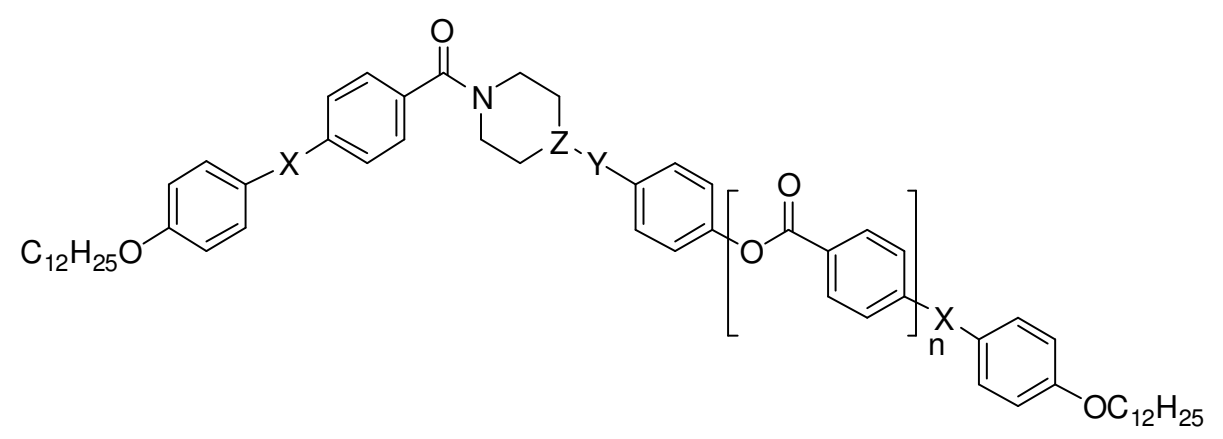

\begin{tabular}{|c|c|c|c|c|}
\hline $\mathbf{n}$ & $\mathbf{X}$ & $\mathbf{Y}$ & $\mathbf{Z}$ & Thermal properties $\left({ }^{\circ} \mathrm{C}\right)$ \\
\hline 0 & $-\mathrm{COO}-$ & $-\mathrm{COO}-$ & $-\mathrm{CH}-$ & $\mathrm{Cr} 110 \mathrm{SmCP} 116 \mathrm{I}$ \\
\hline 0 & $-\mathrm{COO}-$ & $-\mathrm{COOCH}_{2} \mathrm{CH}_{2}-$ & $-\mathrm{N}-$ & $\mathrm{Cr} 101$ (SmCP 96) I \\
\hline 1 & $-\mathrm{COO}-$ & - & $-\mathrm{N}-$ & $\mathrm{Cr} 165 \mathrm{SmCP} 201 \mathrm{I}$ \\
\hline 1 & $-\mathrm{OOC}-$ & - & $-\mathrm{N}-$ & $\mathrm{Cr} 167 \mathrm{SmA}{ }^{\prime} 195 \mathrm{SmAP} 206 \mathrm{SmA} 241 \mathrm{I}$ \\
\hline 1 & $-\mathrm{N}=\mathrm{CH}-$ & - & $-\mathrm{N}-$ & $\mathrm{Cr} 220 \mathrm{SmX} 247 \mathrm{SmA} 253 \mathrm{I}$ \\
\hline
\end{tabular}


Table 6. Transition temperatures $\left({ }^{\circ} \mathrm{C}\right)$ of symmetric 1,3-phenylene based bent-core liquid crystals (Effect of linking groups).<smiles>[X]c1ccc(C(=O)Oc2cccc(OC(=O)c3ccc([X])cc3)c2)cc1</smiles>

\begin{tabular}{|c|c|c|}
\hline $\mathbf{X}$ & $\mathbf{n}$ & Thermal properties $\left({ }^{\circ} \mathrm{C}\right)$ \\
\hline \multirow{2}{*}{$-\mathrm{N}=\mathrm{CH}-$} & 8 & $\mathrm{~B}_{4} 140 \mathrm{~B}_{3} 152 \mathrm{SmCP} 174 \mathrm{I}$ \\
\cline { 2 - 3 } & 12 & $\mathrm{~B}_{4} 141 \mathrm{SmCP} 170 \mathrm{I}$ \\
\hline$-\mathrm{N}=\mathrm{CF}-$ & 8 & $\mathrm{Cr} 70 \mathrm{~B}_{1} 122 \mathrm{SmCP} 160 \mathrm{I}$ \\
\hline \multirow{2}{*}{$-\mathrm{COO}-$} & 8 & $\mathrm{Cr} 125\left(\mathrm{~B}_{1} 121\right) \mathrm{I}$ \\
\cline { 2 - 3 } & 12 & $\mathrm{Cr} 109 \mathrm{SmCP} 119 \mathrm{I}$ \\
\hline$-\mathrm{COS}-$ & 8 & $\mathrm{Cr} 120 \mathrm{~B}_{1} 135 \mathrm{I}$ \\
\hline$-\mathrm{N}=\mathrm{N}-$ & 8 & $\mathrm{Cr} 116 \mathrm{I}$ \\
\hline$-\mathrm{N}=\mathrm{N}(\mathrm{O})-$ & 2 & $\mathrm{Cr} 186 \mathrm{~B}_{6} 224 \mathrm{I}$ \\
\hline$-\mathrm{HC}=\mathrm{CH}-$ & 12 & $\mathrm{Cr} 183 \mathrm{M} 200 \mathrm{~d}$ \\
\hline$-\mathrm{C} \equiv \mathrm{C}-$ & 8 & $\mathrm{Cr} 154 \mathrm{I}$ \\
\hline \multirow{2}{*}{$-\mathrm{CH}=\mathrm{CH}-\mathrm{COO}-$} & 8 & $\mathrm{Cr} 117 \mathrm{~B}_{1} 130$ \\
\cline { 2 - 3 } & 12 & $\mathrm{Cr} 118 \mathrm{I}$ \\
\hline
\end{tabular}


Table 7. Transition temperatures $\left({ }^{\circ} \mathrm{C}\right)$ of $34^{\prime}$-biphenylene-based bent-core liquid crystals (Effect of linking groups).

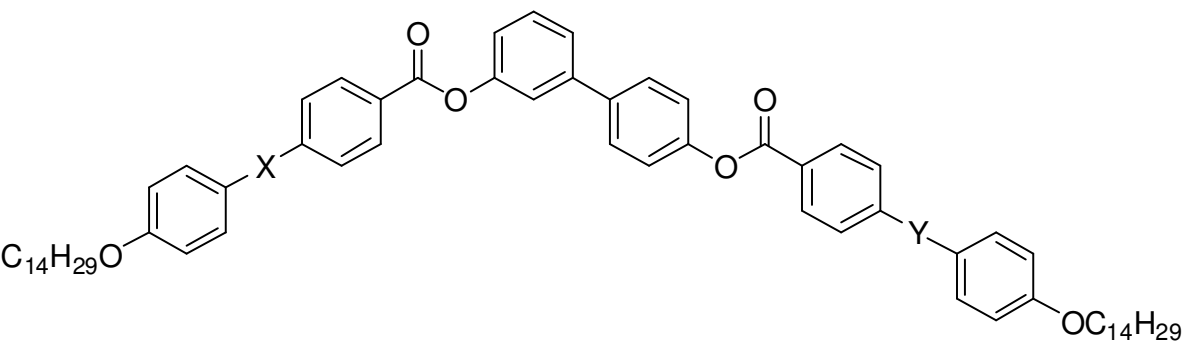

\begin{tabular}{|c|c|c|}
\hline $\mathbf{X}$ & $\mathbf{Y}$ & Thermal properties $\left({ }^{\circ} \mathrm{C}\right)$ \\
\hline$-\mathrm{COO}-$ & $-\mathrm{OOC}-$ & $\mathrm{Cr} 85 \mathrm{SmCP} 162 \mathrm{I}$ \\
\hline$-\mathrm{N}=\mathrm{CH}-$ & $-\mathrm{CH}=\mathrm{N}-$ & $\mathrm{C} 141 \mathrm{SmC}_{\mathrm{S}} \mathrm{P}_{\mathrm{A}} 207 \mathrm{I}$ \\
\hline$-\mathrm{N}=\mathrm{N}-$ & $-\mathrm{N}=\mathrm{N}-$ & $\mathrm{C} 139 \mathrm{Col}_{\mathrm{ob}} 165 \mathrm{I}$ \\
\hline$-\mathrm{N}=\mathrm{N}(\mathrm{O})-$ & $-(\mathrm{O}) \mathrm{N}=\mathrm{N}-$ & $\mathrm{C} 120 \mathrm{SmCP}_{\mathrm{A}} 207 \mathrm{I}$ \\
\hline$-\mathrm{CH}=\mathrm{CH}-\mathrm{COO}-$ & $-\mathrm{OOC}-\mathrm{CH}=\mathrm{CH}-$ & $\mathrm{CmCP} 154 \mathrm{I}$ \\
\hline$-\mathrm{CH}=\mathrm{C}\left(\mathrm{CH}_{3}\right)-\mathrm{COO}-$ & $-\mathrm{OOC}-\left(\mathrm{CH}_{3}\right) \mathrm{C}=\mathrm{CH}-$ & $\mathrm{SmCP} 132 \mathrm{I}$ \\
\hline$-\mathrm{COO}-$ & $-\mathrm{CH}=\mathrm{N}-$ & $\mathrm{C} 116 \mathrm{SmC}_{\mathrm{A}} \mathrm{P}_{\mathrm{A}} 163 \mathrm{I}$ \\
\hline$-\mathrm{COO}-$ & $-\mathrm{N}=\mathrm{N}-$ & $\mathrm{C} 88 \mathrm{SmC}_{\mathrm{A}} \mathrm{P}_{\mathrm{A}} 121 \mathrm{I}$ \\
\hline$-\mathrm{COO}-$ & $-\mathrm{N}=\mathrm{N}(\mathrm{O})-$ & $\mathrm{C} 101 \mathrm{Col}_{\mathrm{ob}} 118 \mathrm{I}$ \\
\hline
\end{tabular}


Table 8. Transition temperatures $\left({ }^{\circ} \mathrm{C}\right)$ of different ester 1,3-phenylene-based bent-core liquid crystals (Effect of the direction of the linking group).

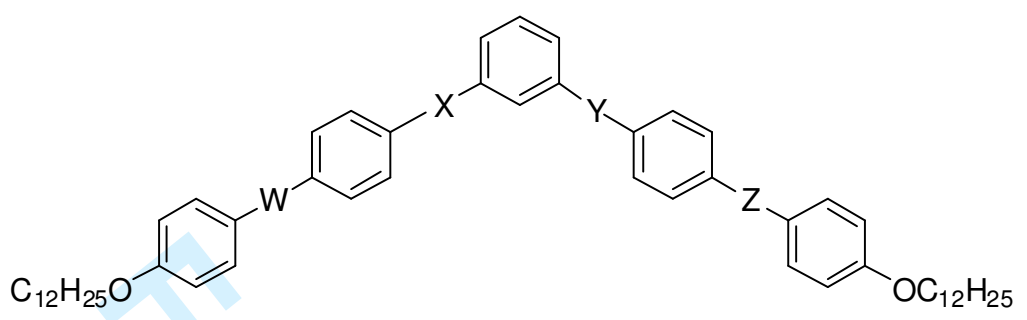

\begin{tabular}{|c|c|c|c|c|}
\hline $\mathbf{W}$ & $\mathbf{X}$ & $\mathbf{Y}$ & $\mathbf{Z}$ & Thermal properties $\left({ }^{\circ} \mathrm{C}\right)$ \\
\hline$-\mathrm{COO}-$ & $-\mathrm{COO}-$ & $-\mathrm{OOC}-$ & $-\mathrm{OOC}-$ & Cr 109 SmCP 119 I \\
\hline$-\mathrm{COO}-$ & $-\mathrm{OOC}-$ & $-\mathrm{COO}-$ & $-\mathrm{OOC}-$ & Cr 157 I \\
\hline$-\mathrm{OOC}-$ & $-\mathrm{COO}-$ & $-\mathrm{OOC}-$ & $-\mathrm{COO}-$ & Cr 152 Col 162 I \\
\hline$-\mathrm{OOC}-$ & $-\mathrm{OOC}-$ & $-\mathrm{COO}-$ & $-\mathrm{COO}-$ & Cr 191 (Col 189) I \\
\hline$-\mathrm{COO}-$ & $-\mathrm{COO}-$ & $-\mathrm{COO}-$ & $-\mathrm{COO}-$ & Cr 105 Col $140 \mathrm{I}$ \\
\hline$-\mathrm{COO}-$ & $-\mathrm{COO}-$ & $-\mathrm{COO}-$ & $-\mathrm{OOC}-$ & Cr 120 (SmCP 112) I \\
\hline$-\mathrm{COO}-$ & $-\mathrm{COO}-$ & $-\mathrm{OOC}-$ & $-\mathrm{COO}-$ & Cr 110 SmCP 133 I \\
\hline$-\mathrm{COO}-$ & $-\mathrm{OOC}-$ & $-\mathrm{COO}-$ & $-\mathrm{COO}-$ & Cr 142 SmCP 158 Col 168 I \\
\hline$-\mathrm{COO}-$ & $-\mathrm{OOC}-$ & $-\mathrm{OOC}-$ & $-\mathrm{COO}-$ & Cr 146 (Col 144) I \\
\hline$-\mathrm{OOC}-$ & $-\mathrm{COO}-$ & $-\mathrm{COO}-$ & $-\mathrm{COO}-$ & Cr 138 Col $168 \mathrm{I}$ \\
\hline
\end{tabular}


Table 9. Transition temperatures $\left({ }^{\circ} \mathrm{C}\right)$ of several imine/ester 1,3-phenylene based bentcore liquid crystals (Effect of the direction of the linking group).

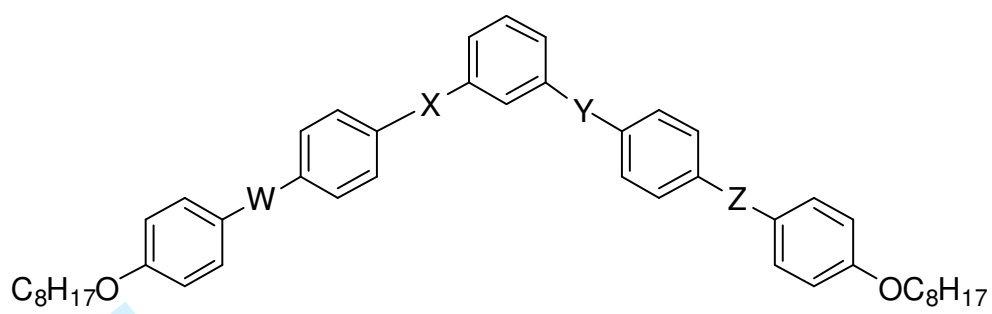

\begin{tabular}{|c|c|c|c|c|}
\hline $\mathbf{W}$ & $\mathbf{X}$ & $\mathbf{Y}$ & $\mathbf{Z}$ & Thermal properties $\left({ }^{\circ} \mathrm{C}\right)$ \\
\hline$-\mathrm{N}=\mathrm{CH}-$ & $-\mathrm{COO}-$ & $-\mathrm{OOC}-$ & $-\mathrm{CH}=\mathrm{N}-$ & $\mathrm{B}_{4} 141 \mathrm{~B}_{3} 152 \mathrm{~B}_{2} 174 \mathrm{I}$ \\
\hline$-\mathrm{CH}=\mathrm{N}-$ & $-\mathrm{COO}-$ & $-\mathrm{OOC}-$ & $-\mathrm{N}=\mathrm{CH}-$ & $\mathrm{Cr} 128 \mathrm{I}$ \\
\hline$-\mathrm{N}=\mathrm{CH}-$ & $-\mathrm{OOC}-$ & $-\mathrm{COO}-$ & $-\mathrm{CH}=\mathrm{N}-$ & Cr $125 \mathrm{~B}_{1} 183 \mathrm{I}$ \\
\hline$-\mathrm{CH}=\mathrm{N}-$ & $-\mathrm{OOC}-$ & $-\mathrm{COO}-$ & $-\mathrm{N}=\mathrm{CH}-$ & $\mathrm{Cr} 186 \mathrm{I}\left(\right.$ for $\left.-\mathrm{OC}_{14} \mathrm{H}_{29}\right)$ \\
\hline$-\mathrm{COO}-$ & $-\mathrm{N}=\mathrm{CH}-$ & $-\mathrm{CH}=\mathrm{N}-$ & $-\mathrm{OOC}-$ & $\mathrm{Cr} 121 \mathrm{~B}_{1} 154 \mathrm{I}$ \\
\hline$-\mathrm{COO}-$ & $-\mathrm{CH}=\mathrm{N}-$ & $-\mathrm{N}=\mathrm{CH}-$ & $-\mathrm{OOC}-$ & Cr 113 B $_{1} 132 \mathrm{I}$ \\
\hline$-\mathrm{OOC}-$ & $-\mathrm{N}=\mathrm{CH}-$ & $-\mathrm{CH}=\mathrm{N}-$ & $-\mathrm{COO}-$ & Cr $120 \mathrm{~B}_{1} 147\left(\mathrm{~B}_{2} 144\right) \mathrm{I}$ \\
\hline$-\mathrm{OOC}-$ & $-\mathrm{CH}=\mathrm{N}-$ & $-\mathbf{N}=\mathbf{C H}-$ & $-\mathrm{COO}-$ & $\mathrm{Cr} 178 \mathrm{~B}_{1} 185 \mathrm{I}$ \\
\hline$-\mathbf{N}=\mathbf{C H}-$ & $-\mathrm{COO}-$ & $-\mathrm{N}=\mathrm{CH}-$ & $-\mathrm{OOC}-$ & Cr 149 I \\
\hline$-\mathrm{COO}-$ & $-\mathrm{N}=\mathrm{CH}-$ & $-\mathrm{OOC}-$ & $-\mathrm{OOC}-$ & $\mathrm{Cr} 106 \mathrm{~B}_{1} 124 \mathrm{I}$ \\
\hline
\end{tabular}


Table 10. Transition temperatures $\left({ }^{\circ} \mathrm{C}\right)$ of different bent-core liquid crystals showing the effect of the lateral core (Effect of the aromatic structures).

\begin{tabular}{|c|c|c|}
\hline & Thermal properties ( \\
\hline
\end{tabular}


Table 11. Transition temperatures $\left({ }^{\circ} \mathrm{C}\right)$ of different substituted bent-core liquid crystals (Effect of lateral substituents).<smiles>[Z]c1ccc(OCCO)c([Y])c1[B]</smiles>

\begin{tabular}{|c|c|c|c|c|}
\hline $\mathbf{A}, \mathbf{A}^{\prime}$ & $\mathbf{B}, \mathbf{B}^{\prime}$ & $\mathbf{Z}$ & $\mathbf{n}$ & Thermal properties $\left({ }^{\circ} \mathrm{C}\right)$ \\
\hline $\mathrm{H}, \mathrm{H}$ & $\mathrm{H}, \mathrm{H}$ & $-\mathrm{HC}=\mathrm{CH}-$ & 12 & $\mathrm{Cr} 183 \mathrm{M} 200 \mathrm{~d}$ \\
\hline $\mathrm{F}, \mathrm{F}$ & $\mathrm{H}, \mathrm{H}$ & $-\mathrm{HC}=\mathrm{CH}-$ & 12 & $\mathrm{Cr} 137 \mathrm{~B}_{\mathrm{x}} 164 \mathrm{I}$ \\
\hline $\mathrm{Cl}, \mathrm{Cl}$ & $\mathrm{H}, \mathrm{H}$ & $-\mathrm{HC}=\mathrm{CH}-$ & 12 & $\mathrm{Cr} 115 \mathrm{~B}_{7} 144 \mathrm{I}$ \\
\hline $\mathrm{Br}, \mathrm{Br}$ & $\mathrm{H}, \mathrm{H}$ & $-\mathrm{HC}=\mathrm{CH}-$ & 12 & $\mathrm{Cr} 118 \mathrm{~B}_{7} 131 \mathrm{I}$ \\
\hline $\mathrm{I}, \mathrm{I}$ & $\mathrm{H}, \mathrm{H}$ & $-\mathrm{HC}=\mathrm{CH}-$ & 12 & $\mathrm{Cr} 114 \mathrm{~B}_{7} 123 \mathrm{I}$ \\
\hline $\mathrm{NO}_{2}, \mathrm{Cl}$ & $\mathrm{H}, \mathrm{H}$ & $-\mathrm{HC}=\mathrm{CH}-$ & 12 & $\mathrm{Cr} 113 \mathrm{~B}_{1 \mathrm{revt}} 147 \mathrm{I}$ \\
\hline $\mathrm{NO}_{2}, \mathrm{NO}_{2}$ & $\mathrm{H}, \mathrm{H}$ & $-\mathrm{HC}=\mathrm{CH}-$ & 12 & $\mathrm{Cr} 141 \mathrm{~B}_{1} 150 \mathrm{~B}_{6} 151 \mathrm{I}$ \\
\hline $\mathrm{NO}_{2}, \mathrm{NO}{ }_{2}$ & $\mathrm{H}, \mathrm{H}$ & $-\mathrm{N}=\mathrm{CH}-$ & 12 & $\mathrm{Cr} 112 \mathrm{~B}_{1} 158 \mathrm{I}$ \\
\hline $\mathrm{H}, \mathrm{H}$ & $\mathrm{H}, \mathrm{H}$ & $-\mathrm{N}=\mathrm{CH}-$ & 12 & $\mathrm{~B}_{4} 141 \mathrm{~B}_{2} 170 \mathrm{I}$ \\
\hline $\mathrm{F}, \mathrm{F}$ & $\mathrm{H}, \mathrm{H}$ & $-\mathrm{N}=\mathrm{CH}-$ & 12 & $\mathrm{~B}_{4} 119 \mathrm{~B}_{2} 161 \mathrm{I}$ \\
\hline $\mathrm{Cl}, \mathrm{Cl}$ & $\mathrm{H}, \mathrm{H}$ & $-\mathrm{N}=\mathrm{CH}-$ & 12 & $\mathrm{Cr} 74 \mathrm{~B}_{2} 140 \mathrm{I}$ \\
\hline $\mathrm{CH}_{3}, \mathrm{CH}$ & $\mathrm{H}, \mathrm{H}$ & $-\mathrm{N}=\mathrm{CH}-$ & 12 & $\mathrm{Cr} 90 \mathrm{SmCP}_{3} 92 \mathrm{I}$ \\
\hline $\mathrm{H}, \mathrm{H}$ & $\mathrm{CH}, \mathrm{CH}$ & $-\mathrm{N}=\mathrm{CH}-$ & 12 & $\mathrm{Cr} 110(\mathrm{SmCP} 80) \mathrm{I}$ \\
\hline $\mathrm{H}, \mathrm{H}$ & $\mathrm{H}, \mathrm{H}$ & $-\mathrm{CH}=\mathrm{N}-$ & 8 & $\mathrm{Cr}_{3} 128 \mathrm{I}$ \\
\hline $\mathrm{H}, \mathrm{H}$ & $\mathrm{OH}, \mathrm{OH}$ & $-\mathrm{CH}=\mathrm{N}-$ & 8 & $\mathrm{Cr} 126 \mathrm{~B}_{2} 175 \mathrm{I}$ \\
\hline
\end{tabular}


Table 12. Transition temperatures $\left({ }^{\circ} \mathrm{C}\right)$ of different fluorine-substituted bent-core liquid crystals (Effect of fluorine substitution).

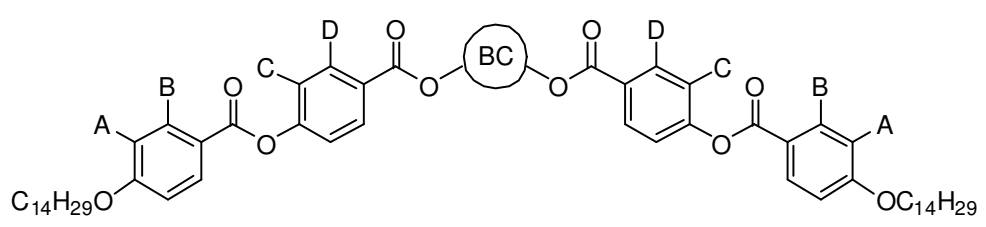

\begin{tabular}{|c|c|c|c|c|c|}
\hline BC & $\mathbf{A}$ & B & C & D & Thermal properties $\left({ }^{\circ} \mathrm{C}\right)$ \\
\hline \multirow[t]{9}{*}{ 1,3-Ph } & $\bar{H}$ & $\mathrm{H}$ & $\mathrm{H}$ & $\mathrm{H}$ & $\mathrm{Cr} 107 \mathrm{SmCP}_{\mathrm{A}} 119 \mathrm{I}$ \\
\hline & $\mathrm{F}$ & $\mathrm{H}$ & $\mathrm{H}$ & $\mathrm{H}$ & $\mathrm{Cr} 124 \mathrm{SmC}_{\mathrm{S}} \mathrm{P}_{\mathrm{F}} 129 \mathrm{I}$ \\
\hline & $\mathrm{H}$ & $\mathrm{F}$ & $\mathrm{H}$ & $\mathrm{H}$ & $\mathrm{Cr} 99 \mathrm{SmCP}_{\mathrm{A}} 106 \mathrm{I}$ \\
\hline & $\mathrm{H}$ & $\mathrm{H}$ & $\mathrm{F}$ & $\mathrm{H}$ & $\mathrm{Cr} 123 \mathrm{I}$ \\
\hline & $\mathrm{H}$ & $\mathrm{H}$ & $\mathrm{H}$ & $\mathrm{F}$ & $\mathrm{Cr} 91 \mathrm{SmCP}_{\mathrm{A}} 109 \mathrm{I}$ \\
\hline & $\mathrm{F}$ & $\mathrm{H}$ & $\mathrm{H}$ & $\mathrm{F}$ & $\mathrm{Cr} 103 \quad \mathrm{SmC}_{\mathrm{S}} \mathrm{P}_{\mathrm{F}} 121 \mathrm{I}$ \\
\hline & $\mathrm{F}$ & $\mathrm{H}$ & $\mathrm{F}$ & $\mathrm{H}$ & $\mathrm{Cr} 152 \mathrm{I}$ \\
\hline & $\mathrm{H}$ & $\mathrm{F}$ & $\mathrm{H}$ & $\mathrm{F}$ & $\mathrm{Cr} 87 \mathrm{SmCP}_{\mathrm{A}} 97 \mathrm{I}$ \\
\hline & $\mathrm{H}$ & $\mathrm{F}$ & $\mathrm{F}$ & $\mathrm{H}$ & Cr $113 \mathrm{I}$ \\
\hline \multirow[t]{5}{*}{ 2,7-Nph } & $\mathrm{H}$ & $\mathrm{H}$ & $\mathrm{H}$ & $\mathrm{H}$ & $\mathrm{Cr} 116 \mathrm{SmCP}_{\mathrm{A}} 172 \mathrm{I}$ \\
\hline & $\mathrm{F}$ & $\mathrm{H}$ & $\mathrm{H}$ & $\mathrm{H}$ & Cr $156 \mathrm{Col}_{\mathrm{ob}} \mathrm{P}_{\mathrm{F}} 175 \mathrm{SmC}_{\mathrm{S}} \mathrm{P}_{\mathrm{F}} 184 \mathrm{I}$ \\
\hline & $\mathrm{H}$ & $\mathrm{F}$ & $\mathrm{H}$ & $\mathrm{H}$ & Cr $116 \mathrm{SmC}_{\mathrm{A}} \mathrm{P}_{\mathrm{A}} 157 \mathrm{I}$ \\
\hline & $\mathrm{H}$ & $\mathrm{H}$ & $\mathrm{F}$ & $\mathrm{H}$ & Cr $127 \mathrm{SmC}_{\mathrm{A}} \mathrm{P}_{\mathrm{A}} 151 \mathrm{I}$ \\
\hline & $\mathrm{H}$ & $\mathrm{H}$ & $\mathrm{H}$ & $\mathrm{F}$ & Cr $99 \mathrm{SmC}_{\mathrm{A}} \mathrm{P}_{\mathrm{A}} 156 \mathrm{I}$ \\
\hline
\end{tabular}


Table 13. Transition temperatures $\left({ }^{\circ} \mathrm{C}\right)$ of some bent-shaped mesogens with different terminal chains.<smiles>[X]c1ccc(-[Y]2ccc(C(=O)Oc3cccc(C(=O)Oc4ccc([Y]([H])c5ccc([Y]([H])[H])cc5)cc4)c3)cc2)cc1</smiles>

\begin{tabular}{|c|c|c|c|c|}
\hline $\mathbf{Y}$ & $\mathbf{X}$ & $\mathbf{m}$ & $\mathbf{n}$ & Thermal properties $\left({ }^{\mathbf{0}} \mathbf{C}\right)$ \\
\hline$-\mathrm{N}=\mathrm{CH}-$ & $\mathrm{O}$ & 6 & 6 & $\mathrm{~B}_{4} 144 \quad \mathrm{~B}_{3} 159 \mathrm{~B}_{1} 173 \mathrm{I}$ \\
\hline$-\mathrm{N}=\mathrm{CH}-$ & $\mathrm{O}$ & 8 & 8 & $\mathrm{~B}_{4} 140 \mathrm{~B}_{3} 152 \mathrm{~B}_{2} 174 \mathrm{I}$ \\
\hline$-\mathrm{N}=\mathrm{CH}-$ & $\mathrm{O}$ & 12 & 12 & $\mathrm{~B}_{4} 141 \mathrm{~B}_{2} 170 \mathrm{I}$ \\
\hline$-\mathrm{N}=\mathrm{CH}-$ & - & 6 & 6 & $\mathrm{Cr} 83 \mathrm{~B}_{3} 149 \mathrm{~B}_{2} 156 \mathrm{I}$ \\
\hline$-\mathrm{N}=\mathrm{CH}-$ & - & 12 & 12 & $\mathrm{Cr} 63 \mathrm{~B}_{3} 130 \mathrm{~B}_{2} 156 \mathrm{I}$ \\
\hline$-\mathrm{COO}-$ & $\mathrm{O}$ & 8 & 8 & $\left.\mathrm{Cr} 125 \mathrm{~B}_{1} 121\right) \mathrm{I}$ \\
\hline$-\mathrm{COO}-$ & $\mathrm{O}$ & 12 & 12 & $\mathrm{Cr} 109 \mathrm{~B}_{2} 119 \mathrm{I}$ \\
\hline$-\mathrm{COO}-$ & $\mathrm{O}$ & 11 & 12 & $\mathrm{Cr} 99 \mathrm{~B}_{2} 113 \mathrm{I}$ \\
\hline$-\mathrm{COO}-$ & $\mathrm{O}$ & 8 & 12 & $\mathrm{Cr} 103\left(\mathrm{~B}_{1} 102\right) \mathrm{I}$ \\
\hline
\end{tabular}


Table 14. Transition temperatures $\left({ }^{\circ} \mathrm{C}\right)$ of some bent-shaped mesogens with different terminal chains.<smiles>[X]c1ccc(/N=C/c2ccc(C(=O)Oc3cccc(OC(=O)c4ccc(/C=N/c5ccc([Y4]([H])[H])cc5)cc4)c3)cc2)cc1</smiles>

\begin{tabular}{|c|c|c|}
\hline & $-\mathbf{X C}_{\mathbf{n}} \mathrm{H}_{2 n+1}$ & Thermal properties $\left({ }^{\circ} \mathrm{C}\right)$ \\
\hline & $-\mathrm{OC}_{10} \mathrm{H}_{21}$ & $\mathrm{Cr} 104 \mathrm{~B}_{4} 151 \mathrm{~B}_{3} 153 \mathrm{~B}_{2} 174 \mathrm{I}$ \\
\hline
\end{tabular}


Table 15. Transition temperatures $\left({ }^{\circ} \mathrm{C}\right)$ of two series of bent-shaped mesogens with different terminal chains.
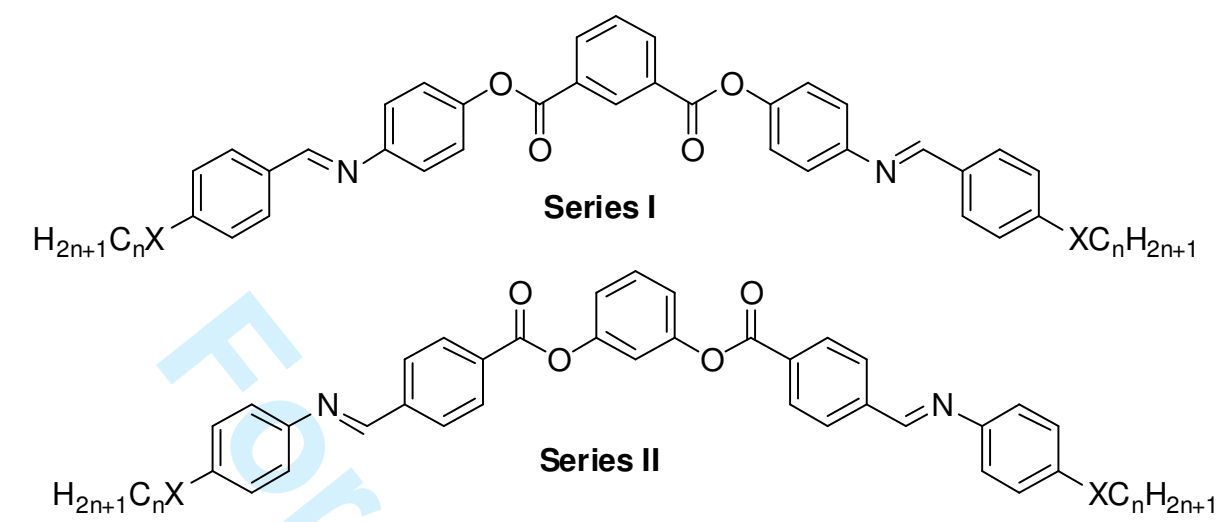

\begin{tabular}{|c|c|c|}
\hline Series & $-\mathbf{X C}_{\mathbf{n}} \mathbf{H}_{2 \mathbf{n + 1}}$ & Thermal properties $\mathbf{(}^{\mathbf{C}} \mathbf{C}$ \\
\hline $\mathrm{I}$ & $-\mathrm{COOC}_{10} \mathrm{H}_{21}$ & $\mathrm{Cr} 174 \mathrm{SmC}_{\mathrm{S}} \mathrm{P}_{\mathrm{A}} 180 \mathrm{SmC}_{\mathrm{S}} \mathrm{G}_{2} \mathrm{P}_{\mathrm{A}} 184 \mathrm{I}$ \\
\hline $\mathrm{I}$ & $-\mathrm{COOC}_{14} \mathrm{H}_{29}$ & $\mathrm{Cr} 170 \mathrm{SmC}_{\mathrm{S}} \mathrm{G}_{2} \mathrm{P}_{\mathrm{A}} 177 \mathrm{I}$ \\
\hline $\mathrm{I}$ & $-\mathrm{OC}_{14} \mathrm{H}_{29}$ & $\mathrm{Cr} 186 \mathrm{I}$ \\
\hline $\mathrm{I}$ & $-\mathrm{CH}=\mathrm{CHCOOC}_{14} \mathrm{H}_{29}$ & $\mathrm{Cr} 160 \mathrm{SmCP}_{\mathrm{A}} 227 \mathrm{I}$ \\
\hline $\mathrm{I}$ & $-\mathrm{OCH}_{2} \mathrm{COOC}_{14} \mathrm{H}_{29}$ & $\mathrm{Cr} 159 \mathrm{I}$ \\
\hline II & $-\mathrm{COOC}_{10} \mathrm{H}_{21}$ & $\mathrm{Cr} 135 \mathrm{~B}_{2} 143 \mathrm{I}$ \\
\hline II & $-\mathrm{COOC}_{14} \mathrm{H}_{29}$ & $\mathrm{Cr} 131\left(\mathrm{SmC} \mathrm{P}_{\mathrm{A}} 116\right) \mathrm{B}_{7} 139 \mathrm{I}$ \\
\hline
\end{tabular}


Table 16. Transition temperatures $\left({ }^{\circ} \mathrm{C}\right)$ of chiral of bent-shaped mesogens.<smiles>[R]c1ccc(/N=C/c2ccc(C(=O)Oc3cccc(OC(=O)c4ccc(/C=N/c5ccc([R])cc5)cc4)c3)cc2)cc1</smiles>

\begin{tabular}{|c|c|c|}
\hline Compound & $\mathbf{R}$ & Thermal properties \\
\hline P-7-O-PIMB5* & & $\mathrm{Cr} 120 \mathrm{SmC}_{\mathrm{S}} \mathrm{P}_{\mathrm{A}} 158 \mathrm{I}$ \\
\hline P-8-O-PIMB6* & & $\mathrm{B}_{3} * 146 \mathrm{SmY}^{*} 159 \mathrm{SmC}_{\mathrm{A}} \mathrm{P}_{\mathrm{F}} * 167 \mathrm{I}$ \\
\hline P-9-O-PIMB7* & & Cr $123 \mathrm{~S} \mathrm{SmC}_{\mathrm{S}} \mathrm{P}_{\mathrm{A}} 167 \mathrm{I}$ \\
\hline P-7-O-PIMB5*-4O & & I $110 \mathrm{SmCP}_{\mathrm{A}} 84 \mathrm{Cr}$ \\
\hline CITRO & & $\operatorname{Cr} 110 \mathrm{~B}_{7}(\mathrm{FE}) 85 \mathrm{X}$ \\
\hline
\end{tabular}


Table 17. Transition temperatures $\left({ }^{\circ} \mathrm{C}\right)$ of bent-shaped mesogens with different terminal chains.<smiles>[R]c1ccc(C(=O)Oc2ccc(C(=O)Oc3ccc(-c4cccc(OC(=O)c5ccc(OC(=O)c6ccc([R2])cc6)cc5)c4)cc3)cc2)cc1</smiles>

\begin{tabular}{|c|c|c|}
\hline $\mathbf{R}_{\mathbf{1}}$ & $\mathbf{R}_{\mathbf{2}}$ & Thermal properties $\left({ }^{\mathbf{0}} \mathbf{C}\right)$ \\
\hline$-\mathrm{OC}_{10} \mathrm{H}_{21}$ & $-\mathrm{OC}_{10} \mathrm{H}_{21}$ & $\mathrm{Cr} 119 \mathrm{Col}_{\mathrm{r}} 166 \mathrm{I}$ \\
\hline$-\mathrm{OC}_{14} \mathrm{H}_{29}$ & $-\mathrm{OC}_{14} \mathrm{H}_{29}$ & $\mathrm{Cr} 85 \mathrm{SmCP} 162 \mathrm{I}$ \\
\hline$-\left(\mathrm{OCH}_{2} \mathrm{CH}_{2}\right)_{4} \mathrm{CH}_{3}$ & $-\left(\mathrm{OCH}_{2} \mathrm{CH}_{2}\right)_{4} \mathrm{CH}_{3}$ & $\begin{array}{c}\mathrm{Cr} 31 \mathrm{SmCP}_{\mathrm{A}} 57 \mathrm{I} \\
\mathrm{I} 51 \mathrm{SmCP}_{\mathrm{A}} 15 \mathrm{~g}\end{array}$ \\
\hline$-\mathrm{O}\left(\mathrm{CH}_{2}\right)_{6} \mathrm{C}_{4} \mathrm{~F}_{9}$ & $-\mathrm{O}\left(\mathrm{CH}_{2}\right)_{6} \mathrm{C}_{4} \mathrm{~F}_{9}$ & $\mathrm{Cr} 127 \mathrm{SmCP}_{\mathrm{A}} 213 \mathrm{I}$ \\
\hline$-\mathrm{O}\left(\mathrm{CH}_{2}\right)_{4} \mathrm{C}_{6} \mathrm{~F}_{13}$ & $-\mathrm{O}\left(\mathrm{CH}_{2}\right)_{4} \mathrm{C}_{6} \mathrm{~F}_{13}$ & $\mathrm{Cr} 150 \mathrm{SmCP}_{\mathrm{A}} 252 \mathrm{I}$ \\
\hline$-\mathrm{OC}_{10} \mathrm{H}_{21}$ & $-\mathrm{O}\left(\mathrm{CH}_{2}\right)_{4} \mathrm{C}_{6} \mathrm{~F}_{13}$ & $\mathrm{Cr} 135 \mathrm{SmCP}_{\mathrm{A}} 211 \mathrm{I}$ \\
\hline
\end{tabular}


Table 18. Transition temperatures $\left({ }^{\circ} \mathrm{C}\right)$ of bent-shaped mesogens with different (oligo)siloxanes at the terminal chains. ( $l$ : linear, $b$ : branched).

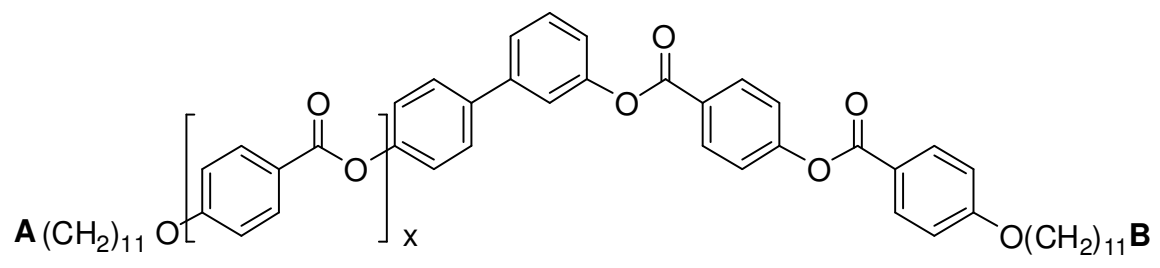

\begin{tabular}{|c|c|c|c|c|}
\hline $\mathbf{x}$ & $\mathbf{A}$ & $\mathbf{B}$ & Type & Thermal properties $\left({ }^{\circ} \mathrm{C}\right)$ \\
\hline 1 & $\mathrm{CH}_{3}$ & $\mathrm{CH}_{3}$ & $l$ & $\mathrm{Cr} 88 \mathrm{SmCP}_{\mathrm{A}} 111 \mathrm{I}$ \\
\hline 1 & $\mathrm{Me}_{3} \mathrm{SiOSiMe}_{2-}$ & $\mathrm{CH}_{3}$ & $l$ & $\mathrm{Cr} 77 \mathrm{SmCP}_{\mathrm{A}} 118 \mathrm{I}$ \\
\hline 1 & $\mathrm{Me}_{3} \mathrm{Si}\left(\mathrm{OSiMe}_{2}\right)_{2}-$ & $\mathrm{CH}_{3}$ & $l$ & $\mathrm{Cr} 70 \mathrm{SmCP}_{\mathrm{F}} 115 \mathrm{I}$ \\
\hline 1 & $\left(\mathrm{Me}_{3} \mathrm{SiO}\right)_{2}-\mathrm{SiMe}-$ & $\mathrm{CH}_{3}$ & $b$ & Cr $63 \mathrm{SmCP}_{\mathrm{F}} 116 \mathrm{I}$ \\
\hline 2 & $\mathrm{Me}_{3} \mathrm{Si}\left(\mathrm{OSiMe}_{2}\right)_{2}-$ & $\mathrm{Me}_{3} \mathrm{Si}\left(\mathrm{OSiMe}_{2}\right)_{2}-$ & $l$ & Cr $89 \mathrm{SmCP}_{\mathrm{F}} 126 \mathrm{SmCP}_{\mathrm{A}} 143 \mathrm{Col}_{\mathrm{ob}} \mathrm{P} 147 \mathrm{Col}_{\mathrm{ob}} 155 \mathrm{I}$ \\
\hline 2 & $\left(\mathrm{Me}_{3} \mathrm{SiO}\right)_{2}-\mathrm{SiMe}-$ & $\left(\mathrm{Me}_{3} \mathrm{SiO}\right)_{2}-\mathrm{SiMe}-$ & $b$ & Cr $78 \mathrm{USmCP}_{\mathrm{A}} 127 \mathrm{Col}_{\mathrm{ob}} \mathrm{P}_{\mathrm{A}} 150 \mathrm{I}$ \\
\hline
\end{tabular}


Table 19. Transition temperatures $\left({ }^{\circ} \mathrm{C}\right)$ of bent-shaped mesogens with different carbosilanes at the terminal chains. (1: linear, $b$ : branched)

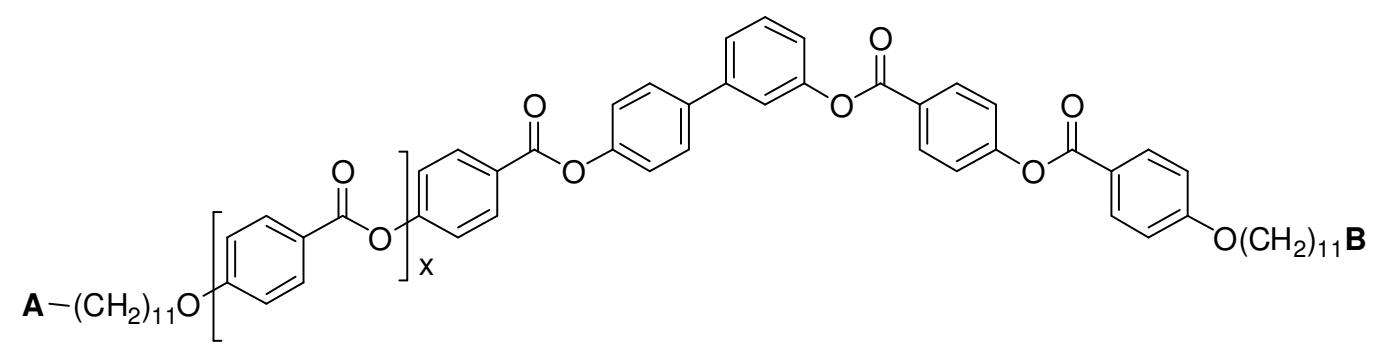

\begin{tabular}{|c|c|c|c|c|}
\hline $\mathbf{x}$ & A & B & Type & Thermal properties \\
\hline 1 & $\mathrm{Me}_{3} \mathrm{Si}\left(\mathrm{CH}_{2}\right) \mathrm{SiMe}_{2}-$ & $\mathrm{CH}_{3}$ & $l$ & $\mathrm{Cr}$ 84 SmCP \\
\hline 1 & $\mathrm{Me}_{3} \mathrm{Si}\left[\left(\mathrm{CH}_{2}\right) \mathrm{SiMe}_{2}\right]_{2}-$ & $\mathrm{CH}_{3}$ & $l$ & $\mathrm{Cr}$ 72 $\mathrm{SmCP}_{\mathrm{F}} 112 \mathrm{I}$ \\
\hline 1 & $\left(\mathrm{Me}_{3} \mathrm{SiCH}_{2}\right)_{2}-\mathrm{SiMe}_{-}$ & $\mathrm{CH}_{3}$ & $b$ & $\mathrm{Cr} 74 \mathrm{SmCP}_{\mathrm{F}} 107 \mathrm{I}$ \\
\hline 1 & {$\left[\mathrm{Me}_{3} \mathrm{Si}\left(\mathrm{CH}_{2}\right)_{3}\right]_{3} \mathrm{Si}-$} & $\mathrm{CH}_{3}$ & $b$ & $\mathrm{Cr} 76 \mathrm{SmCP}_{\mathrm{F}}$ 91 Col ${ }_{\mathrm{ob}} \mathrm{P}_{\mathrm{A}} 107 \mathrm{I}$ \\
\hline 2 & $\mathrm{Me}_{3} \mathrm{Si}\left[\left(\mathrm{CH}_{2}\right) \mathrm{SiMe}_{2}\right]_{2}-$ & $\mathrm{Me}_{3} \mathrm{Si}\left[\left(\mathrm{CH}_{2}\right) \mathrm{SiMe}_{2}\right]_{2}-$ & $l$ & $\mathrm{Cr} 60 \mathrm{SmCP}_{\mathrm{F}} 132 \mathrm{SmCP}_{\mathrm{A}} 139 \mathrm{Col}_{\mathrm{ob}_{\mathrm{A}}} \mathrm{P}_{\mathrm{A}} 150 \mathrm{I}$ \\
\hline
\end{tabular}


Table 20. Transition temperatures $\left({ }^{\circ} \mathrm{C}\right)$ of some bent-shaped dimers.

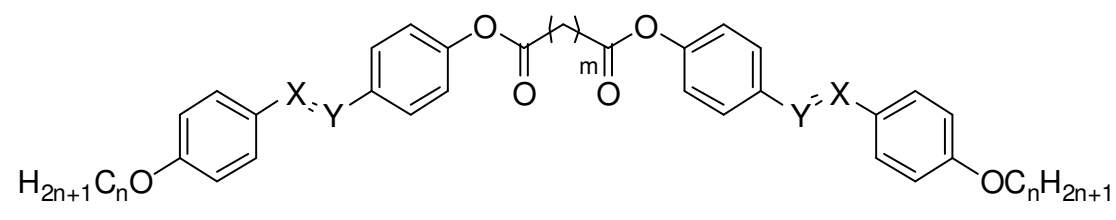

\begin{tabular}{|c|c|c|c|}
\hline $\mathbf{m}$ & $\mathbf{n}$ & $-\mathbf{X}=\mathbf{Y}-$ & Thermal properties $\left({ }^{\circ} \mathbf{C}\right)$ \\
\hline 5 & 10 & $-\mathrm{N}=\mathrm{CH}-$ & $\mathrm{Cr} 165 \mathrm{SmC} 183 \mathrm{I}$ \\
\hline 4 & 10 & $-\mathrm{N}=\mathrm{CH}-$ & $\mathrm{Cr} 149 \mathrm{X}_{2} 177 \mathrm{X}_{1} 225 \mathrm{I}$ \\
\hline 8 & 10 & $-\mathrm{N}=\mathrm{CH}-$ & $\mathrm{Cr} 139 \mathrm{X}_{2} 173 \mathrm{X}_{1} 176 \mathrm{SmA} 182 \mathrm{I}$ \\
\hline 4 & 10 & $-\mathrm{CH}=\mathrm{N}-$ & $\mathrm{Cr} 137 \mathrm{X}_{2} 174 \mathrm{X}_{1} 211 \mathrm{I}$ \\
\hline 8 & 10 & $-\mathrm{CH}=\mathrm{N}-$ & $\mathrm{Cr} 125 \mathrm{X}_{2} 170 \mathrm{X}_{1} 171 \mathrm{I}$ \\
\hline
\end{tabular}


Table 21. Transition temperatures $\left({ }^{\circ} \mathrm{C}\right)$ of some bent-shaped salicylaldimine-based dimers.

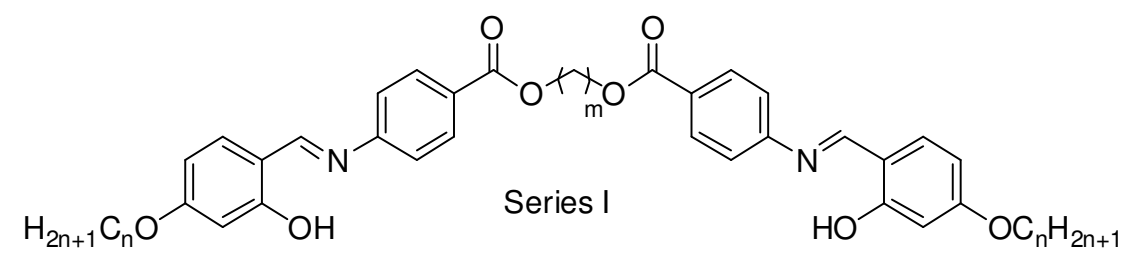

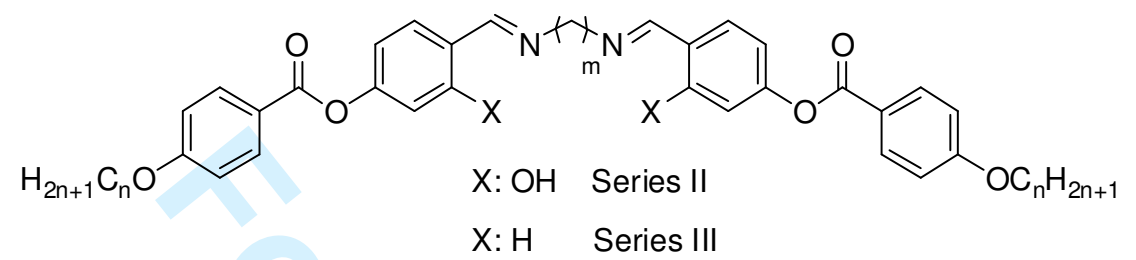

\begin{tabular}{|c|c|c|c|}
\hline Series-m-n & $\mathbf{m}$ & $\mathbf{n}$ & Thermal properties $\left(\mathbf{~}^{\mathbf{0}} \mathbf{C}\right)$ \\
\hline I-3-10 & 3 & 10 & $\mathrm{Cr} 175 \mathrm{I}$ \\
\hline I-5-10 & 5 & 10 & $\mathrm{Cr} 139\left(\mathrm{~B}_{1} 137\right) \mathrm{I}$ \\
\hline I-5-16 & 5 & 16 & $\mathrm{Cr}_{1} 121 \mathrm{Cr}_{2} 132 \mathrm{~B}_{1} 137 \mathrm{I}$ \\
\hline II-5-10 & 5 & 10 & $\mathrm{Cr} 105 \mathrm{Col}_{\mathrm{r}} 111 \mathrm{I}$ \\
\hline II-6-10 & 6 & 10 & $\mathrm{Cr} 151 \mathrm{SmC}_{177} \mathrm{I}$ \\
\hline III-5-10 & 5 & 10 & $\mathrm{Cr} 89 \mathrm{~B}_{6} 110 \mathrm{I}$ \\
\hline III-6-10 & 6 & 10 & $\mathrm{Cr} \mathrm{120} \mathrm{(SmA} \mathrm{116)} \mathrm{N} \mathrm{145} \mathrm{I}$ \\
\hline
\end{tabular}


Table 22. Transition temperatures $\left({ }^{\circ} \mathrm{C}\right)$ of some bent-shaped/rod-like dimers.

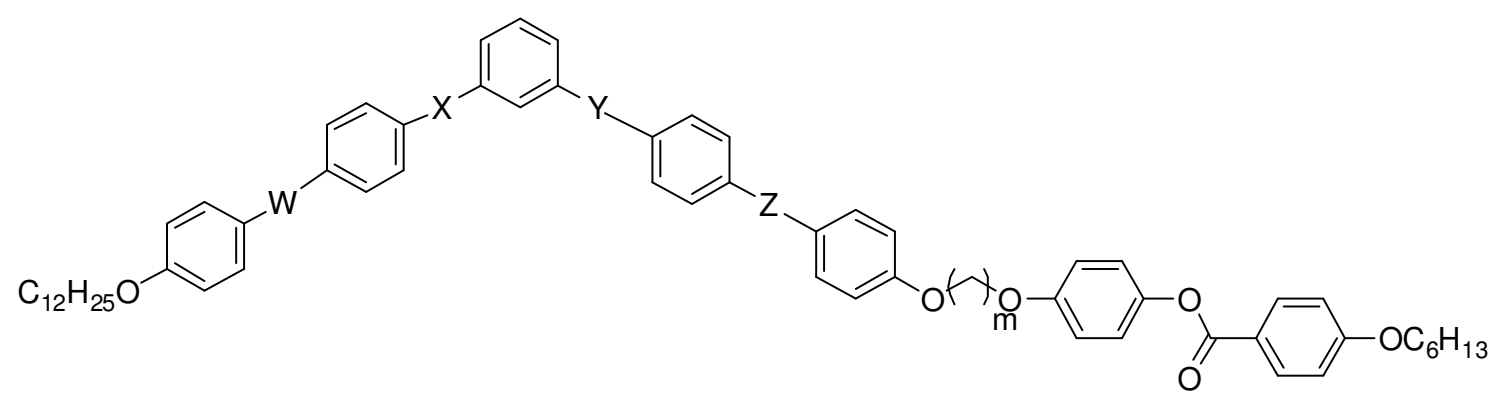

\begin{tabular}{|c|c|c|c|c|c|}
\hline $\mathbf{W}$ & $\mathbf{X}$ & $\mathbf{Y}$ & $\mathbf{Z}$ & $\mathbf{m}$ & Thermal properties $\left(^{\circ} \mathrm{C}\right)$ \\
\hline$-\mathrm{COO}-$ & $-\mathrm{COO}-$ & $-\mathrm{OOC}-$ & $-\mathrm{OOC}-$ & 11 & $\mathrm{Cr} 121 \mathrm{Col}_{\mathrm{ob}} \mathrm{P}_{\mathrm{FE}} 133 \mathrm{I}$ \\
\hline$-\mathrm{COO}-$ & $-\mathrm{COO}-$ & $-\mathrm{OOC}-$ & $-\mathrm{OOC}-$ & 6 & $\mathrm{Cr} 149\left(\mathrm{Col}_{\mathrm{x}} 126 \mathrm{~N} 146\right) \mathrm{I}$ \\
\hline- OOC- & $-\mathrm{COO}-$ & $-\mathrm{OOC}-$ & $-\mathrm{OOC}-$ & 11 & $\mathrm{Cr} 126 \mathrm{USmC}_{\mathrm{a}} \mathrm{P}_{\mathrm{AF}} 130 \mathrm{I}$ \\
\hline- OOC- & $-\mathrm{COO}-$ & $-\mathrm{OOC}-$ & $-\mathrm{OOC}-$ & 6 & $\mathrm{Cr} 146 \mathrm{SmA}_{149} \mathrm{~N} 150 \mathrm{I}$ \\
\hline$-\mathrm{COO}-$ & - OOC- & $-\mathrm{OOC}-$ & $-\mathrm{OOC}-$ & 6 & $\mathrm{Cr}_{1} 159\left(\mathrm{SmC}_{\mathrm{x}} 148\right) \mathrm{N} 166 \mathrm{I}$ \\
\hline$-\mathrm{COO}-$ & $-\mathrm{COO}-$ & $-\mathrm{COO}-$ & $-\mathrm{OOC}-$ & 6 & $\mathrm{Cr} 145\left(\mathrm{Col}_{\mathrm{x}} 130\right) \mathrm{N} 161 \mathrm{I}$ \\
\hline$-\mathrm{COO}-$ & $-\mathrm{COO}-$ & $-\mathrm{OOC}-$ & $-\mathbf{C O O}-$ & 6 & $\mathrm{Cr} 140\left(\mathrm{Col}_{\mathrm{x}} 130\right) \mathrm{N} 143 \mathrm{I}$ \\
\hline
\end{tabular}


Table 23. Thermal properties of different meta-substituted 'hockey stick' mesogens.

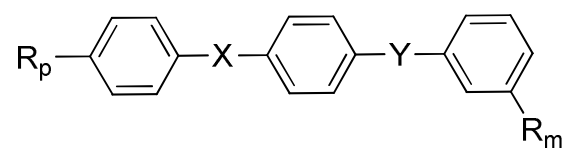

\begin{tabular}{|c|c|c|c|c|}
\hline $\mathbf{R}_{\mathbf{p}}$ & $\mathbf{R}_{\mathbf{m}}$ & $\mathbf{X}$ & $\mathbf{Y}$ & Thermal properties $\left.{ }^{\circ} \mathrm{C}\right)$ \\
\hline$-\mathrm{OC}_{8} \mathrm{H}_{17}$ & $-\mathrm{OC}_{5} \mathrm{H}_{17}$ & $-\mathrm{OOC}-$ & $-\mathrm{OOC}-$ & $\mathrm{Cr} 88$ (N 43) I \\
\hline$-\mathrm{OC}_{12} \mathrm{H}_{25}$ & $-\mathrm{OC}_{10} \mathrm{H}_{21}$ & $-\mathrm{COO}-$ & $-\mathrm{CH}=\mathrm{N}-$ & $\mathrm{Cr} 65$ (SmCa 59) SmCs 66 I \\
\hline$-\mathrm{OC}_{12} \mathrm{H}_{25}$ & $-\mathrm{OC}_{10} \mathrm{H}_{21}$ & $-\mathrm{CH}=\mathrm{CH}-$ & $-\mathrm{OOC}-$ & $\mathrm{Cr} 81$ (SmCa 69 SmCs 81) I \\
\hline$-\mathrm{OC}_{12} \mathrm{H}_{25}$ & $-\mathrm{OC}_{4} \mathrm{H}_{9}$ & $-\mathrm{CH}=\mathrm{CH}-$ & $-\mathrm{OOC}-$ & $\mathrm{Cr} 74 \mathrm{SmCa} 82 \mathrm{SmCs} 83 \mathrm{SmA} 87 \mathrm{I}$ \\
\hline$-\mathrm{OC}_{12} \mathrm{H}_{25}$ & $-\mathrm{OC}_{10} \mathrm{H}_{21}$ & $\begin{array}{c}-\mathrm{CH}=\mathrm{CH}- \\
\mathrm{COO}-\end{array}$ & $-\mathrm{CH}=\mathrm{N}-$ & $\mathrm{Cr} 93 \mathrm{SmCa} 95 \mathrm{SmCs} 100 \mathrm{I}$ \\
\hline
\end{tabular}


Figure 1. Schematic representation of bent-core mesogens (a) where BC means the central bent-core and LC the lateral core; bent mesogenic dimers (b) and the so-called 'hockey stick' molecules (c).

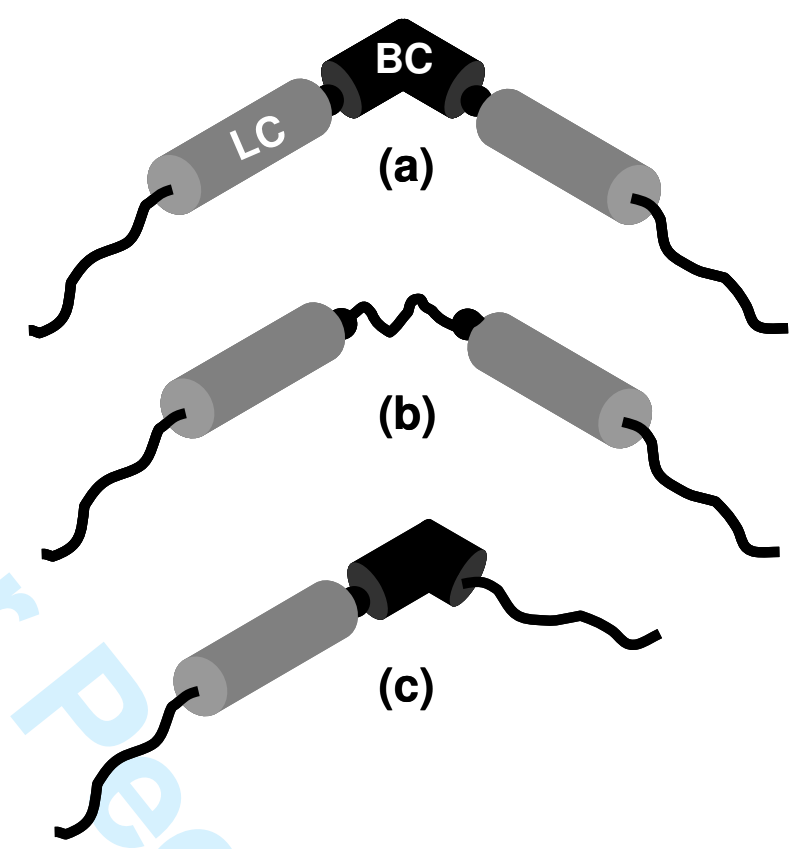

Figure 2. Chemical structures of some bent-core dimers.<smiles>[X]c1cc(C(=O)Oc2ccc(C(=O)Oc3cccc(OC(=O)c4ccc(OC(=O)c5ccc(OCCNC(C)(C)C)cc5)cc4[Y])c3)cc2)ccc1OCNC(=O)NCCCNC(=O)c1ccc(OCC(C)C)cc1</smiles> 
Figure 3. Chemical structure of some Si-based bent-core dimers.

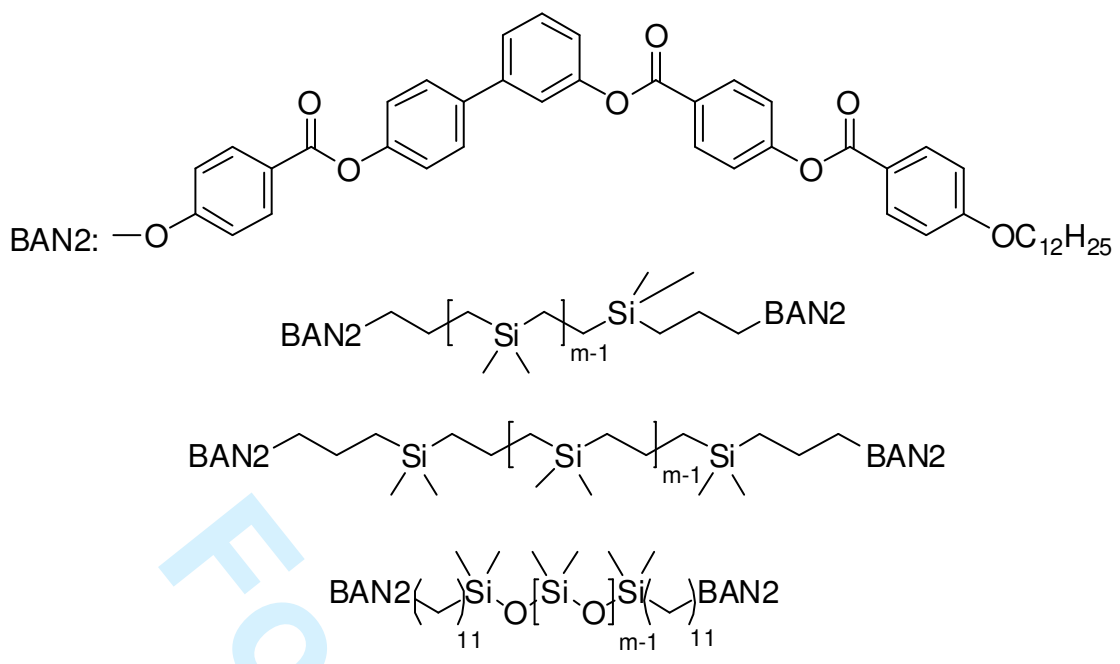

Figure 4. Chemical structure of some Si-based bent-core oligomers. (See BAN1 and BAN2 in Figs. 2 and 3)
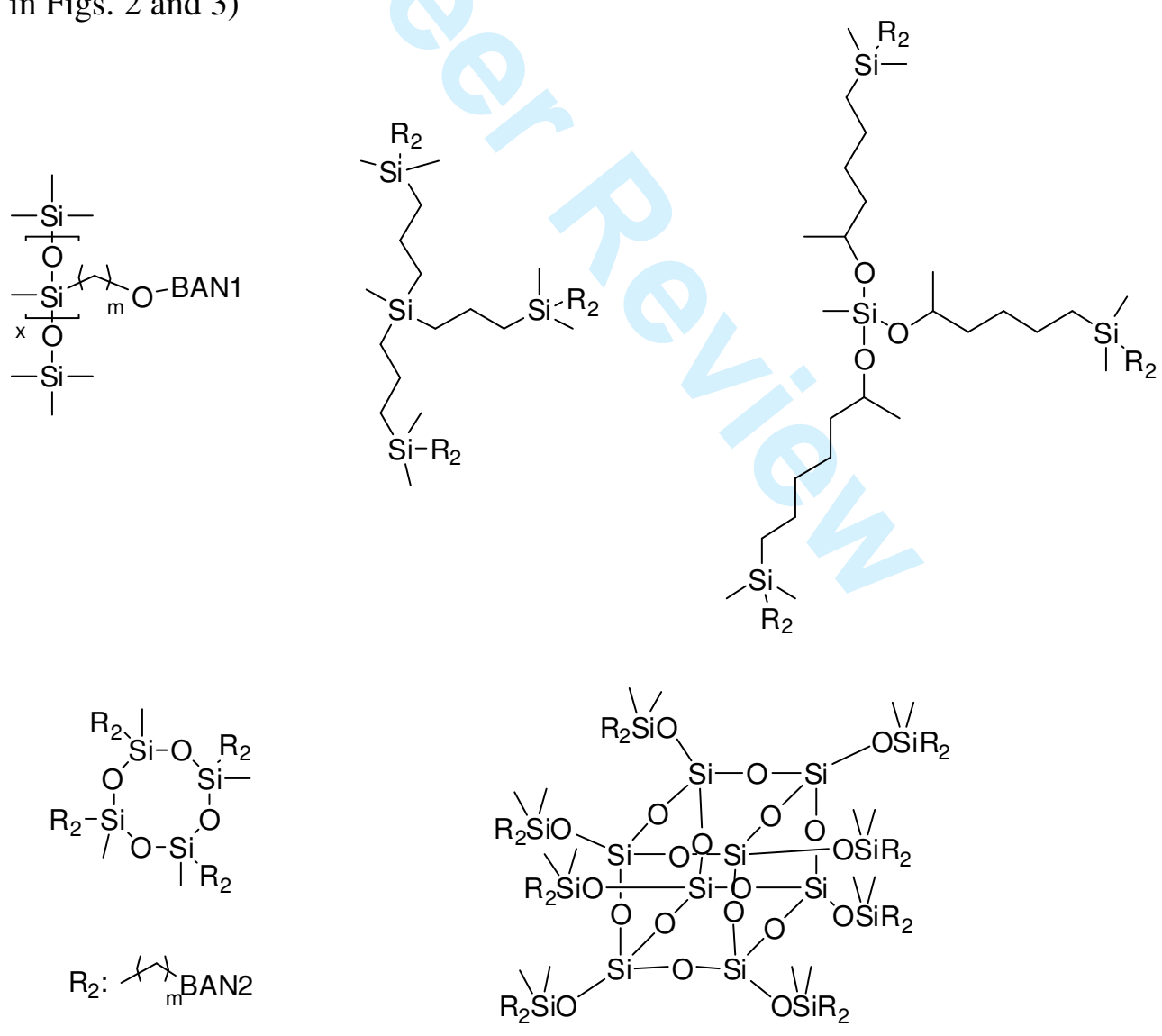
Figure 5. Chemical structures of some Si-based bent-core side-chain copolymers.

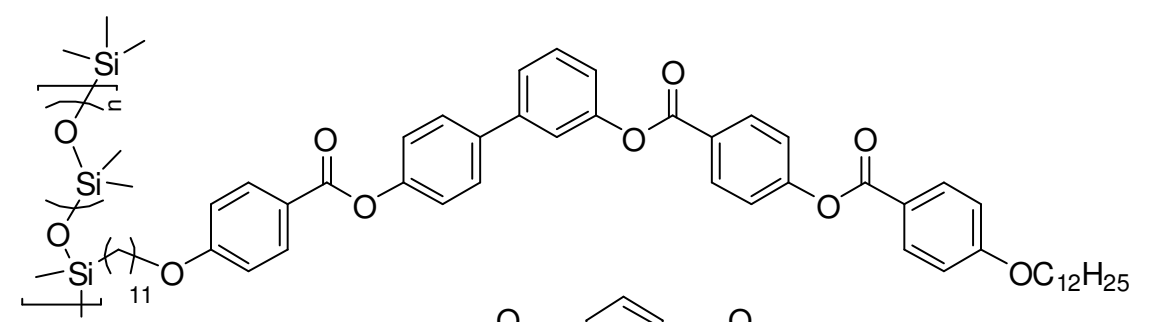

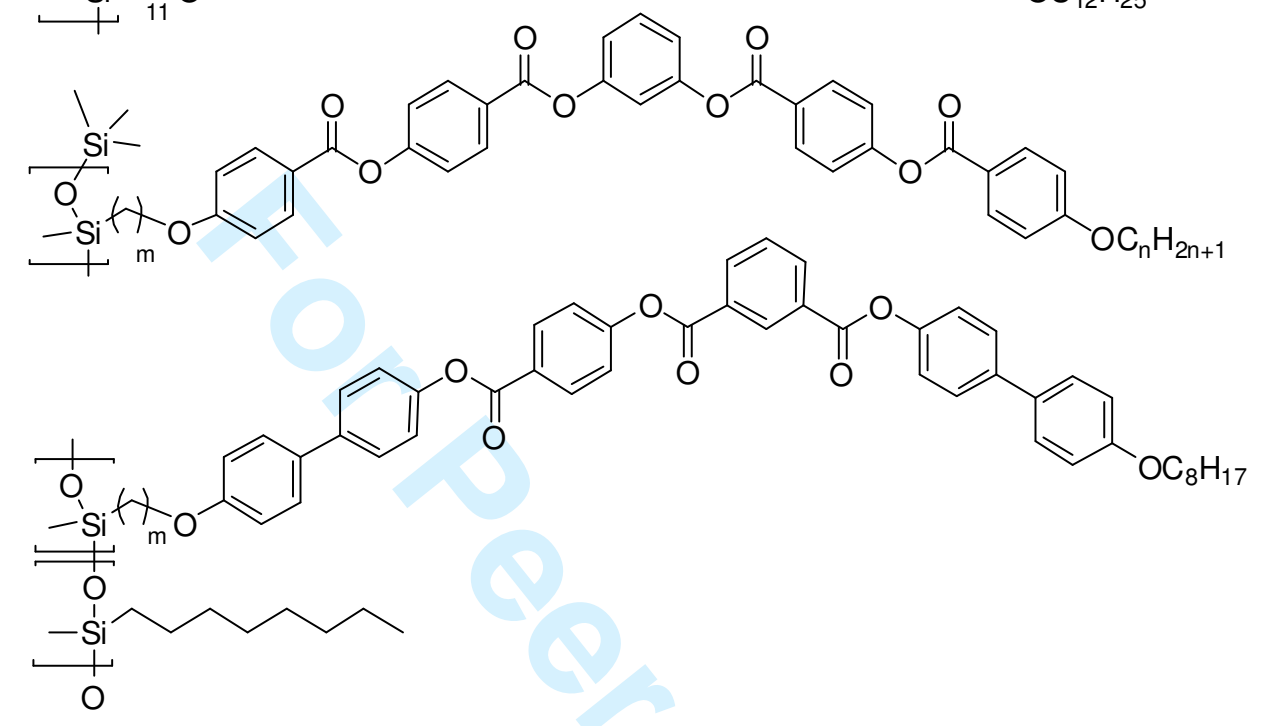

Figure 6. Chemical structures of bent-core mesogen-jacketed liquid crystalline polymers.

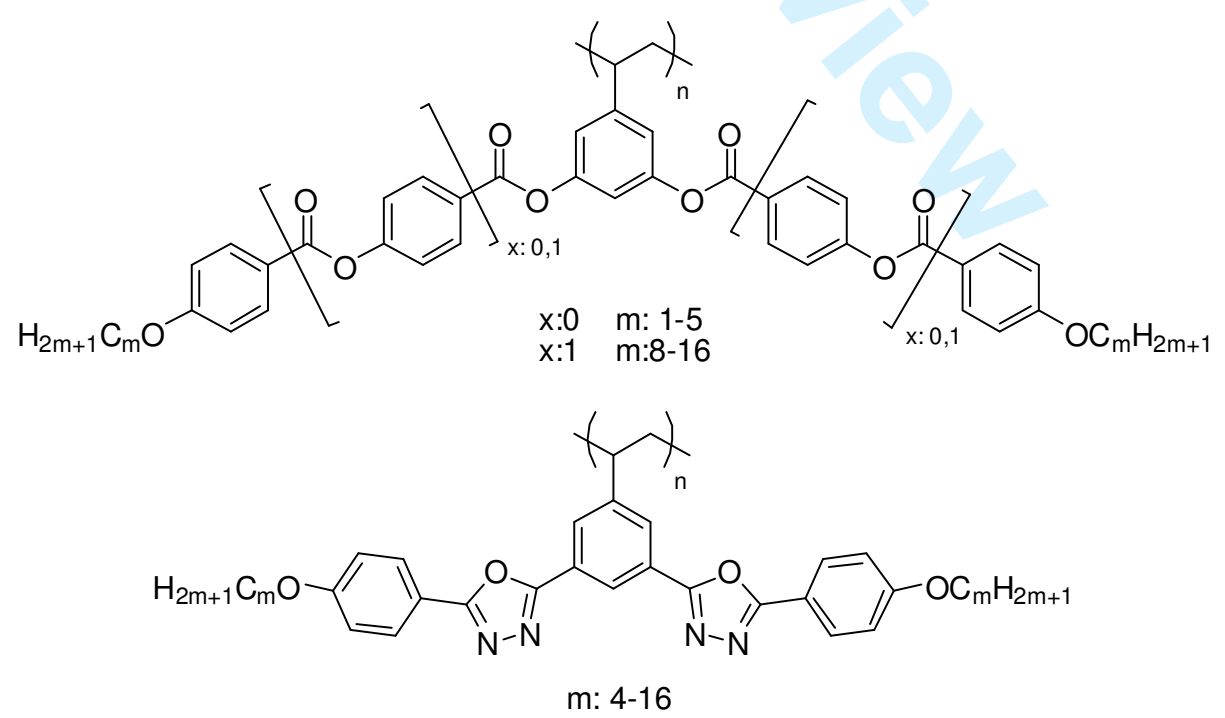


Figure 7. Chemical structures of some bent-core main-chain polymers.
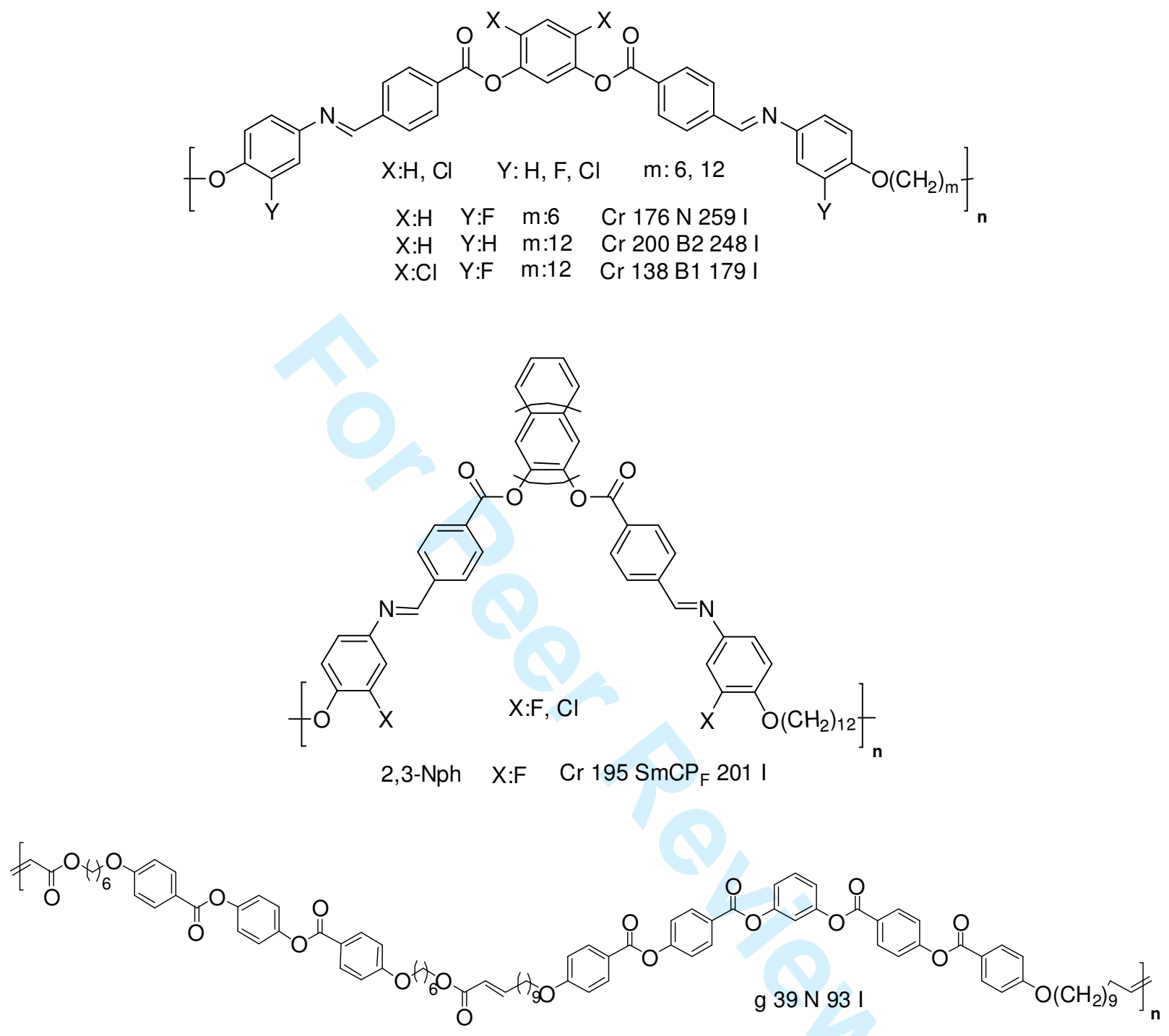<smiles>COc1ccc(C(=O)Oc2ccc(C(=O)Oc3ccc(-c4cccc(OC(=O)c5ccc(OC(=O)c6ccc(OC)cc6)cc5)c4)cc3)cc2)cc1</smiles> 
Page 71 of 78

VCH Books

Figure 8. Chemical structures of different direactive bent-core monomers.<smiles>[X][X]C([Y])(C)Oc1ccc(N=Cc2ccc(C(=O)Oc3cccc(OC(=O)c4ccc(/C=N/c5ccc(OC([Y])(C)C)cc5)cc4)c3)cc2)cc1</smiles>

$28 \mathrm{n}: 8,10,14 \mathrm{X}:$

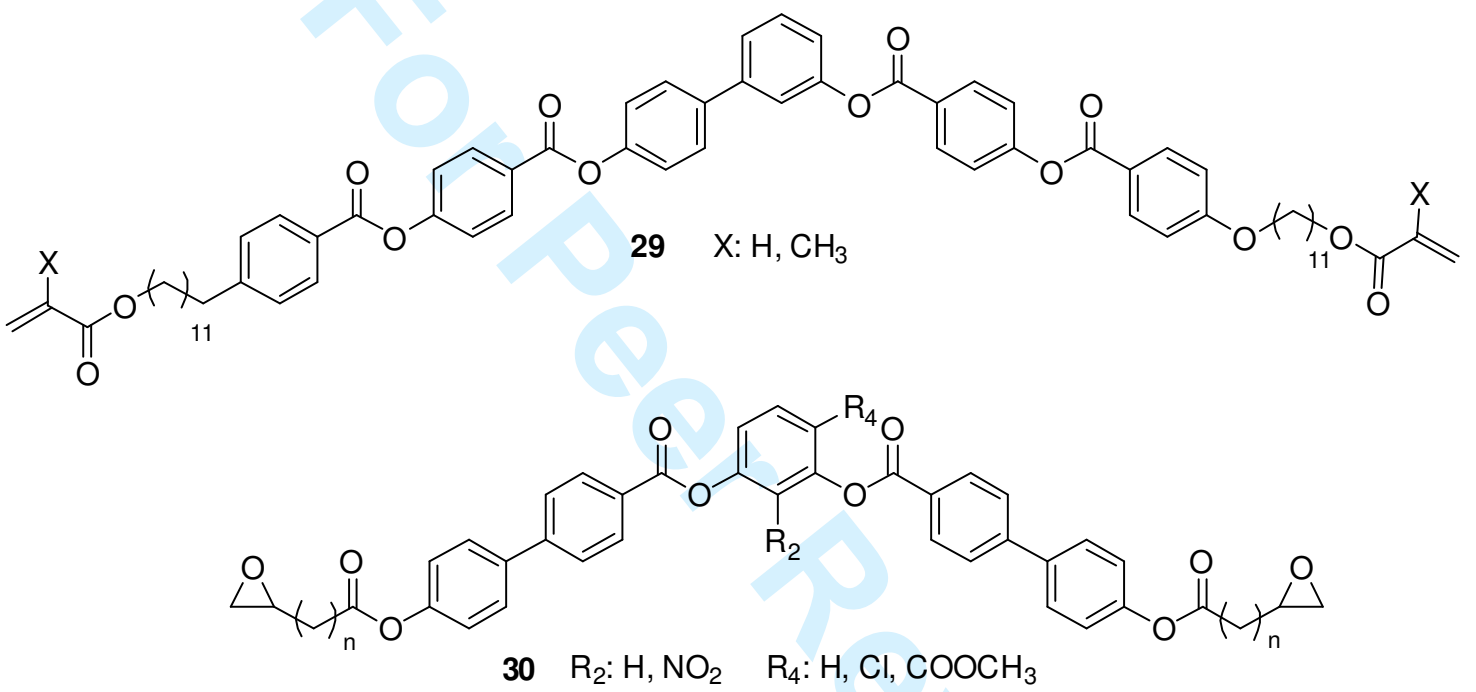

5

http://mc.manuscriptcentral.com/wiley-vch-books 
Figure 9. Chemical structure and thermal properties of the 1,3-phenylene based structures described by $\mathrm{Yu}$ et al.

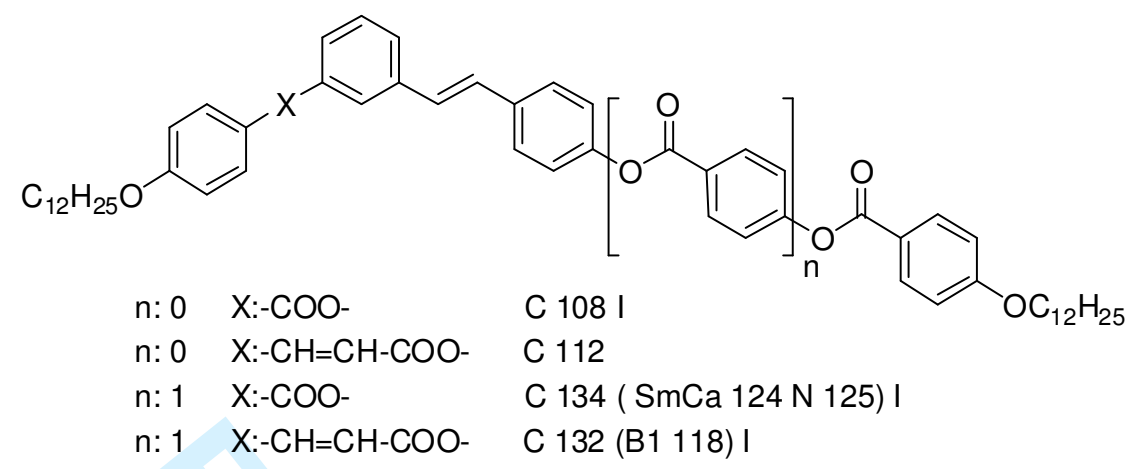

Figure 10. General molecular structures of different highly asymmetric 'hockey-stick' mesogens.<smiles>[R]Oc1ccc(C(=O)Oc2ccc(C(=O)Oc3ccc(C(=O)Oc4ccc5ccc(OC(=O)c6ccc(OC(=O)c7ccc(OCCCC)cc7)cc6)cc5c4)cc3)cc2)cc1</smiles> 
Figure 11. Representative meta-substituted mesogens described by Hird et al.
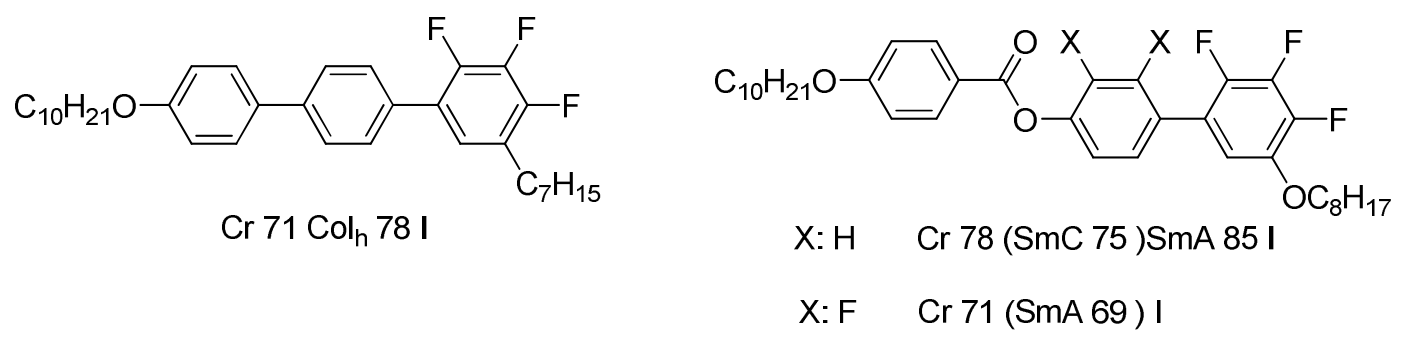
Figure 12. Representative synthetic strategies used to prepare symmetric bent-core liquid crystals (strategies A1 and A2).

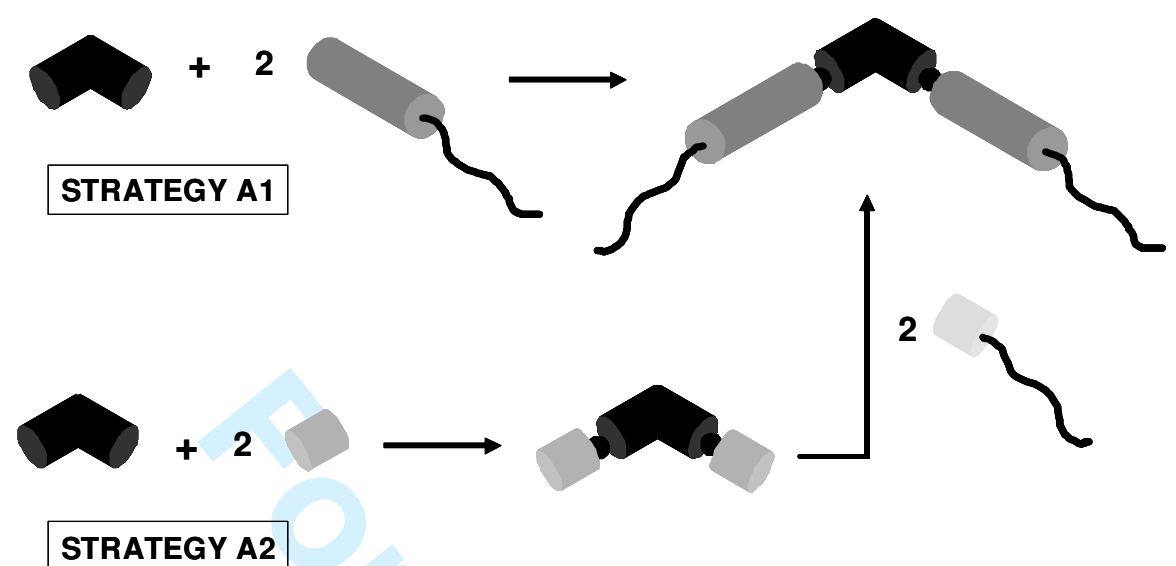

Figure 13. Representative synthetic strategies used to prepare non-symmetric bent-core liquid crystals (strategies B1 and B2).

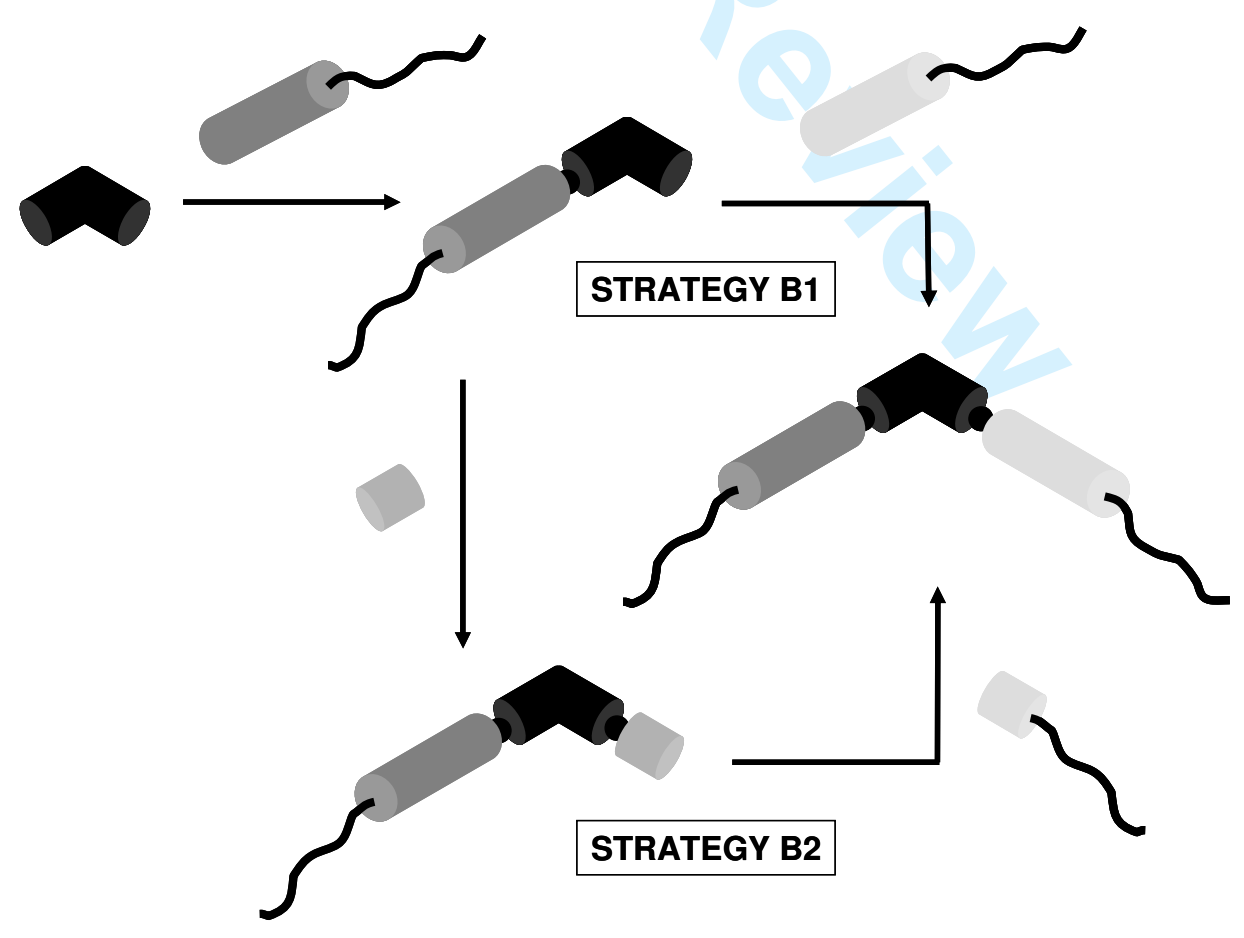


Scheme 1. Synthetic pathway used to prepare symmetric substituted bent-core structures.<smiles>[13CH3]Oc1ccc(N)cc1</smiles><smiles>[R5]c1c([R5])c(O)c([R5])c(O)c1[R5]</smiles> 
Scheme 2. Synthetic pathway used for seven-ring bent-core systems.

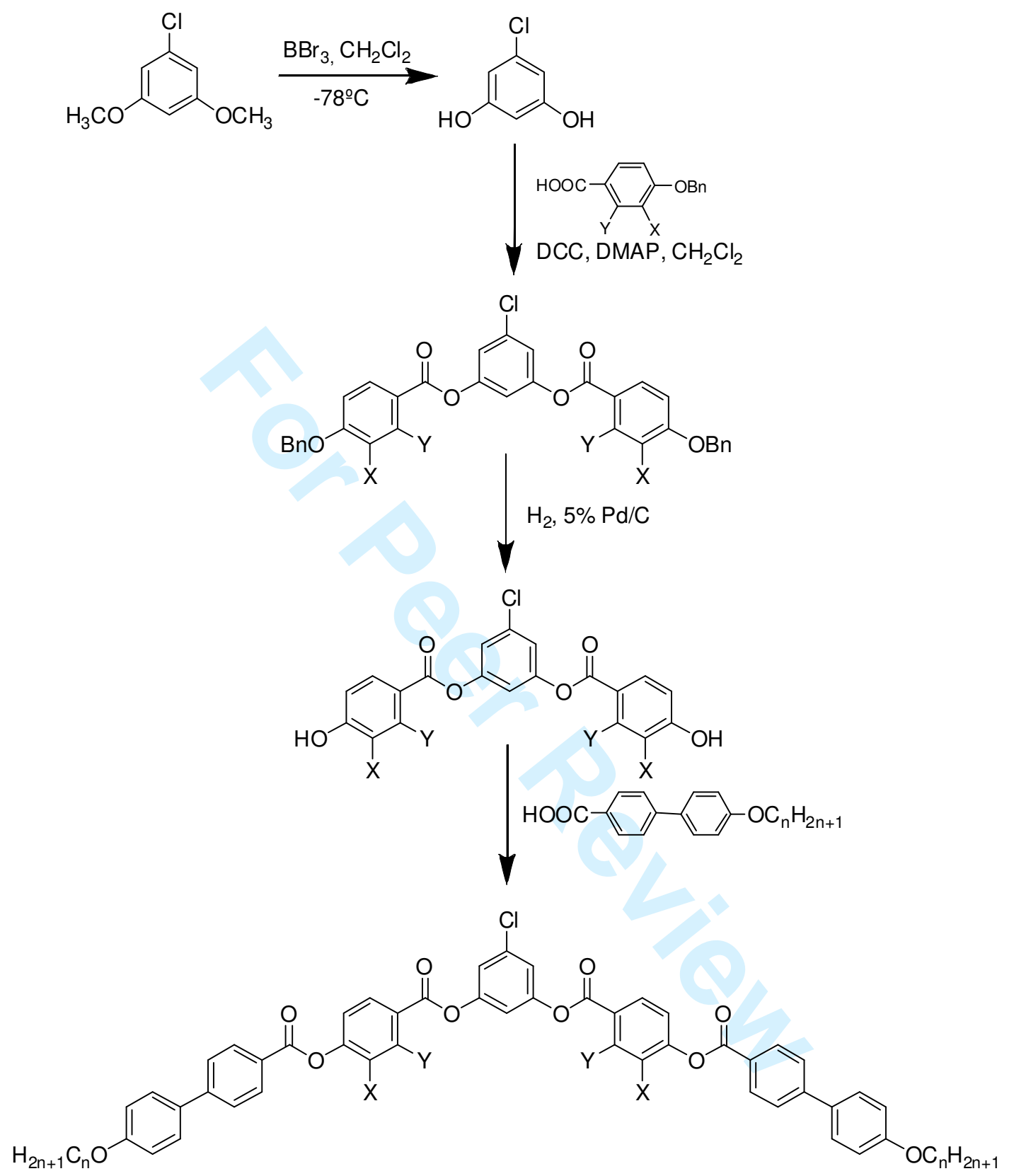


Scheme 3. Synthetic pathway used to prepare bent-core molecules with different terminal chains.

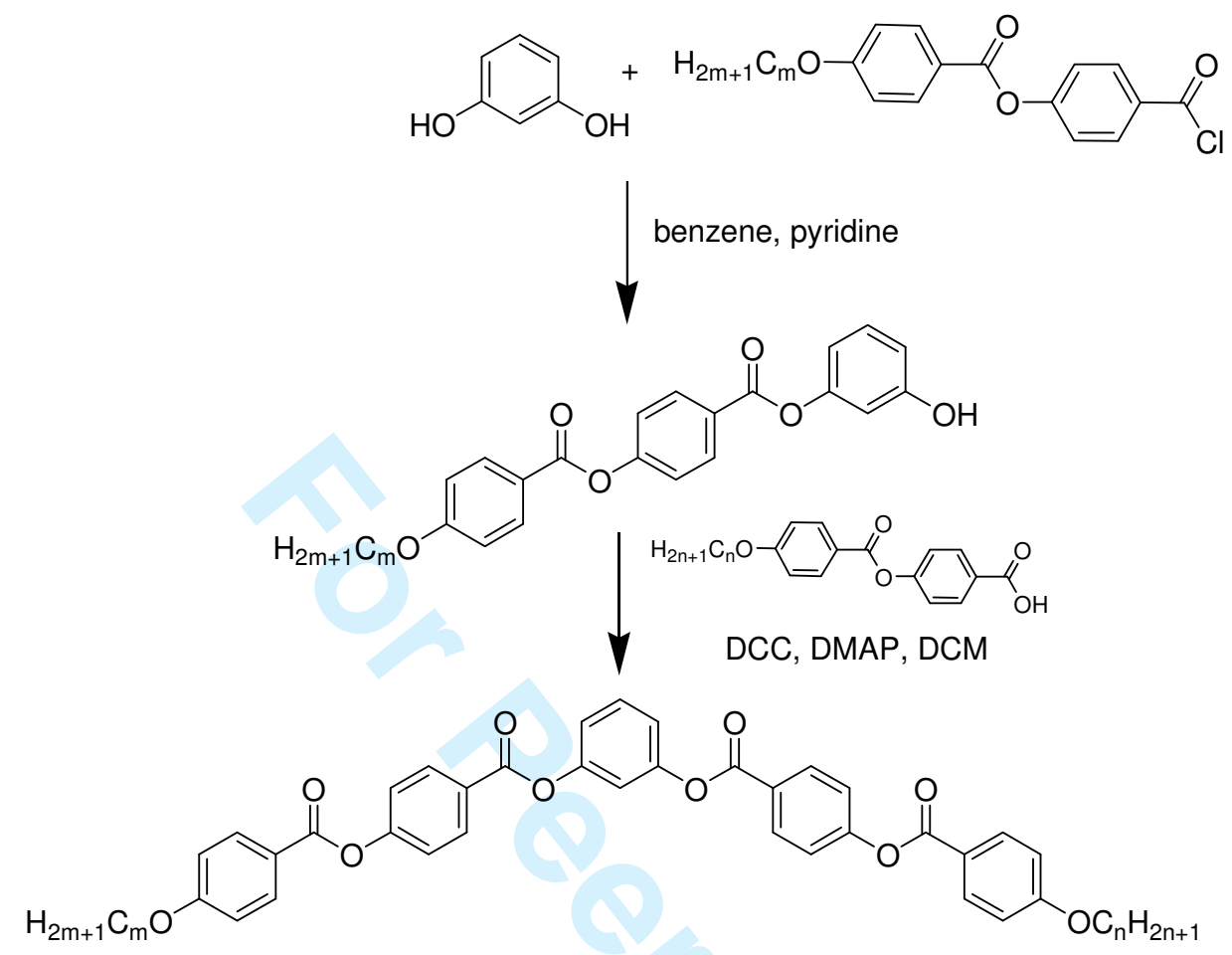


Scheme 4. Synthetic pathway used to prepare asymmetric bent-core molecules.

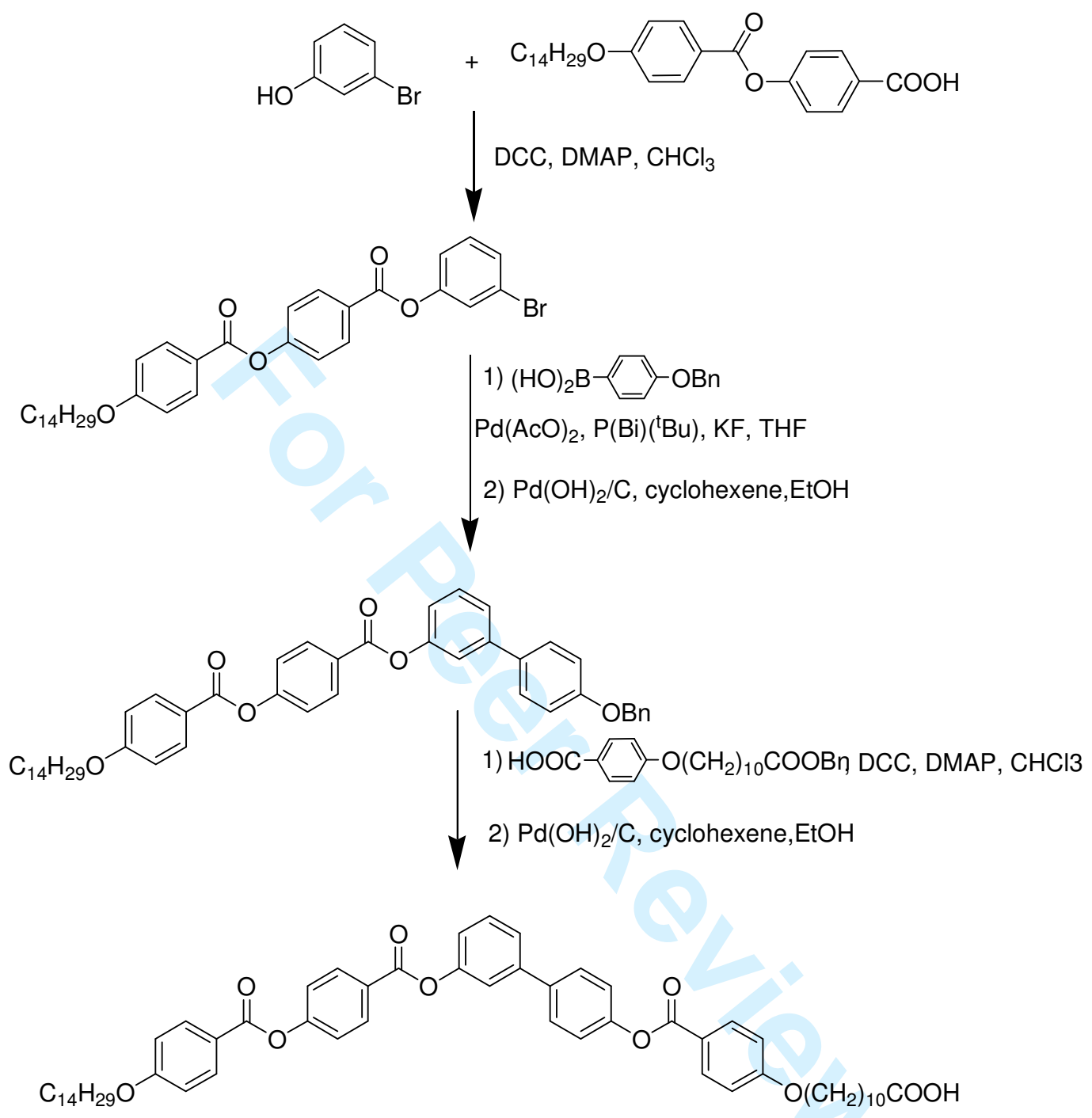

